Tesis presentada para optar por el grado de Doctor de la Facultad de Ciencias Naturales y Museo Universidad Nacional de La Plata

\title{
Respuestas fisiológicas y bioquímicas a la inundación en álamo (Populus spp.)
}

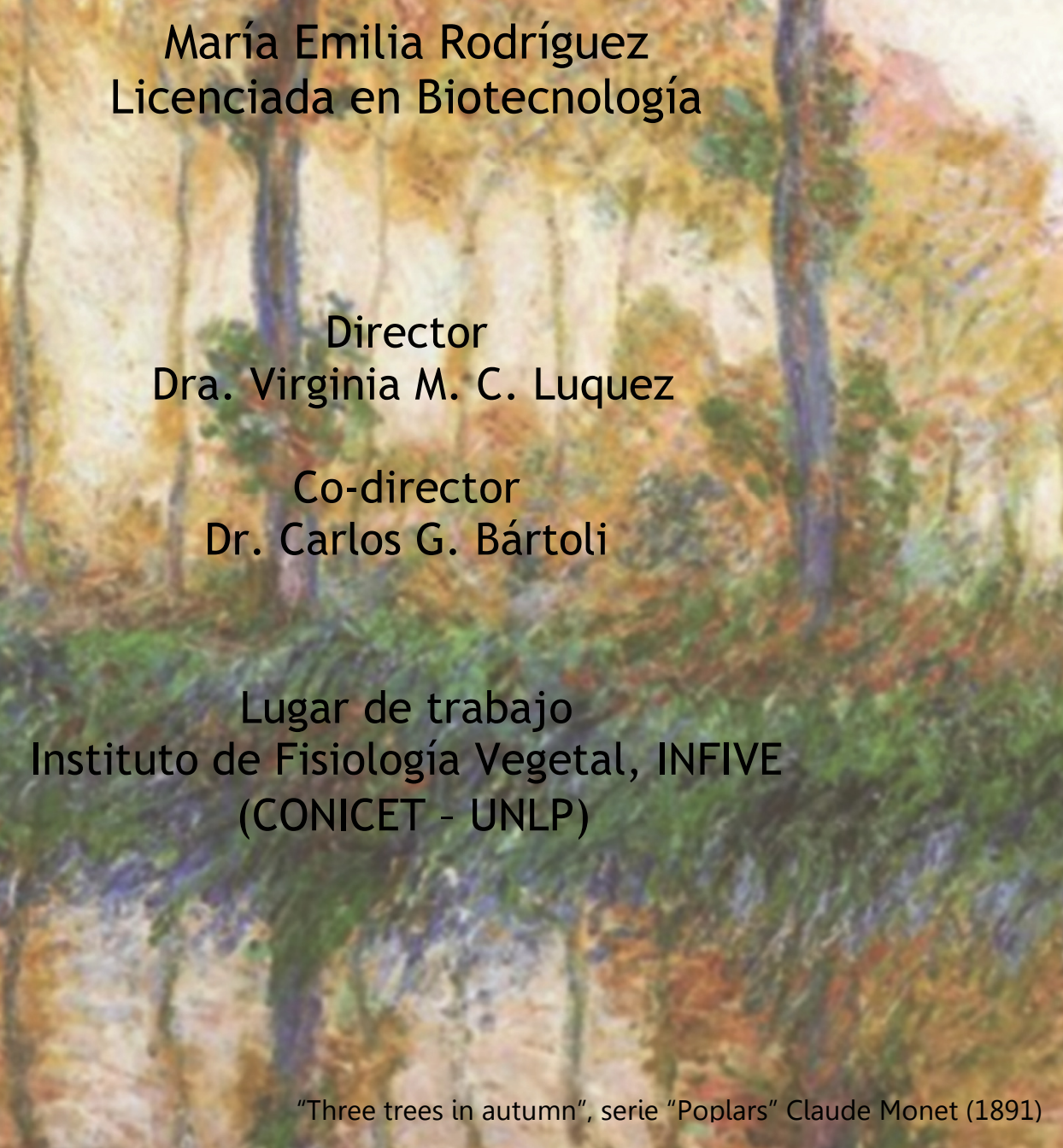


"El viaje no termina jamás. Solo los viajeros terminan. Y también ellos pueden subsistir en memoria, en recuerdo, en narración... El objetivo de un viaje es solo el inicio de otro viaje" José Saramago 
En memoria de Florencia Álvarez.

Sencillez y bondad, mirada trasparente y sonrisa infinita.

Te extraño amiga. 


\section{AGRADECIMIENTOS}

Quiero agradecer enormemente a mi directora, Dra. Virginia M.C. Luquez por permitirme realizar este doctorado; por dirigirme con absoluto compromiso; por enseñarme, ayudarme y escucharme; por guiarme, acompañarme y apoyarme durante estos años de crecimiento personal y profesional.

A mi codirector, Dr. Carlos G. Bártoli, por brindarme su apoyo y consejo en los experimentos realizados en esta tesis.

A Silvia Cortizo y Javier Álvarez, de la Estación Experimental Agropecuaria Delta del Paraná, INTA, por proveer las estacas de álamo utilizadas en los ensayos de esta tesis, y por las productivas charlas!

A Fabio Achinelli y Guillermo Doffo por su enorme ayuda en los ensayos en el invernáculo, y a Gustavo Gergoff, Lorenza Costa, Eugenia Senn, y Mariela Bayardo por enseñarme y ayudarme en los trabajos de laboratorio realizados.

A Santiago Martínez por las horas, y más horas, realizando cortes de material para observación microscópica; por la paciencia y el mejor humor siempre!

Al Laboratorio de Morfología Comparada de Espermatofitas (LAMCE) por la disposición de su laboratorio e instrumentos para realizar los cortes histológicos.

A Corina Graciano y Lorenza Costa por su excelente predisposición siempre; por escucharme y ayudarme ante toda necesidad, sea de índole académica o personal... les agradezco infinitamente! 
A Laura Fernández y Eduardo Tambussi tan dispuestos desde mi llegada al INFIVE a atender a cualquier inquietud que me surgiera.

A Pedro Subeldía por ayudarme cada vez que necesité una mano.

A cada uno de mis compañeros del INFIVE, por las experiencias compartidas en esta etapa y por el ambiente de trabajo que generamos juntos, el cual agradezco día a día. Somos un excelente grupo!!

A mis compañeros INFIBECARIOS, con quienes compartimos tanto durante estos años. Hicieron que esta experiencia sea de lo más gratificante!!

A los amigos INFIVIANOS que me dejó esta experiencia, Agus, Ale, Laurita, Lu, Mari, Maru, Na, Augusto, Cristián, Diego, Fer, Gusta, Luis, Pepe, Santi... por su contención y su amistad siempre, gracias gracias gracias!

A mis viejos, por la vida que me dieron y el camino que me permitieron elegir! $Y$ por acompañarme siempre por el camino elegido... Si no fuese por ustedes no estaría acá! A mis hermanos, abuelos, tíos, primos, amigos... en fin, a toda mi familia por acompañarme en todo momento y alentarme a llevar adelante este trabajo.

A la Agencia Nacional de Promoción Científica y Tecnológica y al CONICET, por haberme becado y así permitirme desarrollar este doctorado. Esta tesis fue financiada con fondos de los proyectos PICT 00487 (Agencia Nacional de Promoción Científica y Tecnológica) y PIP 0269 (CONICET). 
Dedico esta tesis a cada una de las personas que en

distintos momentos y lugares, y por distintas vías, me ayudaron y acompañaron en su morfogénesis!

Gracias!!! 
"Declaro que el material incluido en esta tesis es, a mi mejor saber y entender, original, producto de mi propio trabajo (salvo que se identifique explícitamente las contribuciones de otros), y que este material no ha sido presentado, en forma parcial o total, como una tesis en ésta u otra institución."

María Emilia Rodríguez 
TRABAJOS DERIVADOS DE ESTA TESIS

Presentaciones en congresos y jornadas científicas

Rodríguez M. E., Achinelli F., Doffo G., Luquez V.M.C. (2010). Efectos de la inundación sobre el crecimiento, la partición de la materia seca y las características foliares en 4 clones de álamo (Populus spp.). XXVIII Reunión Argentina de Fisiología Vegetal. La Plata, Argentina.

Rodríguez M.E., Doffo G., Achinelli F., Bartoli C., Luquez V. M.C. (2011). Characterization of responses to flooding and post - flooding recovery in two Populus deltoides clones: physiological and biochemical aspects. IUFRO Tree Biotechnology Conference 2011, From genomes to Integration and Delivery. Arraial d'Ajuda, Brasil.

Luquez V. M.C., Cortizo S., Rodríguez M.E., Achinelli F., Doffo G. (2011). Respuestas a la inundación de clones comerciales y experimentales de álamo (Populus spp.). V Reunión GeMFo. Balcarce, Argentina.

Rodríguez M. E., Gergoff G., Luquez V.M.C., Bártoli C. G. (2012). Caracterización del sistema antioxidante de dos clones de Populus deltoides con respuestas contrastantes frente a la inundación. XXIX Reunión Argentina de Fisiología Vegetal. Mar del Plata, Argentina. 
ÍNDICE GENERAL

Contenido

Página

Índice de figuras

XII

Índice de tablas

XIV

Glosario de abreviaturas

XV

Resumen

$X V I$

Abstract

XVIII

Capítulo 1: Introducción general y objetivos

1.1 Introducción general

1.1.1 El álamo y su cultivo

1.1.2 Inundación

1.1.3 Respuestas de las plantas a la inundación

1.1.4 El Delta del Paraná

1.1.5 Fundamentos de la elección del tema

1.2 Objetivos e hipótesis de trabajo

Capítulo 2: Respuestas morfológicas y anatómicas de tres clones de $\boldsymbol{P}$. deltoides frente a un episodio de estrés por inundación y su posterior recuperación

2.1 Introducción

2.1.1 Respuestas morfológicas a la inundación

2.1.2 Respuestas anatómicas a la inundación

2.2 Objetivo e hipótesis

2.3 Materiales y métodos

2.3.1 Material vegetal, diseño experimental y tratamiento de estrés

2.3.2 Tasa de difusión de oxígeno (ODR)

2.3.3 Crecimiento

2.3.4 Partición de materia seca

2.3.5 Características foliares 


\begin{tabular}{|c|c|}
\hline 2.3.6 Lenticelas hipertrofiadas y raíces adventicias & 29 \\
\hline 2.3.7 Aerénquima de raíz & 30 \\
\hline 2.3.8 Análisis estadístico & 30 \\
\hline 2.4 Resultados & 31 \\
\hline 2.4.1 ODR & 31 \\
\hline 2.4.2 Crecimiento & 31 \\
\hline 2.4.3 Partición de materia seca & 33 \\
\hline 2.4.4 Características foliares & 36 \\
\hline 2.4.5 Lenticelas hipertrofiadas y raíces adventicias & 42 \\
\hline 2.4.6 Aerénquima de raíz & 43 \\
\hline 2.5 Discusión & 45 \\
\hline 2.5.1 Respuestas de los álamos a un período de inundación & 45 \\
\hline $\begin{array}{l}\text { 2.5.2 Respuestas de los álamos durante el período de recuperación } \\
\text { posterior a un episodio de inundación }\end{array}$ & 48 \\
\hline 2.6 Conclusiones & 52 \\
\hline $\begin{array}{l}\text { Capítulo 3: Formación de aerénquima iniciada por etileno en raíces de } \\
\text { álamo sometidas a hipoxia }\end{array}$ & 53 \\
\hline 3.1 Introducción & 54 \\
\hline 3.1.1 Tipos de aerénquima & 55 \\
\hline 3.1.2 Hipoxia, etileno y desarrollo de aerénquima & 56 \\
\hline 3.2 Objetivo e hipótesis & 59 \\
\hline 3.3 Materiales y métodos & 60 \\
\hline 3.3.1 Material vegetal y cultivo de las plantas & 60 \\
\hline 3.3.2 Determinación de la porosidad de raíz & 60 \\
\hline 3.3.3 Cortes histológicos de la raíz & 61 \\
\hline 3.3.4 Diseño experimental & 61 \\
\hline 3.3.5 Análisis estadístico & 63 \\
\hline 3.4 Resultados & 64 \\
\hline 3.4.1 Experimento de inundación & 64 \\
\hline 3.4.2 Experimentos de aplicación exógena de etileno & 64 \\
\hline
\end{tabular}


3.5 Discusión

3.6 Conclusiones

Capítulo 4: Respuestas fisiológicas de tres clones de P.deltoides frente a un episodio de estrés por inundación y su posterior 70 recuperación

4.1 Introducción $\quad 71$

$\begin{array}{ll}\text { 4.1.1 Respuestas fisiológicas a la inundación } & 71\end{array}$

$\begin{array}{ll}4.2 \text { Objetivo e hipótesis } & 74\end{array}$

4.3 Materiales y métodos $\quad 75$

4.3.1 Material vegetal, diseño experimental y tratamiento de estrés $\quad 75$

4.3.2 Actividad fotosintética $\quad 75$

4.3.3 Conductancia estomática $\quad 75$

4.3.4 Contenido de Clorofila $\quad 76$

4.3.5 Contenido de RuBisCO 77

4.3.6 Análisis estadístico $\quad 77$

$\begin{array}{ll}4.4 \text { Resultados } & 78\end{array}$

4.4.1 Actividad fotosintética $\quad 78$

4.4.2 Conductancia estomática $\quad 78$

4.4.3 Contenido de clorofila 82

4.4.4 Contenido de RuBisCO 82

4.5 Discusión 83

4.5.1 Actividad fotosintética 83

4.5.2 Conductancia estomática $\quad 84$

4.5.3 Contenido de clorofila y RuBisCO 85

$\begin{array}{ll}4.6 \text { Conclusiones } & 87\end{array}$

Capítulo 5: Caracterización de la respuesta antioxidante en dos clones de $P$. deltoides con distinta susceptibilidad a la inundación

5.1 Introducción $\quad 89$

5.1.1 Especies Activas del Oxígeno (EAO) en plantas 89

5.1.2 Sistemas antioxidantes en plantas 91 


\begin{tabular}{|c|c|}
\hline 5.1.3 Antioxidantes & 91 \\
\hline 5.1.4 Enzimas antioxidantes & 95 \\
\hline 5.1.5 Inundación y estrés oxidativo & 96 \\
\hline 5.2 Objetivo e hipótesis & 98 \\
\hline 5.3 Materiales y métodos & 99 \\
\hline 5.3.1 Material vegetal, diseño experimental y tratamiento de estrés & 99 \\
\hline 5.3.2 Antioxidantes & 99 \\
\hline 5.3.3 Enzimas antioxidantes & 102 \\
\hline 5.3.4 Análisis estadístico & 103 \\
\hline 5.4 Resultados & 104 \\
\hline 5.4.1 Contenido de AA y DHA en las hojas & 104 \\
\hline 5.4.2 Contenido de GSH y GSGG en las hojas & 104 \\
\hline 5.4.3 Contenido de AA y DHA en la raíz & 105 \\
\hline 5.4.4 Contenido de GSH y GSSG en la raíz & 108 \\
\hline 5.4.5 Contenido de antocianinas en la raíz & 109 \\
\hline 5.4.6 Actividad de enzimas antioxidantes en la raíz & 109 \\
\hline 5.5 Discusión & 112 \\
\hline 5.5.1 Respuesta antioxidante de las hojas & 112 \\
\hline 5.5.1 Respuesta antioxidante de las raíces & 113 \\
\hline 5.6 Conclusiones & 115 \\
\hline \multicolumn{2}{|l|}{ Capítulo 6: Consideraciones finales } \\
\hline 6.1 Contraste de hipótesis & 117 \\
\hline 6.2 Conclusiones generales & 121 \\
\hline 6.3 Aportes de esta tesis & 124 \\
\hline $\begin{array}{l}\text { 6.4 Resumen de los mecanismos que confieren tolerancia a la } \\
\text { inundación en álamo }\end{array}$ & 125 \\
\hline Capítulo 7: Referencias & 127 \\
\hline 7.1 Referencias & 128 \\
\hline
\end{tabular}


1.1 Viejo ejemplar de álamo carolino

1.2 Esquema de las diferentes situaciones de inundación que puede experimentar una planta

1.3 Esquema de modificaciones metabólicas y fisiológicas, y respuestas adaptativas, de una planta bajo inundación

1.4 Mapa de ubicación general de la región del Delta del Paraná

1.5 Representación esquemática de los dos principales sistemas de producción para el sector forestal en el Delta del Río Paraná

2.1 Lenticelas hipertrofiadas y raíces adventicias

2.2 Cortes transversales de raíz mostrando los cuatro tipos principales de aerénquima

2.3 Vista general del experimento 2009

2.4 Altura del tallo (experimentos 2009 y 2011-A)

2.5 Índice de Volumen al final del experimento 2009

2.6 Partición de materia seca entre raíces, tallo y hojas (experimento 2009)

2.7 Rasgos foliares (experimento 2009)

2.8 Área foliar total, área foliar expandida antes-durante inundación y área foliar expandida pos inundación (experimento 2011-A)

2.9 Impresiones de la superficie abaxial de hojas de la cohorte L2 (experimento 2011-A)

2.10 Corte transversal de una porción de hoja rodeando a la vena principal de hojas de la cohorte L3 (experimento 2011-A)

2.11 Impresiones de la superficie abaxial de hojas de la cohorte L3 (experimento 2011-A) 
2.12 Detalle de lenticelas hipertrofiadas y raíces adventicias desarrolladas en respuesta a la inundación (experimento 2009)

2.13 Corte transversal de la región apical de raíz (experimento 2009)

3.1 Diagrama representativo de la formación de los distintos tipos de aerénquima

3.2 Modelo de inducción por hipoxia de muerte celular programada en células corticales de raíz, que llevan a la formación de aerénquima

3.3 Corte transversal de la región apical de raíz de ALT (experimento 2012-A)

4.1 Vista de la medición de fotosíntesis y conductancia estomática con un IRGA CIRAS II, PP Systems

4.2 Tasa de fotosíntesis y conductancia estomática (experimento 2011-A)

4.3 SDS-PAGE de proteínas foliares de la última hoja completamente expandida, cohortes L1 y L2 (experimento 2011-A)

5.1 Vías de eliminación de Especies Activas de Oxigeno (EAO) en plantas

5.2 Formación de EAO en plantas bajo estrés debido a la inhibición del ciclo de Calvin

5.3 Contenido de AA y DHA de la última hoja completamente expandida (experimento 2011-B)

5.4 Contenido de glutatión de la última hoja completamente expandida (experimento 2011-B)

5.5 Contenido de AA y DHA de raíz (experimento 2011-B)

5.6 Contenido de glutatión de raíz (experimento 2011-B)

5.7 Contenido de antocianinas de raíz (experimento 2011-B)

5.8 Actividad de peroxidasas totales y ascorbato peroxidasas de raíz (experimento 2011-B)

6.1 Representación esquemática de los mecanismos involucrados en la tolerancia a la inundación en $\mathrm{P}$. deltoides 
2.1 P. deltoides usados en esta tesis

2.2 Correlaciones entre área foliar total e índice de volumen, y área foliar total y biomasa de raíces (Experimento 2009)

2.3 Número de hojas expandidas antes-durante inundación y pos inundación

2.4 Área foliar individual, número de estomas, número de células epidérmicas, índice estomático y grosor de hojas en tres cohortes de hojas (experimento 2011-A)

3.1 Porosidad de raíz (POR) de ALT (experimento 2012-A)

3.2 Porosidad de raíz (POR) de ALT (experimentos 2012-B y 2012-C)

4.1 Rendimiento cuántico máximo del fotosistema II (Fv/Fm) en hojas adaptadas a la oscuridad durante 20 minutos (experimento 2009)

4.2 Análisis de correlación entre fotosíntesis y conductancia estomática (Experimento 2011-A)

4.3 Contenido de clorofila y RuBisCO en tres cohortes de hojas (experimento 2011-A)

5.1 Mecanismos y sitio de producción de Especies Activas de Oxigeno (EAO) en las plantas

5.2 Mecanismos de eliminación de Especies Activas de Oxigeno (EAO) en las plantas 


\section{GLOSARIO DE ABREVIATURAS}

149-82: clon 149-82, P. deltoides

149-82 C: plantas control 149-82

149-82 I: plantas inundadas $149-82$

149 I: plantas inundadas $149-82$

AA: ácido ascórbico

ACC: 1-aminociclopropano-1-carboxilato

ALT: clon Alton, $P$. deltoides

ALT C: plantas control Alton

ALT I: plantas inundadas Alton

APX: ascorbato peroxidasa

CAT: catalasa

DHA: ácido dehidroascórbico

DHAR: dehidroascorbato reductasa

DTT: ditiotreitol

EAO: especies activas de oxígeno (en

inglés Reactive Oxygen Species, ROS)

EDTA: etilendiaminotetraacético

Fv/Fm: rendimiento cuántico potencial del PSII

GPX: glutatión peroxidada

GR: glutatión reductasa

GSH: glutatión reducido
GSSG: glutatión oxidado

HPLC: cromatografía liquida de alta

eficiencia (del inglés High-Performance

Liquid Chromatography)

IE: Índice estomático

MDA: ácido monodehidroascórbico

MDAR: monodehidroascorbato reductasa

$\mathrm{NAD}(\mathrm{P}) \mathrm{H}$ : nicotinamida adenina

dinucleótido fosfato

NADH: nicotinamida adenina

dinucleótido

POR: porosidad de raíz

PSI: fotsistema I

PSII: fotosistema II

PX: peroxidasas

SOD: superoxido dismutasa

ST67: clon Stoneville 67, $P$. deltoides

ST67 C: plantas control Stoneville 67

ST67 I: plantas inundadas Stoneville 67

TCR: tasa de crecimiento relativo

TFA: ácido trifluoroacético 


\section{RESUMEN}

En Argentina, diferentes especies del género Populus (álamos), son de gran importancia económica por ser una fuente importante de madera, pulpa y fibra. La zona más importante de plantación de álamos es el Delta del Río Paraná. En esta región, el estrés por inundación ocasionado por la crecida de ríos o lluvias intensas, resulta limitante para la productividad, pudiendo causar severas pérdidas económicas en plantaciones comerciales. Modelos de posibles escenarios de cambio climático, indican que las inundaciones serán más frecuentes en la zona, por lo que es necesario disponer de genotipos de álamo con gran tolerancia a la inundación. Comprender los mecanismos fisiológicos y bioquímicos que contribuyen a la tolerancia a la inundación en álamo, servirá como base de programas de mejoramiento genético clásico o de posibles desarrollos biotecnológicos destinados a incrementar la tolerancia a la inundación de esta especie.

Para contribuir en la comprensión de los mecanismos que confieren tolerancia a inundación en álamo, en esta tesis se utilizaron tres clones pertenecientes a la especie Populus deltoides, la cual es ampliamente cultivada en la zona región del Delta del Paraná. El objetivo general de este trabajo fue caracterizar los cambios ocasionados por la inundación, durante y después del episodio de estrés, a nivel morfológico, anatómico, fisiológico y bioquímico, en diferentes órganos de clones de P. deltoides con diverso grado de susceptibilidad a la inundación. En base a un ensayo en el que se evaluó el efecto de la inundación sobre el crecimiento, se seleccionaron tres clones con distinto grado de tolerancia, siendo Alton el clon más tolerante, 149-82 el más susceptible y Stoneville 67 de tolerancia intermedia. Estos tres clones fueron utilizados en los experimentos de esta tesis para evaluar los objetivos particulares que derivan del objetivo general. 
En el primer objetivo se evaluaron las respuestas morfológicas y anatómicas, de la parte aérea y radical de los tres clones, tanto a la inundación como a un período de recuperación posterior. En un siguiente objetivo, que deriva del primero, se intentó determinar si la formación de aerénquima, tejido que se forma en las raíces en respuesta a la inundación en clones tolerantes, está iniciada por la hormona etileno, la cual se acumula en las condiciones hipóxicas generadas por la inundación. En el segundo objetivo, se evaluaron las respuestas fisiológicas de los tres clones tanto en el período de inundación como de recuperación posterior. En el tercer objetivo se estudió la respuesta de la capacidad antioxidante de los clones Alton y Stoneville 67, durante la inundación y el periodo pos anóxico inmediato a la finalización de la inundación.

De acuerdo a los resultados obtenidos en los diferentes experimentos realizados, la mayor tolerancia a la inundación observada en Alton, está relacionada con la capacidad para desarrollar estructuras adaptativas, como la formación de aerénquima, lenticelas hipertrofiadas y raíces adventicias, que permiten retener una mayor área foliar y biomasa de raíces durante el episodio de estrés; esto a su vez, le confiere la posibilidad de mantener una mejor apertura estomática y capacidad fotosintética. Además, la mayor disponibilidad de fotoasimilados que implicaría el mantenimiento de la fotosíntesis durante la inundación, el rápido desarrollo de nuevas raíces y la retención de mayor biomasa radical, y la capacidad antioxidante para eliminar especies toxicas durante la reoxigenación, le asegurarían a este clon el rápido reestablecimiento del crecimiento óptimo de la planta.

Con respecto a la determinación sobre si la hormona etileno participa en la formación de aerénquima en Populus deltoides, no fue posible alcanzar este objetivo con el enfoque experimental utilizado en la tesis. 


\section{ABSTRACT}

In Argentina, a number of species of the genus Populus (poplars) are of great economic importance as a major source of timber, pulp and fiber. The most important area of poplar plantation is the Paraná River Delta, where flooding caused by high water levels of the rivers or heavy local rains can limit productivity, and can cause severe economic losses in commercial plantations. Climate change models indicate an increase of flooding events frequency in this area, so poplar genotypes with a higher flooding tolerance will be needed for forestry. A better understanding of physiological and biochemical mechanisms that contribute to flooding tolerance in poplar, will serve as a basis of classical breeding programs or possible biotechnological developments designed to increase flooding tolerance of this species.

In this thesis were used three clones belonging Populus deltoides species, widely cultivated in the Paraná Delta region. The overall objective of this study was to characterize the changes caused by flooding, during and after the episode of stress, at morphological, anatomical, physiological and biochemical level in different organs of Populus clones with varying degrees of susceptibility to flooding. Based on an assay in which the flooding effect on growth was assessed, 3 clones were selected with different degrees of tolerance, Alton being the most tolerant clone, 149-82 the most susceptible and Stoneville 67 having an intermediate behavior between both. These three clones were used in the experiments of this thesis to evaluate the particular objectives from the overall goal.

In the first objective, morphological and anatomical responses of shoot and root of the three clones, to flooding and a subsequent recovery period, were assessed; in the second objective physiological responses in the same periods were evaluated. In the third objective the response of the antioxidant capacity of Alton 
and Stoneville 67 clones during flooding and the post-anoxic period occurring immediately after the end of flooding were evaluated. The fourth objective was to determine whether the formation of aerenchyma, tissue formed in the roots in response to flooding in tolerant clones is initiated by the hormone ethylene, which accumulates in hypoxic conditions generated by flooding.

According to the results obtained in the different experiments performed, flooding tolerance is related to the ability to develop adaptive structures, such as the formation of aerenchyma, hypertrophied lenticels and adventitious roots, which enable to hold a greater foliar area and root biomass during the episode of stress, which in turn facilitates the possibility of having a better stomatal opening and photosynthetic capacity. In addition, the increased availability of photoassimilates which would involve the maintenance of photosynthesis during flood, the retention of bigger root biomass and rapid development of new roots, and antioxidant capacity to remove toxic species during reoxygenation, would ensure the rapid restoration of optimum growth of the plant.

With respect to the determination of whether the hormone ethylene participates in the formation of aerenchyma in Populus deltoides, it was not possible to achieve this goal with the experimental approach used in this thesis. 
CAPÍTULO 1

INTRODUCCIÓN GENERAL Y OBJETIVOS

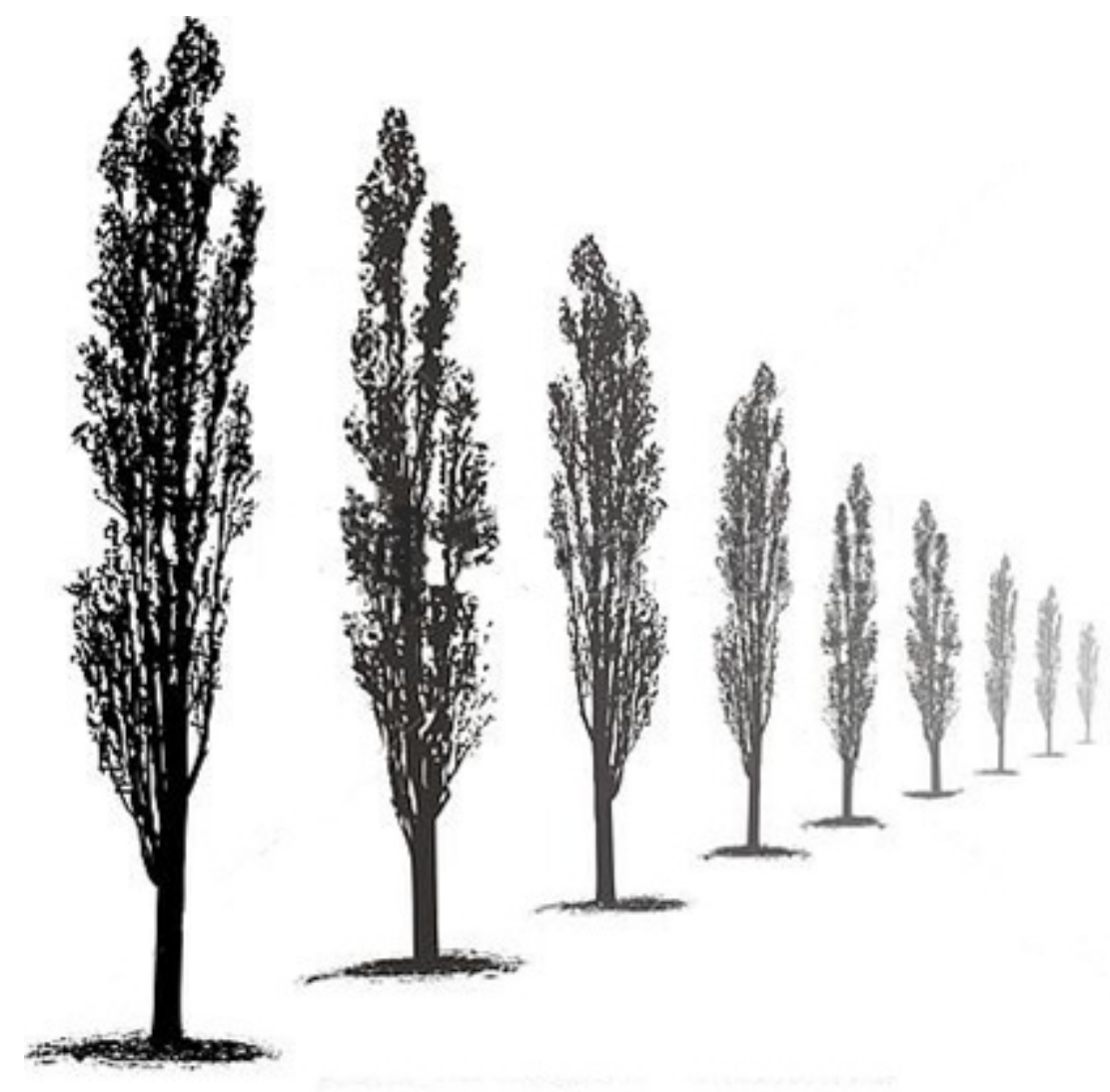




\subsection{INTRODUCCIÓN GENERAL}

\subsubsection{El álamo y su cultivo}

El género Populus L. pertenece a la familia de las Salicáceas (junto a los sauces, Salix) y comprende alrededor de 30 especies (Eckenwalder, 1996), en su mayoría colonizadoras de áreas disturbadas por inundaciones, fuego o hielo, en humedales, riberas, orillas de lagos y tierras elevadas como sistemas fluviales de alta montaña o planicies de pie de montaña (Braatne et al., 1996; Rood et al., 2007).

Combinando registros fósiles con información de análisis filogenéticos, Eckenwalder (1996) especula que el género se originó en América del Norte o Asia tropical durante el Paleoceno, y que las tres secciones Populus, Aigeiros y Tacamahaca, evolucionaron rápidamente en sus hábitats durante el Mioceno. Estudios recientes basados en marcadores moleculares concuerdan en términos generales con las delimitaciones de las secciones y sus relaciones evolutivas (Cervera et al., 2005; Hamzeh et al., 2006).

Las distintas especies del genero son de tronco único, deciduas y la mayoría se propaga clonalmente a través de estacas, característica de interés en el manejo de plantaciones. Se encuentran entre los árboles de mayor velocidad de crecimiento de climas templados, cualidad ligada a su rol como pioneros. Son dioicos y florecen antes de la emergencia de hojas (Eckenwalder, 1996). Pueden encontrarse en bosques nativos del hemisferio norte y en plantaciones en latitudes templadas de ambos hemisferios, ya sea en cortinas como barrera de viento, rodales para prevenir la erosión del suelo, plantaciones en galería para estabilizar los márgenes de arroyos y canales, o en sistemas agroforestales y silvopastoriles (Stettler et al., 1996; Pincemin et al., 2007).

$P$. deltoides es una especie originaria de Estados Unidos y Canadá. Es un árbol de gran porte que puede alcanzar una altura mayor a los $45 \mathrm{~m}$ y un diámetro de $3 \mathrm{~m}$. Crece 
naturalmente en tierras bajas, aluviales, orillas de lagos y riberas, como en las islas del río Mississipi, con óptimo crecimiento en suelos arenosos o limosos (Ragonese et al., 1987; Dickmann y Kuzovkina, 2008). Los P. deltoides originarios del sudeste de los Estados Unidos son los más aptos para una zona con inviernos suaves, veranos húmedos y elevadas precipitaciones anuales como la del Delta del Paraná (Borodowski, 2006).

El cultivo de álamos posee una larga historia, con antecedentes de su plantación en el Imperio Romano y en China (Dickmann y Kuzovkina, 2008). La palabra latina Populus derivaría de la denominación de origen romana arbor populi o "árbol del pueblo" ya que eran ampliamente plantados (Dickmann y Kuzovkina, 2008). La domesticación del género comenzó en Europa, Asia y Medio Oriente hacia finales del siglo XVIII, probablemente como consecuencia de la introducción de $P$. deltoides (Dickmann, 2006; Stanton et al., 2010; DiFazio et al., 2011).

Los álamos han sido extensamente cultivados debido su rápido crecimiento, fácil propagación vegetativa, buena capacidad de rebrote, adaptabilidad a diferentes sitios, alta plasticidad en respuesta a los cambios ambientales y variados usos de la madera (aserrado, debobinado, celulosa, fibras y/o partículas para producción de tableros y biomasa con fines energéticos) (Zsuffa et al., 1996; Balatinecz et al., 2001; Ceulemans, 2011). Además, juegan un importante rol en el mejoramiento y la conservación ambiental, protegiendo la tierra del viento y la erosión fluvial, biorremediando aguas y suelos contaminados, y mejorando el balance de dióxido de carbono de la atmósfera (Zsuffa et al., 1996).

En Argentina, los primeros cultivos de álamos en el Delta del Paraná se atribuyen a la introducción del “álamo Carolino” ( $P$. deltoides spp. angulata cv. Carolinensis, Fig. 1.1) por inmigrantes franceses a finales del siglo XIX (Golfari, 1958; Borodowski y Suárez, 2004). Su cultivo se extendió hasta inicios del siglo XX, utilizándose su madera como astillas y leña para hornos panaderos y de ladrillos. Luego de una gran inundación 


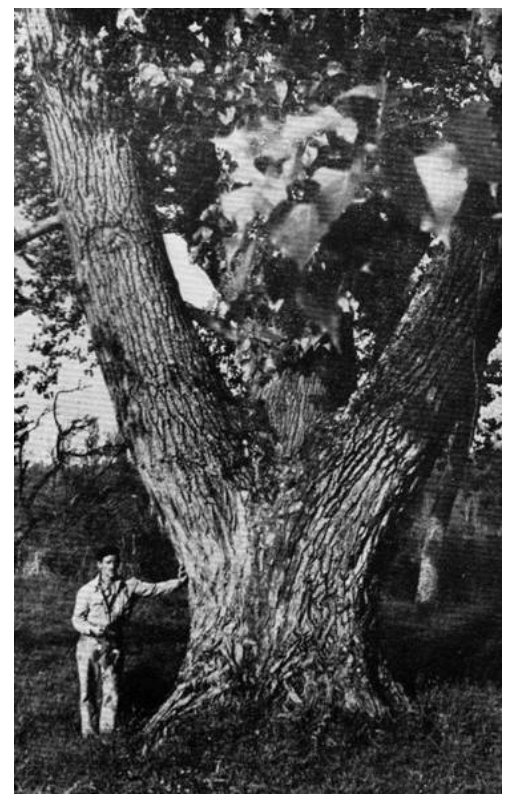

Fig. 1.1. Viejo ejemplar de álamo carolino ( $P$. deltoides carolinensis) de más de 60 años de edad a la fecha; Brazo de La Tinta, Delta del Paraná. Fotografía obtenida de Golfari (1958).

en 1905, que culminó con un grave ataque de roya (Melampsora sp.) que se repitió por varios años, las plantaciones se fueron perdiendo. En 1920, luego de finalizada la Primera Guerra Mundial, se introduce el álamo criollo ( $P$. nigra cv. itálica) (Golfari, 1958; Borodowski y Suárez, 2004), traído probablemente de tierra firme donde se encontraba desde hace más de un siglo. Al igual que el álamo carolino, el álamo criollo fue decayendo por varios ataques de langosta (Schistocerca cancellata Serv.) y roya (Melampsora sp.) (Golfari, 1958). Luego de la Segunda Guerra Mundial comenzó la introducción de híbridos a la región del Delta, sucediéndose la incorporación de clones en búsqueda de aquellos que se adapten a las condiciones ecológicas de la región, incorporación y búsqueda que continua hasta hoy (Borodowski y Suárez, 2004). En la actualidad, en la región se utilizan para forestación clones de la especie $P$. deltoides mayoritariamente (y una menor cantidad de $P . x$ canadensis), que fueron introducidos, ya que no existen especies de Populus nativas de la zona (Ragonese et al., 1987).

Informes de la Comisión Internacional del Álamo del año 2004, indicaron que la superficie cubierta por álamos era de más de 80 millones de hectáreas en todo el 
mundo. La superficie ocupada por álamos en condición natural es mayor a 70 millones de hectáreas, principalmente en Canadá, Rusia y Estados Unidos y la superficie de plantaciones de álamos de 6,7 millones de hectáreas (Ball et al., 2005). En Argentina se cultivan alrededor de 64.000 ha, 23.500 ha bajo sistemas agroforestales y 40.500 ha en macizos, ocupando así, el tercer y décimo lugar de importancia a nivel mundial respectivamente (Ball et al., 2005; Cortizo, 2011). Las principales áreas productivas son el Delta del Río Paraná, Cuyo, Patagonia y zonas de secano de la Provincia de Buenos Aires, cada una con particularidades que definen las especies utilizadas, las características de las plantaciones y su finalidad (Cortizo, 2011). Tradicionalmente, la pulpa, el papel y el cartón han sido los destinos principales de la producción de álamo; en los últimos años se ha incrementado su uso para obtención de productos de madera sólida, como madera de construcción, contrachapado, tablero de partículas y chapa laminada, además de palés y cajones (Stanton et al., 2002; Ball et al., 2005).

\subsubsection{Inundación}

Las inundaciones son un estrés ambiental que afecta ecosistemas naturales y artificiales en todo el mundo debido a los efectos negativos que provocan en la mayoría de las plantas terrestres, dificultando su crecimiento y pudiendo ocasionar su muerte (Bailey-Serres y Voesenek, 2008; Colmer y Voesenek, 2009). La inundación del suelo pone en marcha una variedad de procesos físicos, químicos y biológicos que alteran la capacidad de los suelos para sostener el crecimiento de las plantas (Kozlowski, 1997), siendo el principal efecto la disminución de la difusión de los gases; el exceso de agua en el suelo ocasiona un severo descenso en la tasa de difusión de oxígeno, disminuyendo $10^{4}$ veces en comparación con su tasa de difusión en el aire (Armstrong, 1979). Además, el rápido consumo por parte de las raíces del escaso oxígeno disponible, agentes reductores del suelo y microorganismos, provoca una serie de cambios químicos en el 
suelo que incluyen la acumulación de compuestos tóxicos como acetaldehído, ácido acético y metanol, y la formación de formas tóxicas reducidas de hierro, manganeso y azufre. Estos compuestos llevan a una disminución progresiva del potencial de oxidoreducción del suelo y contribuyen a la generación de daño, reducción del crecimiento y muerte de plantas leñosas (Ponnamperuma, 1972; Kozlowski, 1997; Pezeshki, 2001).

El término inundación se utiliza para describir diferentes situaciones en las que el exceso de agua puede variar de suelo saturado de agua (anegamiento, Fig. 1.2), a columnas de aguas profundas que causan la inmersión, parcial o completa, de las plantas (inundación, Fig. 1.2). En condiciones de anegamiento, solo las raíces de la planta se encuentran en un entorno anaerobio impuesto por la falta de oxígeno (Striker, 2012). En condiciones de inundación, existe una capa de agua por encima de la superficie del suelo, que puede ser superficial o profunda, provocando inmersión parcial o completa de las plantas. El grado de inmersión dependerá, a un mismo nivel de profundidad del agua, de la etapa de desarrollo en la que se encuentre la planta (por ejemplo si es plántula o adulta) y el hábito de crecimiento (si es de crecimiento rastrero o erecto) (Striker, 2012). En condiciones de inmersión parcial, las plantas, además de tener sus raíces completamente sumergidas en el suelo saturado de agua, tienen una parte de sus tallos sumergidos bajo el agua. Bajo condiciones de inmersión completa, las plantas se enfrentan al escenario más estresante porque al estar tanto las raíces como el tallo bajo el agua, la oportunidad de captar oxígeno y la de continuar con la fijación de carbono se encuentran restringidas (Striker, 2012).

Otro aspecto importante a tener en cuenta, además de la profundidad del agua, es la duración del episodio de inundación, considerado como uno de los componentes principales de la supervivencia a la inundación (Gill, 1970; Vervuren et al., 2003; Colmer y Voesenek, 2009). Una especie de cierta edad y tamaño que es capaz de sobrevivir a un período corto de inundación, puede perecer si se expone a uno más largo (Kozlowski, 1997; Glenz et al., 2006). 


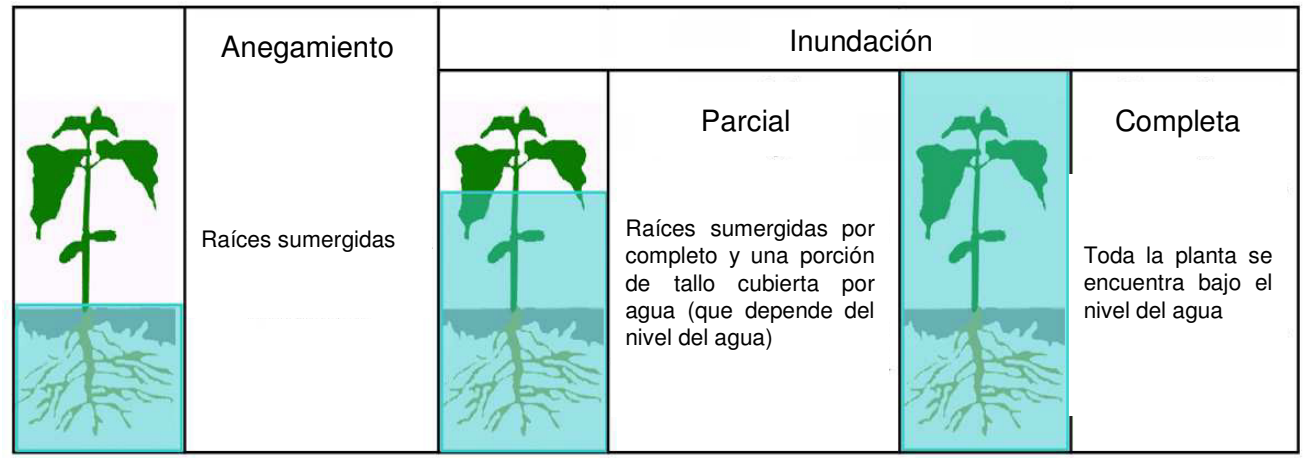

Fig. 1.2. Esquema de las diferentes situaciones que pueden experimentar las plantas frente a niveles crecientes de exceso de agua, que van desde el anegamiento hasta la inmersión completa. Modificado de Striker (2012).

En esta tesis, el termino inundación se referirá a la condición de inundación parcial, ya que debido al tamaño de la planta seleccionada y a las condiciones climáticas a las que es sometida durante su cultivo en la región del Delta del Paraná, el escenario de mayor probabilidad de ocurrencia, es la inmersión parcial de la planta.

\subsubsection{Respuestas de las plantas a la inundación}

Las respuestas de las plantas leñosas a la inundación varían de acuerdo a la especie y genotipo, la edad de la planta, la duración del período de estrés, el grado de cobertura por el agua y si la inundación ocurre durante el período de crecimiento o de reposo (Kozlowski, 1997; Li et al., 2006; Glenz et al., 2006). Los álamos son generalmente considerados como bastante tolerantes al exceso de humedad del suelo (Harrington, 1987), sin embargo, la falta de aireación del suelo reduce el crecimiento en algunas especies (Smit et al., 1989; Liu y Dickmann, 1992). A diferencia de la sequía, las inundaciones disminuyen el crecimiento de las raíces (Liu y Dickmann, 1992). Además, las inundaciones causan disminución de la absorción de los nutrientes (Harrington, 1987). 

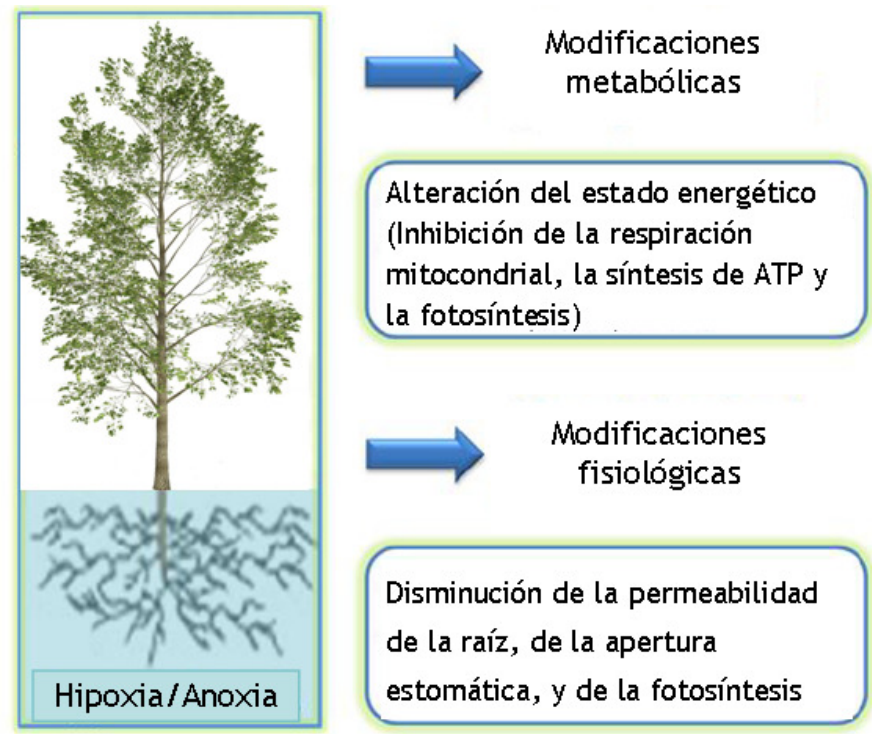

Respuestas

adaptativas

Metabolismo anaeróbico

(se activa primero la fermentación láctica y luego la alcohólica)

\section{Morfológicas y anatómicas}

(Reducción del crecimiento, abscisión foliar, desarrollo de lenticelas hipertrofiadas, raíces adventicias y aerénquima)

Fig. 1.3. Esquema de modificaciones metabólicas y fisiológicas, y respuestas adaptativas de una planta bajo inundación. Modificado de Parent et al. (2008).

Entre las respuestas más sobresalientes (Fig. 1.3) frente a una situación de inundación durante el periodo de crecimiento en una especie perenne se encuentran: reducción del crecimiento, cierre de estomas y disminución de la actividad fotosintética (Kozlowski, 1997); desarrollo de lenticelas hipertrofiadas, raíces adventicias y formación de aerénquima; acelerada senescencia y abscisión foliar; cambios en la absorción y disponibilidad de nutrientes minerales, y varios cambios metabólicos causados por las condiciones de hipoxia o anoxia (Kozlowski, 1997; Vartapetian y Jackson, 1997; Braendle y Crawford, 1999; Bailey-Serres y Voesenek, 2008).

Tanto a la parte aérea como a las raíces se ven afectadas por la reducción de crecimiento ocasionada por la inundación, pero el efecto es mayor en las raíces, disminuyendo la relación raíz / vástago (Kozlowski, 1997). Las especies más sensibles a inundación manifiestan mayor reducción del crecimiento, porque experimentan reducciones en la tasa de formación y expansión de nuevas hojas (Angelov et al., 1996). El área foliar fotosintéticamente activa puede ser reducida también por la aceleración 
de la senescencia y abscisión foliar (Kozlowski, 1997). Además, durante la hipoxia generada en la raíces, la actividad fotosintética puede ser reducida por el cierre estomático (Bejaoui et al., 2006; Gong et al., 2007; Guo et al., 2011).

Uno de los principales efectos de la inundación es la reducción del contenido de oxígeno del suelo debido a que el agua ocupa los poros que antes ocupaba el gas. La respiración de las raíces y de los microorganismos agota el oxígeno remanente y el ambiente se vuelve primero hipóxico (los niveles de oxígeno limitan la respiración mitocondrial), y luego anóxico (la respiración se inhibe completamente) (Blom y Voesenek, 1996; Bailey-Serres y Voesenek, 2008). El agotamiento de oxígeno es el principal factor de alteración del metabolismo de raíces de plantas sometidas a inundación, impidiendo la generación de ATP en la mitocondria por respiración aeróbica, y favoreciendo la fermentación (Agarwal y Grover, 2006; Bailey-Serres y Voesenek, 2008). Inicialmente, las raíces activan la fermentación láctica. La acumulación de ácido láctico acidifica el citoplasma y, a un pH crítico, el metabolismo cambia de fermentación láctica a fermentación alcohólica (Kreuzwieser et al., 2004). En raíces inundadas de $P$. x canescens se observó el estímulo de la glucólisis y la fermentación alcohólica (Kreuzwieser et al., 2009).

Una de las primeras respuestas fisiológicas a la disminución de oxígeno en las raíces, es la reducción de la conductancia estomática, lo que también contribuye al descenso de la tasa fotosintética (Guo et al., 2011). El cierre estomático parcial es una respuesta característica a la inundación de suelos (Kozlowski, 1997) y se relaciona con un aumento del contenido de ácido abscísico foliar, que se generaría en respuesta al estado de hipoxia de las raíces (Guo et al., 2011). En Populus, la inundación causa cierre estomático y reducción de la tasa fotosintética (Liu y Dickman, 1993; Kozlowski, 1997; Cao y Conner, 1999; Béjaoui et al., 2006; Gong et al. 2007).

La reapertura de los estomas se ha relacionado con el desarrollo de lenticelas hipertrofiadas y/o raíces adventicias (Sena Gomes y Kozlowski, 1980 a; Gravatt y Kirby, 
1998). La inundación provoca la muerte de las raíces, y las raíces principales de la mayoría de las plantas terrestres no son capaces de desarrollar adaptaciones efectivas contra la inundación. En especies tolerantes, un nuevo sistema radicular adventicio se desarrolla en el tallo y raíz superficial (Blom y Voesenek, 1996; Glenz et al., 2006). Para ayudar a contrarrestar el efecto ocasionado por la falta de disponibilidad de oxígeno, la respuesta anatómica más común es la generación de aerénquima en los tejidos (Justin y Armstrong, 1987; Seago et al., 2005; Bailey-Serres y Voesenek, 2008). En las condiciones de hipoxia generada en el suelo por inundación, algunas especies desarrollan aerénquima de tipo lisígeno en respuesta a la acumulación de la hormona etileno (Drew et al., 2000).

El resultado de la formación de estas estructuras es un aumento de la difusión de oxígeno del tallo hacia las raíces y la rizósfera (Colmer, 2003 b), lo que a su vez permite el mantenimiento del metabolismo aeróbico, mucho más eficiente en la producción de energía que la fermentación (Bailey Serres y Voesenek, 2008).

Varios trabajos han mostrado diferencias en la tolerancia a la inundación entre especies, híbridos y clones de Populus, por ejemplo en Populus trichocarpa (Smit y Stachowiak, 1988), Populus deltoides (Cao y Conner, 1999), P. x canadensis (Bejaoui et al., 2006; Gong et al., 2007; Guo et al.; 2011), P. trichocarpa x P. deltoides (Gong et al., 2007; Guo et al., 2011) y P. trichocarpa x P. nigra (Guo et al., 2011). Las especies o genotipos tolerantes, estarían adaptados a la inundación pudiendo mantener la actividad fotosintética y el crecimiento, mientras que los no tolerantes presentarían fotosíntesis y crecimiento reducidos (Guo et al., 2011).

\subsubsection{El Delta del Paraná}

En Argentina, la zona de mayor importancia en el de cultivo de álamos es el Delta del Río Paraná. Esta región está constituida por un extenso grupo de islas, 

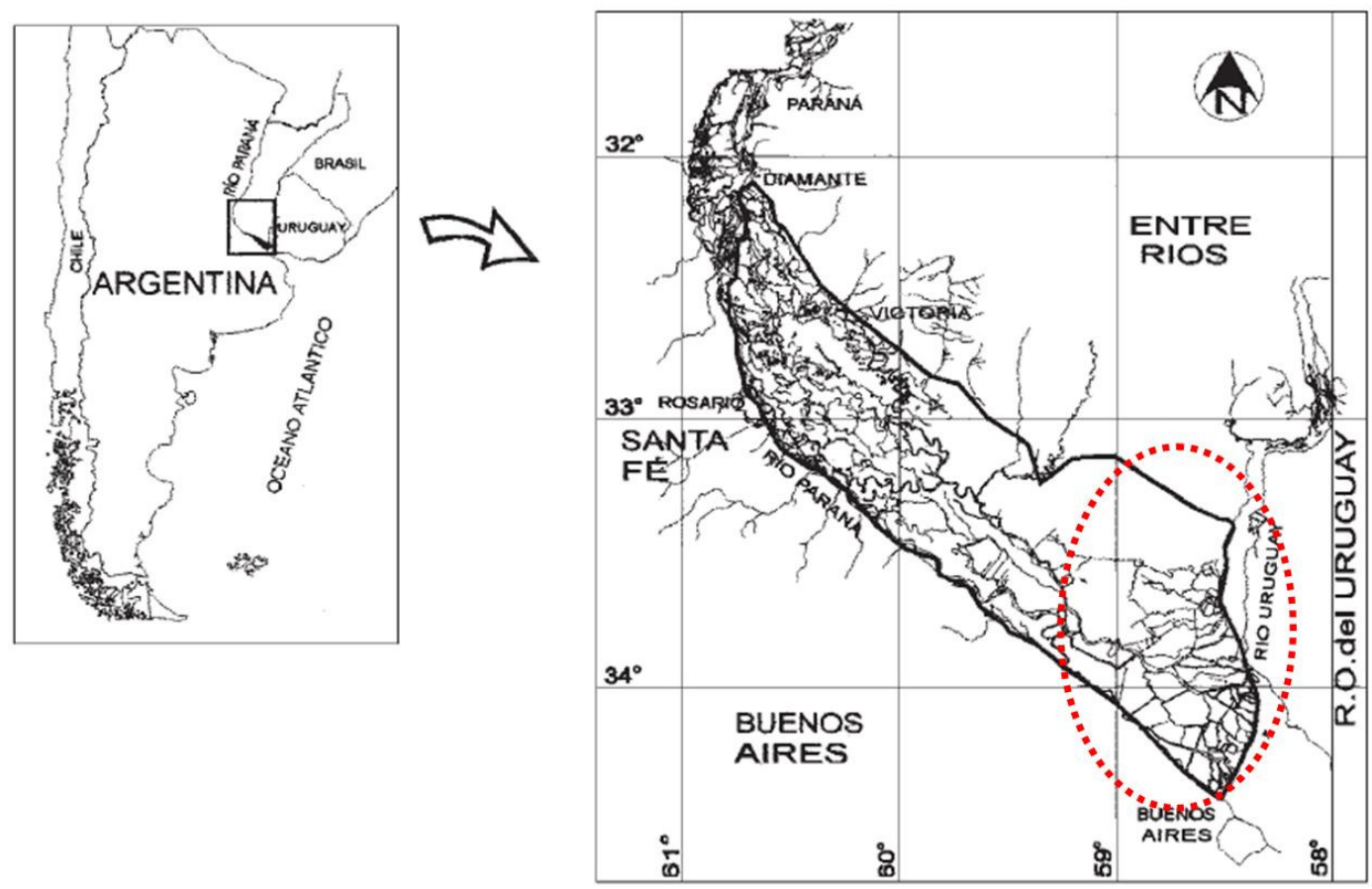

Fig. 1.4. Mapa de ubicación general de la región del Delta del Paraná. Modificado de Malvárez (1999).

ubicadas entre los $32^{\circ} 5^{\prime}$ y $34^{\circ} 29^{\prime}$ latitud sur, y los $58^{\circ} 22^{\prime}$ y $60^{\circ} 45^{\prime}$ longitud oeste, entre la localidad de Diamante y el Río de la Plata (Fig 1.4) (Borodowski, 2006). El Delta del Paraná, que posee una superficie de $14.000 \mathrm{Km}^{2}$ (Bonetto y Hurtado, 1998), se ubica en la confluencia de los ríos Paraná y Uruguay con el Río de La Plata, siendo el primero el mayor contribuyente a la formación de las islas que lo componen (Borodowski, 2006). La actividad económica más importante de esta región es la forestación con Salicáceas (álamos y sauces), siendo de aproximadamente 15.000 ha la superficie utilizada para la plantación de álamos (Borodowski, 2006).

La región del Delta experimenta episodios de inundación de distinta magnitud cuando el nivel normal de las aguas se ve alterado por alguno de los siguientes factores: crecida del los ríos Paraná, Uruguay o sus afluentes, precipitaciones en sus cuencas, 
vientos del sudeste que provocan rápidas crecidas (sudestada), o intensas lluvias locales sobre la cuenca Paraná-La Plata (Borodowski, 2006). Las islas del río Paraná han sufrido largos periodos de inundación con una ocurrencia irregular. Durante el siglo XX, hubo episodios de inundación en 1905, 1914, 1922, 1940, 1958, 1959, 1966, 1973, 1977, $1982-$ 1984 y 1998. La recurrencia y variabilidad de estos episodios ha sido una de las principales limitantes productivas de la región. Sumado a esto, en los últimos 20 años, los niveles medios del río han crecido, haciendo necesarias obras de infraestructura de protección contra inundaciones (Borodowski, 2006).

En las islas del Delta del Paraná se pueden distinguir dos zonas características: una zona costera alta, llamada albardón, que constituye el $20 \%$ de la superficie, y una zona central baja, llamada estero o pajonal, que constituye el $80 \%$ de la superficie de las islas. El albardón se caracteriza por una vegetación natural boscosa, mientras que los pajonales son zonas pantanosas dominadas por juncos (Malvárez, 1999; Luquez et al., 2012).

Las zonas bajas son especialmente susceptibles a experimentar episodios de inundación, por lo tanto en las áreas forestadas, los productores sistematizan los campos construyendo canales que desaguan en el río para facilitar el drenaje. Este sistema, denominado "a zanja abierta" (Fig. 1.5, a) es eficiente en tanto el nivel del río no suba al punto de impedir la salida del agua por el canal de desagüe (Luquez et al., 2012). En este tipo de sistema, los álamos son plantados en las zonas más elevadas y los sauces, más tolerantes a la inundación, en las zonas más bajas (Borodowski, 2006), asemejándose a las condiciones naturales en los ríos del hemisferio norte, donde las especies de sauces crecen en las partes bajas propensas a inundaciones, mientras que las de álamo crecen en las partes más altas de las riberas (Amlin y Rood, 2001). A este sistema básico se le puede agregar una compuerta, para impedir la entrada del agua a través del canal de desagüe, y un pequeño dique, que consiste en elevar la altura 


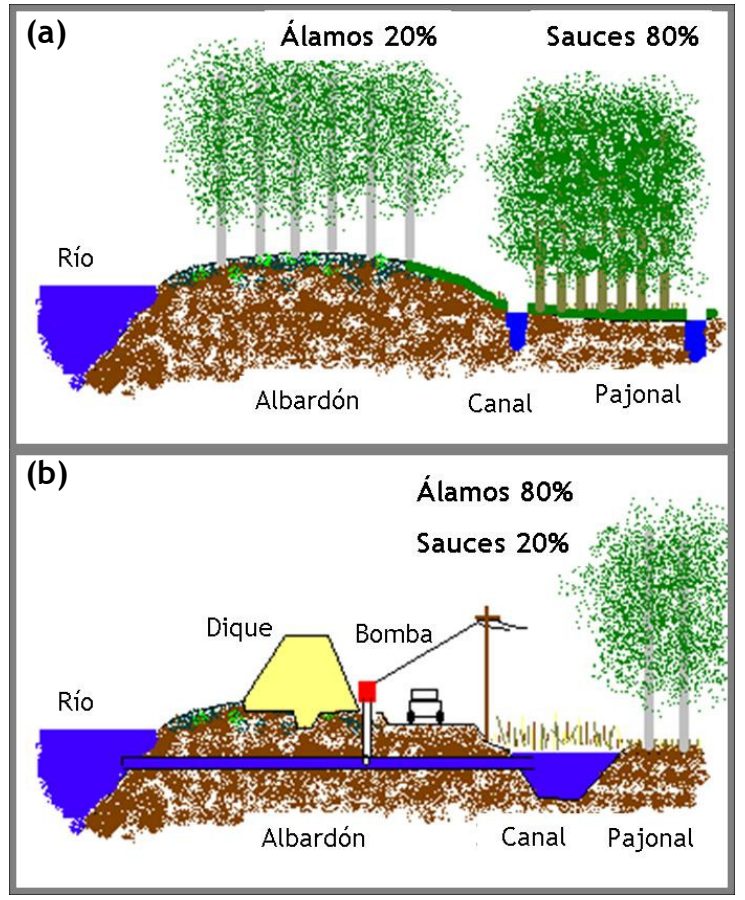

Fig. 1.5. Representación esquemática de los dos principales sistemas de producción para el sector forestal en el Delta del Río Paraná. (a) Sistema "a zanja abierta" sin diques, con canales que desembocan en el río, y donde sólo la parte más alta de la isla $(20 \%$ de la superficie) está plantada con álamos. (b) "Sistema cerrado" con diques, canales de drenaje, compuertas de cierre de los canales, y bombas para eliminar el exceso de agua cuando las puertas están cerradas. En este sistema, el $80 \%$ de la superficie está plantada con álamos. Modificado de Luquez et al. (2012).

natural de los albardones (de 0,5-1,5 $\mathrm{m}$ sobre el nivel del mar) hasta $2 \mathrm{~m}$ (sistema “atajarepuntes”).

Algunos productores han desarrollado un "sistema cerrado" (Fig. 1.5 b), con diques elevados $(6 \mathrm{~m})$, para evitar grandes inundaciones que afectan a los sistemas “atajarepuntes” y “a zanja abierta”, y bombas para desagotar el agua, ya que el “sistema cerrado" no posee compuertas. En este régimen, los álamos son plantados en las zonas bajas, ocupando el $80 \%$ de la superficie (Luquez et al., 2012). El endicamiento protege de inundaciones causadas por crecientes extraordinarias de la cuenca ParanáDe La Plata que ocurren con intervalos de años o décadas (Borodowski, 2006). Sin embargo, una temporada de precipitaciones extraordinarias, combinada con elevados niveles del río, puede causar episodios de inundación en campos endicados que, incluso con bombeo a máxima capacidad, pueden durar varias semanas (Luquez et al., 2012). 


\subsubsection{Fundamentos de la elección del tema}

Las distintas especies del género Populus constituyen una fuente importante de madera, pulpa y fibra, y en los últimos años han adquirido importancia como fuente de energía renovable (Taylor, 2002). Además de su importancia económica, el álamo se ha convertido en un organismo forestal modelo para estudios fisiológicos, genómicos y moleculares (Taylor, 2002; Wullschleger et al., 2002; Jansson y Douglas, 2007), estudios facilitados por la secuenciación del genoma de Populus trichocarpa (Tuskan et al., 2006). La ventaja de Populus como planta modelo para estudios fisiológicos y moleculares es que, siendo una especie de importancia económica, los resultados obtenidos pueden utilizarse directamente como una herramienta para el mejoramiento genético, tanto en álamo como en otras especies forestales. En la zona del Delta del Paraná, donde la forestación con Salicáceas (álamos y sauces) constituye la actividad económica más importante, el estrés por inundación, reduce sensiblemente su productividad (Luquez et al., 2012) y puede causar severas pérdidas económicas en plantaciones comerciales (Borodowski, 2006). Los modelos de posibles escenarios de cambio climático indican que las inundaciones serán más frecuentes en la zona, debido al aumento en la frecuencia de sudestadas y precipitaciones localmente intensas (Camilloni, 2005; Barros et al., 2006). Para que la producción forestal en la zona pueda adaptarse a este nuevo escenario, será necesario disponer de genotipos de álamo con mayor tolerancia a la inundación. Para ello, es imprescindible una mayor comprensión de los mecanismos fisiológicos y bioquímicos que contribuyen a la tolerancia a la inundación en álamo. Este conocimiento servirá como base tanto para los programas de mejoramiento genético clásico como para posibles desarrollos biotecnológicos destinados a incrementar la tolerancia a la inundación en álamo. 


\subsection{OBJETIVOS E HIPÓTESIS DE TRABAJO}

Objetivo general. Caracterizar los cambios morfológicos, anatómicos, fisiológicos y bioquímicos en diferentes órganos de clones de Populus con diversa susceptibilidad a estrés por inundación, durante y después del episodio de estrés.

Hipótesis general. La variación en la tolerancia de las plantas de álamo a la inundación, se relaciona con diferencias en los cambios producidos a nivel morfológico, anatómico, fisiológico y del sistema antioxidante en respuesta al estrés.

\section{Objetivos particulares.}

1. Analizar los cambios morfológicos y anatómicos a nivel de hoja, tallo y raíz, durante un episodio de estrés por inundación y el posterior período de recuperación, en tres clones de Populus deltoides con distinto grado de susceptibilidad a la inundación.

1.1. Determinar si la hormona etileno está involucrada en el desarrollo de aerénquima en respuesta a hipoxia en Populus deltoides.

2. Analizar las respuestas fisiológicas a nivel de hoja durante un episodio de estrés por inundación y el posterior período de recuperación, en tres clones de Populus deltoides con distinto grado de susceptibilidad a la inundación.

3. Caracterizar la respuesta del sistema antioxidante, principalmente a través del contenido de ácido ascórbico y glutatión, durante un período de inundación y el posterior período de recuperación, en dos clones de Populus deltoides con diferente grado de susceptibilidad a la inundación. 


\section{CAPÍTULO 2}

RESPUESTAS MORFOLÓGICAS Y ANATÓMICAS DE

TRES CLONES DE P. DELTOIDES FRENTE A UN EPISODIO DE ESTRÉS POR INUNDACIÓN Y SU POSTERIOR RECUPERACIÓN

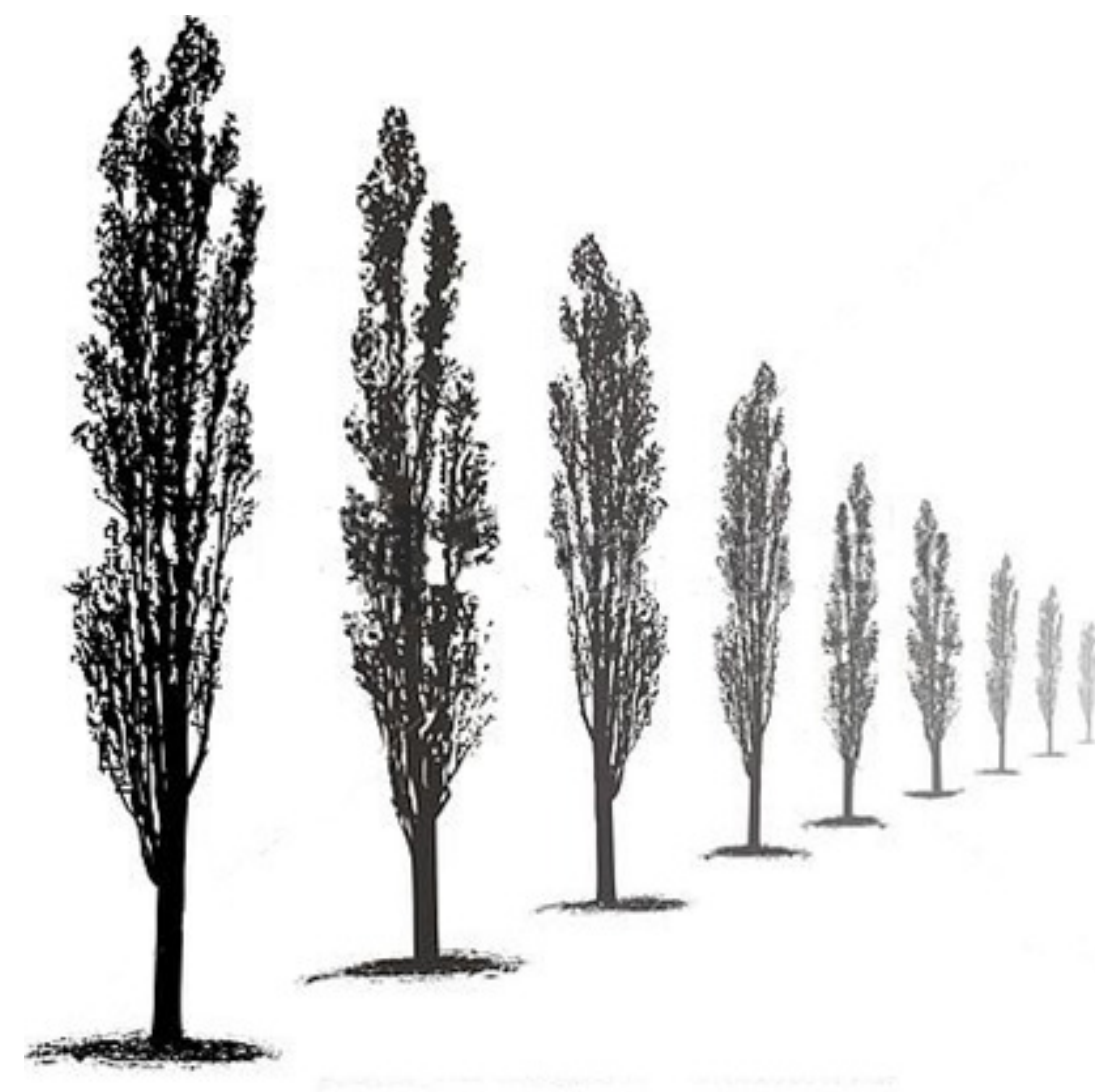




\subsection{INTRODUCCIÓN}

\subsubsection{Respuestas morfológicas a la inundación}

En suelos inundados, la difusión de los gases a través de los poros del suelo está tan restringida por el contenido de agua, que no permite satisfacer las necesidades de las raíces en crecimiento. La ralentización de la entrada de oxígeno, es la principal causa del daño en las raíces, y por lo tanto del tallo que de ellas depende (Vartapetian y Jackson, 1997). El oxígeno disuelto en el agua de un suelo inundado en equilibrio con el aire es aproximadamente un $3 \%$ de la que tendría el mismo volumen de aire $(0,006$ 0,01 moles $\mathrm{O}_{2} \mathrm{~m}^{-3}$ en lugar de 0,25 moles $\mathrm{O}_{2} \mathrm{~m}^{-3}$ ). Esta pequeña cantidad es rápidamente consumida por microorganismos aeróbicos y las raíces (Jackson, 2004).

La inundación del suelo reduce el crecimiento de las raíces de la mayoría de las plantas leñosas induciendo el deterioro de las raíces existentes e inhibiendo la formación y el crecimiento de raíces nuevas (Kozlowski, 1997; Cao y Conner, 1999). La interrupción del crecimiento de las raíces y su muerte, se producen principalmente porque la demanda de ATP es mayor que la disponibilidad (debido al cambio de metabolismo aeróbico a anaeróbico), y por envenenamiento con productos del metabolismo anaeróbico (Jackson, 2004).

La formación de raíces adventicias es una de las respuestas más comunes en especies tolerantes a inundación. Estas raíces, que pueden ser más porosas (Visser et al., 1996), se desarrollan en la parte sumergida del tallo, en la región donde las lenticelas hipertrofiadas son más abundantes, y su crecimiento, es paralelo y cercano a la superficie del agua (Yamamoto et al., 1995; Parent et al., 2008). La formación de estas raíces especializadas ocurre cuando las raíces basales, bajo las condiciones anaeróbicas generadas por la inundación, ya no son capaces de continuar abasteciendo 
a la planta de agua y minerales debido al insuficiente suministro de energía respiratoria (Mergemann y Sauter, 2000). El desarrollo de estas raíces se ha observado en distintos clones de $P$. deltoides sometidos a inundación (Fig. 2.1) (Pereira y Kozlowski, 1977; Cao y Conner, 1999).

De acuerdo a Jackson (2004), existen tres mecanismos de generación de estas raíces de reemplazo: (I) estimulo del crecimiento de primordios radicales preexistentes en la base del tallo (como en Zea mays); (II) Inducción de formación de nuevos primordios radicales y su posterior desarrollo (como en Helianthus annuus y Rumex palustris); el etileno estaría involucrado en estos dos mecanismos, aumentando la sensibilidad de los tejidos a la hormona auxina (Visser et al., 1996); y (III) ubicación de las raíces en la superficie del suelo debido a la reorientación de su crecimiento; las raíces laterales de algunas especies leñosas (Pereira y Kozlowski, 1977) y herbáceas (Gibberd et al., 2001) crecen hacia arriba en suelos inundados emergiendo del suelo hacia la superficie del agua.

Además de los cambios morfológicos en raíces, el tallo también se ve afectado en un episodio de inundación. Diferentes clones de $P$. deltoides sometidos a inundación parcial disminuyen la elongación del tallo, hasta que se produce la formación de raíces adventicias, y el crecimiento se incrementa nuevamente (Cao y Conner, 1999). En otros casos, la elongación del tallo de plantas inundadas de $P$. deltoides, se mantiene igual que la de sus contrapartes no inundadas (Regehr et al., 1975).

Varios rasgos morfológicos foliares, relacionados con la productividad en Populus, son afectados por la inundación, como el área total (Rae et al., 2004; Monclus et al., 2005; Marron et al., 2005), el número de hojas del tallo principal (Rae et al., 2004), el área foliar individual (Monclus et al., 2005; Marron et al., 2005), el área foliar específica (Marron et al., 2005) y el índice estomático (Al Afas et al., 2006). Clones de $P$. deltoides inundados hasta $3 \mathrm{~cm}$ por encima de la superficie del suelo, reducen el 


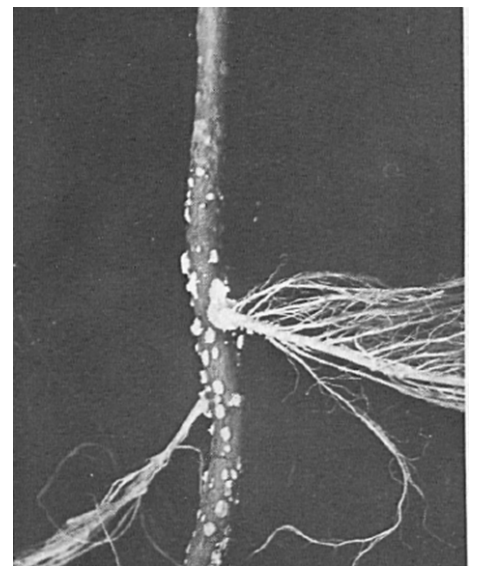

Fig. 2.1. Lenticelas hipertrofiadas y raíces adventicias desarrolladas en la base del tallo de $P$. deltoides sometido a 37 días de inundación. Pereira y Kozlowski (1977).

área foliar deteniendo la formación y el crecimiento de nuevas hojas, e induciendo la abscisión de hojas viejas (Cao y Conner, 1999). En P. trichocarpa x deltoides, la hipoxia de la zona radical disminuye la tasa de crecimiento foliar, y el tamaño final de la hoja, a través de la reducción del tamaño y número de células por una menor extensibilidad de la pared celular (Smit et al., 1989). En P. angustifolia, la inundación reduce el número y, principalmente, el tamaño de las hojas (Rood et al., 2010). Plantas de Populus con sus raíces inundadas, sufren un aumento del peso específico foliar (o disminución del área foliar específica) (Liu y Dickman, 1992). La combinación de la reducción de la tasa de expansión foliar y la aceleración de la senescencia y abscisión foliar, reducen el área fotosintéticamente activa, disminuyendo así la productividad de la planta debido a una gran disminución en la disponibilidad de fotosintatos destinados para el crecimiento de la planta.

La densidad estomática es un parámetro ecofisiológico importante que afecta el intercambio gaseoso, la conductancia estomática y la eficiencia del uso del agua instantánea (Ceulemans et al., 1995). Las especies de álamos poseen gran variación interespecífica e interclonal, en la dimensión y densidad de estomas e índice estomático (IE, ver definición en materiales y métodos) (Pallardy y Kozlowski, 1979; Ceulemans et 
al., 1984; Ceulemans et al., 1995; Al Afas et al., 2006). Además, existen variaciones en la dimensión y densidad estomática según la ontogenia y nivel de inserción de la hoja (Masarovicova, 1991; Ceulemans et al., 1995; Al Afas et al., 2006).

En plantas leñosas, una característica morfológica importante de especies tolerantes a inundación, es la formación de lenticelas hipertrofiadas en la base del tallo (Fig. 2.1) (Yamamoto et al., 1995; Kozlowski, 1997). Clones de P. deltoides tolerantes a la inundación, desarrollan lenticelas hipertrofiadas unos días antes de la aparición de raíces adventicias (Pereira y Kozlowski, 1977; Cao y Conner, 1999). Se ha observado que luego de una disminución transitoria, la conductancia estomática de plantas sometidas a inundación, vuelve a los niveles de las plantas control de forma asociada al desarrollo de lenticelas hipertrofiadas (Pezeshki y Anderson, 1997; Folzer et al., 2006).

Las lenticelas hipertrofiadas son un tejido blanco y esponjoso con gran volumen de espacios gaseosos intercelulares, que surge en el exterior del tallo por divisiones celulares sucesivas del felógeno (Armstrong et al., 1994). Este tejido es aerénquima secundario hipertrofiado, distinto morfológica y anatómicamente del aerénquima primario (aerénquima lisígeno o esquizógeno) (Shimamura et al., 2010).

La morfología y anatomía de las lenticelas las hacen aptas para el intercambio de agua, $\mathrm{O}_{2}$ y CO $\mathrm{CO}_{2}$ (Lendzian, 2006). Según Kozlowski (1997) y Shimamura et al. (2010), estas estructuras permitirían la entrada de oxígeno a raíces poco profundas de plantas anegadas, a través de aerénquima y espacios intercelulares. Otros autores han propuesto que su función principal sería ayudar a mantener el estado hídrico de la planta durante inundaciones, mediante el suministro parcial de agua a los tallos, reemplazando a las raíces poco funcionales (Parent et al., 2008).También se ha propuesto que su función sería permitir la disipación de compuestos volátiles generados metabólicamente, como etanol, etileno y acetaldehído (Jackson, 2004). 


\subsubsection{Respuestas anatómicas a la inundación}

La formación de aerénquima en el córtex de la raíz es una de las respuestas a la inundación más estudiadas (Justin y Armstrong, 1987; Colmer et al., 1998; Drew et al., 2000; Visser et al., 2000; Evans, 2003; Seago et al., 2005; Striker et al., 2007). El termino aerénquima se utiliza para designar a aquellos tejidos vegetales que poseen grandes espacios de aire, mayores a los espacios intracelulares encontrados normalmente (Jackson y Armstrong, 1999; Evans, 2003; Seago et al., 2005). Este tejido se forma en raíces y tallos de especies adaptadas a humedales y en algunas especies de tierras secas en condiciones adversas, ya sea constitutivamente o debido a estrés abiótico (Evans, 2003) como, inundación (Jackson, 1990) e hipoxia (Sairam et al., 2009) entre otros.

El aerénquima de raíz es un sistema de espacios aéreos interconectados que se extiende hasta el tallo, y provee a la planta de un sistema continuo de baja resistencia para el transporte de oxígeno desde tallos no sumergidos a raíces sumergidas, evitando la anoxia en la zona radical y permitiendo así que las raíces se sigan elongando y explorando el suelo en las condiciones anaeróbicas generadas por inundación (Jackson, 1990; Colmer, 2003 b). Además, el aerénquima reduce el número de células que respiran, característica que puede ayudar en un ambiente con baja presión de $\mathrm{O}_{2}$ (Drew et al., 2000).

El arreglo espacial del aerénquima formado en el córtex de la raíz en respuesta a inundación, es variable entre especies y genotipos (Justin y Armstrong, 1987; Visser et al., 2000; Colmer, 2003 b; Seago et al., 2005). Los diferentes tipos de aerénquima surgen de la combinación de 4 tipos estructurales generales, Gramíneas, Ciperáceas, Apium y Rumex, que han sido descriptos de acuerdo al arreglo espacial del tejido aerenquimático y de la forma de empaquetamiento de las células del córtex (Justin y 


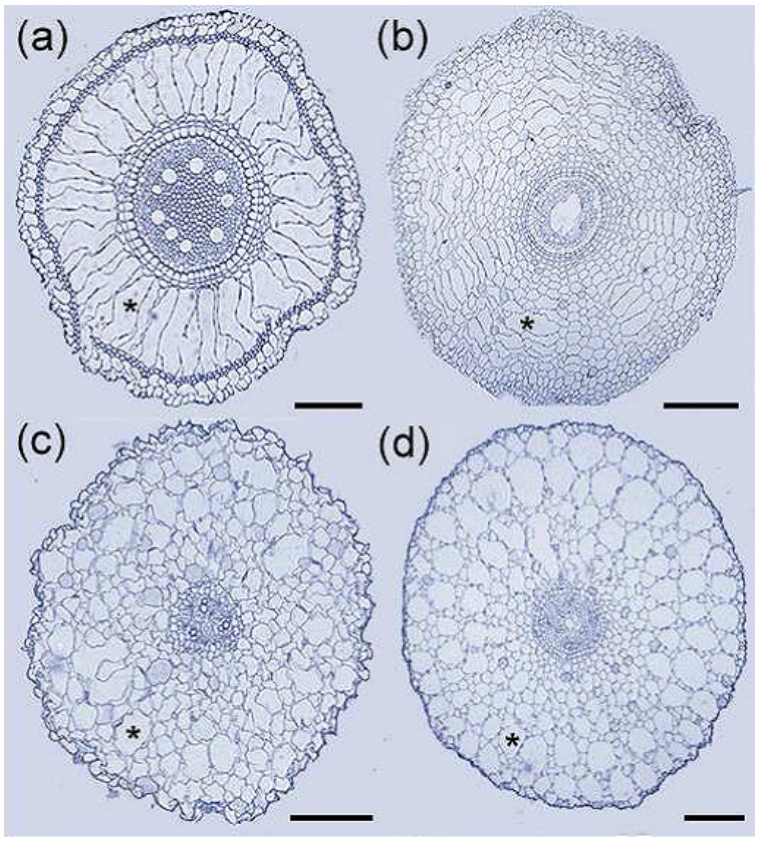

Fig. 2.2. Cortes transversales de raíz mostrando los cuatro tipos principales de aerénquima: (a) rueda de bicicleta en Paspalum dilatatum Poir. (Gramíneas), (b) tela de araña en Cyperus eragrostis Lam. (Ciperáceas), (c) no organizada en Lotus tenuis Waldst. Y Kit. (tipo Apium), y (d) panal de abejas en Rumex crispus L. (tipo Rumex). Los asteriscos señalan lagunas aerenquimaticas. Las barras de escala representan $150 \mu \mathrm{m}$. Modificado de Striker (2012).

Armstrong, 1987; Seago et al., 2005). La forma de estos tipos de raíz (Fig. 2.2) se asemeja a una rueda de bicicleta (Gramíneas), una tela de araña (Ciperáceas), un panal de abejas (Rumex), y una estructura no organizada con lagunas aerenquimáticas irregulares (Apium) (Justin y Armstrong, 1987; Striker et al., 2007). 


\subsection{OBJETIVO E HIPÓTESIS}

Objetivo. Analizar los cambios morfológicos y anatómicos a nivel de hoja, tallo y raíz, durante un episodio de estrés por inundación y el posterior período de recuperación, en tres clones de Populus deltoides con distinto grado de susceptibilidad a la inundación.

Hipótesis. Los clones más tolerantes a la inundación mantienen el crecimiento gracias al desarrollo de respuestas adaptativas que les permiten retener una mayor área foliar y una mayor biomasa radical que los clones más susceptibles 


\subsection{MATERIALES Y MÉTODOS}

\subsubsection{Material vegetal, diseño experimental y tratamiento de estrés}

Para los experimentos se utilizaron clones con diferente grado de susceptibilidad a la inundación en base a un screening de clones comerciales y experimentales de Populus deltoides y de Populus $x$ canadensis más comúnmente plantados en la región del Delta del Paraná (Luquez et al., 2012). La susceptibilidad a la inundación se determinó en base a la reducción del crecimiento en altura y diámetro de dichos clones ante un episodio de anegamiento, el grado de desarrollo de raíces adventicias y lenticelas hipertrofiadas, y el mantenimiento del área foliar (Luquez et al., 2012). En base a este screening se eligieron tres clones de Populus deltoides, Alton (ALT), Stoneville 67 (ST67) y 149-82 (Tabla 2.1), con comportamientos contrastantes frente a la inundación, siendo ALT el más tolerante, 149-82 el más afectado y ST67 intermedio entre ambos.

Se realizaron dos experimentos con los clones seleccionados:

Experimento 2009. Estacas de 1 año de edad, de $60 \mathrm{~cm}$ de longitud, se obtuvieron de un estaquero y se almacenaron a $4^{\circ} \mathrm{C}$ hasta el día de su plantación, 7 de agosto de 2009. Las estacas fueron sumergidas completamente en agua durante toda la noche y luego tratadas, por sumersión, con Captan $(3 \mathrm{~g} / \mathrm{L})$ y Oxicloruro de cobre $(4$ $\mathrm{g} / \mathrm{L}$ ), durante $1 \mathrm{~h}$ con cada fungicida. A continuación, las estacas fueron plantadas en macetas de $7 \mathrm{~L}$ rellenas con tierra. Las macetas fueron colocadas en invernáculo en un diseño totalmente aleatorizado, colocando 10 replicas para cada clon y cada tratamiento. Las macetas se regaron a capacidad de campo hasta el inicio del experimento. La irradiancia dentro del invernáculo en días despejados alcanzó un valor máximo de $1282 \mu$ moles $\mathrm{m}^{-2} \mathrm{~s}^{-1}$. 


\begin{tabular}{|cccc|}
\hline Clon & Padres & País de origen & Sexo \\
\cline { 1 - 3 } $\begin{array}{c}\text { Alton } \\
\text { (ALT) }\end{array}$ & $\begin{array}{c}\text { Desconocidos, } \\
\text { polinización abierta }\end{array}$ & Estados Unidos & Masculino \\
$\begin{array}{c}\text { Stoneville } 67 \\
\text { (ST67) }\end{array}$ & $\begin{array}{c}\text { Madre seleccionada, } \\
\text { polinización abierta }\end{array}$ & $\begin{array}{c}\text { Condado de Issaquena, } \\
\text { Mississippi, Estados Unidos }\end{array}$ & Masculino \\
$\begin{array}{c}\text { 149-82 } \\
(149-82)\end{array}$ & $\begin{array}{c}\text { Madre seleccionada, } \\
\text { polinización abierta }\end{array}$ & Mississippi, Estados Unidos & Masculino \\
\hline
\end{tabular}

Tabla 2.1. Populus deltoides usados en esta tesis. El país de origen se refiere a la región geográfica de donde proviene la madre.

Todas las plantas brotaron entre el 20 y el 31 de agosto de 2009. Un fertilizante comercial de liberación lenta (NPK 12:5:14 plus Mg, S, Ca, Zn, Fe, Mo y B) fue aplicado a las macetas para asegurar la disponibilidad adecuada de nutrientes. La dosis fue de 1 g de fertilizante por maceta y fue realizado 2 veces antes del inicio del tratamiento de inundación. Para evitar enfermedades fúngicas, los árboles fueron tratados una vez por semana con 2 fungicidas comerciales (Benomyl 50\% WP y Carbendazim 50\% SC) de acuerdo a las instrucciones de los fabricantes. Antes de iniciar el tratamiento, los árboles fueron podados y solo se mantuvo un brote a fin de minimizar la variabilidad inducida por diferencias en el número de brotes por planta.

El período de inundación se inició cuando los brotes tenían 2 meses de edad, 28 de octubre de 2009, y duró 35 días. El tratamiento de estrés fue impuesto colocando las macetas de $7 \mathrm{~L}$ dentro de macetas selladas de $10 \mathrm{~L}$ llenas con agua hasta aproximadamente $5 \mathrm{~cm}$ por encima del nivel del suelo (Fig. 2.3); se añadió agua para mantener el nivel cuando fue necesario. Las plantas control fueron regadas regularmente manteniendo el suelo a capacidad de campo. Luego de 35 días, el tratamiento de estrés fue finalizado. 

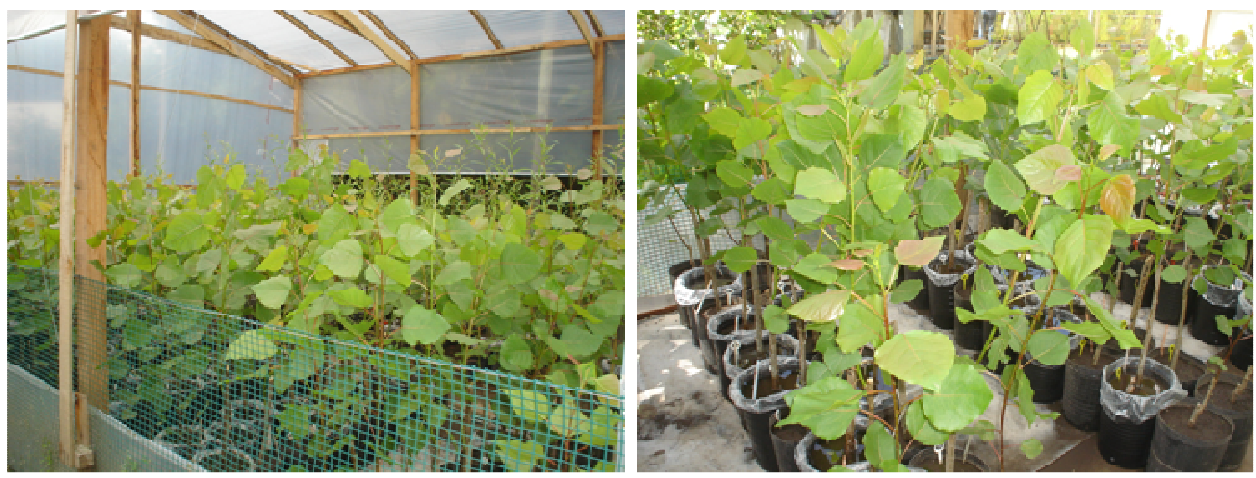

Fig. 2.3. Vista general del experimento 2009.

Experimento 2011-A. Estacas de 1 año de edad, de $20 \mathrm{~cm}$ de longitud, fueron obtenidas de estaqueros y almacenadas a $4^{\circ} \mathrm{C}$ hasta su plantación, el 3 de agosto de 2011, en macetas de 2,5 L rellenas con una mezcla 1:1 de tierra - arena. Las estacas fueron tratadas con fungicidas como se describe para el experimento 2009. Las macetas fueron colocadas en invernáculo en un diseño totalmente aleatorizado con 12 réplicas por cada clon y tratamiento. Las condiciones de crecimiento fueron similares a las descriptas para el experimento 2009, excepto por la fertilización. En este experimento, las macetas fueron regadas semanalmente con $50 \mathrm{ml}$ de solución de Hoagland completa (Legget y Frere, 1971).

La inundación fue impuesta colocando las macetas de 2,5 L dentro de macetas selladas de $4 \mathrm{~L}$ como se describió anteriormente. Las plantas control se mantuvieron a capacidad de campo. El tratamiento de estrés por inundación comenzó el 2 de noviembre de 2011 y duró 28 días. Luego, las plantas previamente inundadas, fueron removidas de las macetas selladas permitiendo el drenaje del agua y se mantuvieron a capacidad de campo durante 44 días.

En este experimento se marcaron 3 hojas en cada planta, como se describe en Luquez et al. (2012), representado distintas cohortes: una hoja expandida previo al inicio de la inundación (L1), una expandida durante la inundación (L2) y una expandida 
luego del final del período de inundación (L3). En estas hojas se realizaron distintas mediciones morfológicas, fisiológicas y bioquímicas.

\subsubsection{Tasa de difusión de oxígeno (ODR)}

La tasa de difusión de oxígeno (ODR, Oxygen Diffusion Rate) fue medida en el suelo circundante a las raíces utilizando un medidor de ODR (Biocontrol, Buenos Aires) de acuerdo a las instrucciones del fabricante. Las mediciones se realizaron al final del período de inundación del experimento 2009 en 5-8 réplicas por clon y tratamiento.

\subsubsection{Crecimiento}

Altura del tallo. La altura del tallo $(\mathrm{en} \mathrm{cm}$ ) fue medida semanalmente con una vara graduada en ambos experimentos.

Diámetro del tallo. El diámetro basal del tallo $(\mathrm{mm})$ fue medido semanalmente en el experimento 2009 con un calibre.

Índice de Volumen (IV). El IV (en $\mathrm{cm}^{3}$ ) (Luquez et al., 2012) al final del experimento 2009, fue calculado como:

$$
\mathrm{IV}=(\text { diámetro basal })^{2 *} \text { altura total }
$$

Tasa de Crecimiento Relativo en Altura (TCR). La TCR del tallo al finalizar el período de inundación en el experimento 2009 fue calculada como:

$$
T C R=\left(\ln A_{f}-\ln A_{i}\right) / \text { número de días }
$$


donde, $A_{f}$ es la altura final, $A_{i}$ es la altura, y numero de días, son los días transcurridos entre las mediciones inicial y final de altura (Whitehead y Myerscough, 1962).

\subsubsection{Partición de materia seca}

La relación raíz / vástago (tallo + hojas) se calculó en el experimento 2009. Para ello, una vez finalizado el experimento, las hojas, el tallo y las raíces fuero secadas en estufa a $65^{\circ} \mathrm{C}$ hasta peso constante para determinar el peso seco.

\subsubsection{Características foliares}

Número de hojas del tallo principal. Fue registrado contando todas las hojas mayores a $2 \mathrm{~cm}$ de longitud (Ceulemans et al., 1988), al final del experimento 2009.

Al final del experimento 2011-A, se realizó el recuento del número de hojas expandidas antes-durante el episodio de inundación y las expandidas en el período pos inundación.

Área foliar. En el experimento 2009, el área foliar total $\left(\mathrm{cm}^{2}\right)$ se midió al final del experimento con un medidor de área foliar LICOR LI 3100. A continuación, las hojas se secaron en estufa por 72 hs a $65^{\circ} \mathrm{C}$ para determinar el peso seco. El área foliar individual $\left(\mathrm{cm}^{2}\right)$ y el área foliar especifica $\left(\mathrm{cm}^{2} \mathrm{~g}^{-1}\right)$ fueron determinados en la última hoja completamente expandida.

En el experimento 2011-A, las hojas fueron escaneadas y el área foliar total y área foliar individual fueron determinados con el programa Image $\mathrm{J}$ (http://rsbweb.nih.gov/ij/). 
Índice estomático (IE). Se tomaron impresiones de la superficie abaxial de las hojas L1, L2 y L3 (ver Material vegetal, diseño experimental y tratamiento de estrés, experimento 2011-A), utilizando esmalte incoloro y cinta adhesiva transparente. Las impresiones fueron fijadas en portaobjetos, observadas a $20 \times$ y fotografiadas con una cámara digital Olympus Evolt E-330. Se tomaron 4 fotografías por cada impronta, representando cada una un campo de observación diferente. El número de estomas por campo (densidad estomática) y el número de células epidérmicas por campo (densidad células epidérmicas) fueron contados utilizando el programa Image J (http://rsbweb.nih.gov/ij/). El IE fue calculado de acuerdo a Masle et al. (2005):

$\mathrm{IE}=100 \times(($ densidad estomática $) /($ densidad estomática + densidad células epidérmicas $))$

Grosor de lámina. Una porción de hoja rodeando a la vena principal de las hojas L1, L2 y L3 (ver Material vegetal, diseño experimental y tratamiento de estrés, experimento 2011-A), fue fijada en FAA (formol : ácido acético glacial : alcohol etílico una relación 10 : 5 : 50; D`ambrogio de Argueso, 1986). Las hojas fueron cortadas a mano alzada con hoja de afeitar. Siete cortes por cada muestra fueron observados a 10 x y fotografiados con una cámara digital Olympus Evolt E-330. Se realizaron 3 mediciones a cada lado de la vena principal en cada corte. El grosor de lámina de cada muestra fue calculado como un promedio de las 6 mediciones hechas en los 7 cortes.

\subsubsection{Lenticelas hipertrofiadas y raíces adventicias}

En el experimento 2009 se registró el desarrollo de lenticelas hipertrofiadas y raíces adventicias en la base del tallo (parte sumergida) a lo largo del período de inundación. Las observaciones se hicieron a diario, registrando la aparición de alguna de estas estructuras en todas las plantas inundadas de cada uno de los 3 clones. 


\subsubsection{Aerénquima de raíz}

Al final del periodo de inundación en el experimento 2009, se tomaron muestras de las regiones apicales de raíces nuevas de los distintos clones. Las muestras fueron fijadas en FAA hasta el momento de realizar cortes para determinar la presencia o ausencia de aerénquima. Las muestras fueron incluidas en parafina, cortadas con micrótomo, observadas a 10 x y fotografiadas con una cámara digital Olympus Evolt E330.

\subsubsection{Análisis estadístico}

El análisis estadístico fue llevado a cabo con los programas STATISTICA versión 7.1 (StatSoft, Inc., 2005) y $\mathrm{R}$ versión 2.8.1 (R Development Core Team, 2010). Se realizaron análisis de medias y de varianza (ANOVA de una vía), utilizando el paquete agricolae $R$. Los análisis de correlación de variables fueron realizados con el STATISTICA. Los datos fueron transformados para satisfacer los requerimientos del ANOVA cuando fue necesario. En caso de transformación de datos se indica en el gráfico o tabla correspondiente a la variable transformada. 


\subsection{RESULTADOS}

\subsubsection{ODR}

La inundación de las raíces redujo dramáticamente la tasa de difusión de oxígeno (ODR) en el experimento 2009; el valor promedio para las plantas control fue de $36,5 \mu \mathrm{g}$ $\mathrm{cm}^{-2} \min ^{-1}$ mientras que para las plantas inundadas fue de $2,7 \mu \mathrm{g} \mathrm{cm}^{-2} \min ^{-1}$. Hubo problemas de heterocedasticidad con estos datos y las transformaciones realizadas sobre los datos, no resolvieron estos problemas. Sin embargo, la gran diferencia en la disponibilidad de oxígeno para las raíces entre los tratamientos es muy evidente.

\subsubsection{Crecimiento}

Durante las primeras 2 semanas de inundación, no hubo diferencias de altura entre las plantas control e inundadas de ninguno de los clones, pero luego de 3 semanas comenzaron a aparecer diferencias marcadas entre los clones (Fig. 2.4), en ambos experimentos. El crecimiento en altura de ALT (Fig. 2.4, a y d) no fue afectado por la inundación, mientras que las plantas de 149-82 (Fig. 2.4, b y e) y ST67 (Fig. 2.4, c y f) inundadas redujeron su altura significativamente con respecto a las plantas control. Al final del período de inundación en el experimento 2009, 149-82 inundado redujo su altura en un $26 \%$ comparado con el control mientras que ST67 lo hizo en un $13 \%$. Los resultados fueron similares en ambos experimentos.

En el experimento 2011-A, la recuperación de las plantas inundadas fue monitoreada durante 42 días luego de finalizado el episodio de inundación. No hubo diferencias significativas de crecimiento entre las plantas inundadas y control de ALT (Fig. 2.4, d). Al final del período de recuperación, las plantas de ST67 (Fig. 2.4, e) previamente inundadas alcanzaron el nivel de altura de las plantas control, mientras 

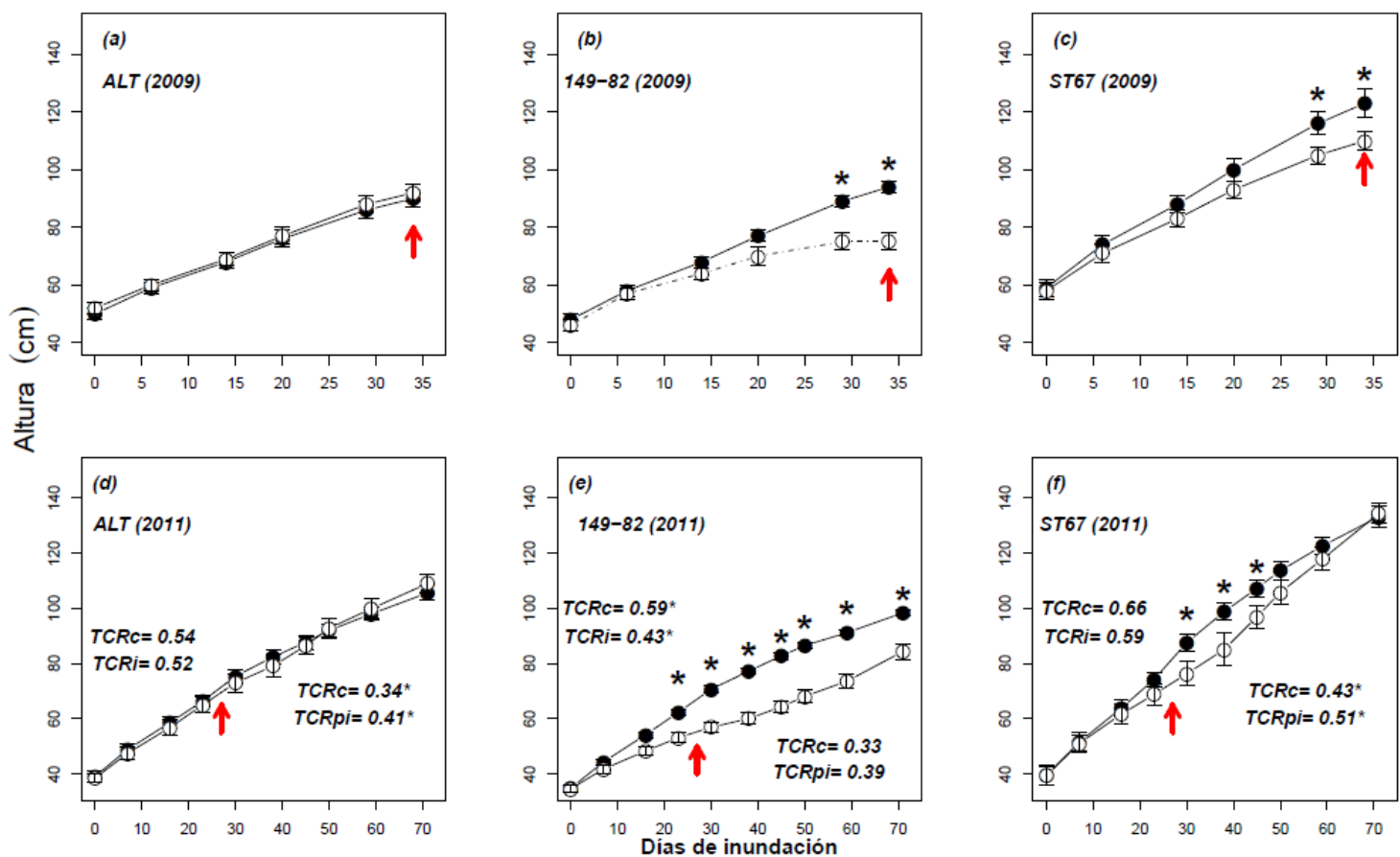

Fig. 2.4. Altura del tallo ( $\mathrm{cm}$ ) en los experimentos 2009 ( $a$, b y c) y 2011 ( $d$, e y f) de los clones ALT, 149-82 y ST67. Los círculos negros corresponden a las plantas control y los blancos a las plantas inundadas. La flecha roja indica el final del tratamiento de inundación. Los valores de TCR indicados en el Experimento 2011-A, son del período de inundación a la izquierda, y del periodo de recuperación a la derecha. C: control, I: inundado, pi: pos inundación. Los asteriscos señalan diferencias estadísticamente significativas $(p<0.05$ LSD) entre las plantas control e inundadas de un mismo clon.

que las de 149-82 (Fig. 2.4, f) previamente inundadas continuaron siendo significativamente de menor altura que las plantas control.

La TCR no varía significativamente durante la inundación en los clones ALT Y ST67 pero si se reduce en 149-82 (TCRc y TCRi, Fig. 2.4, d, e y f). Durante el período de recuperación, la TCR de ALT y ST67 previamente inundados, aumenta significativamente (TCRC y TCRpi, Fig. 2.4, d, e y f).

Con los datos del diámetro y altura del tallo al final del experimento 2009, se calculó el Índice de Volumen (IV), medida que refleja el crecimiento combinando ambos 


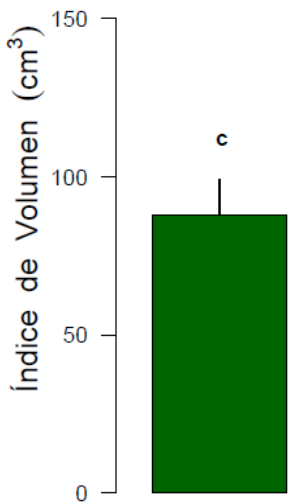

ALT C

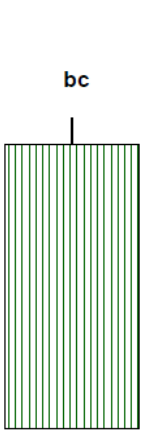

ALT

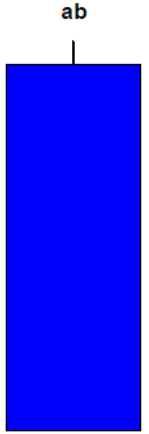

$149 \mathrm{C}$

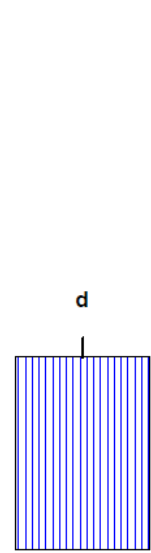

149 I

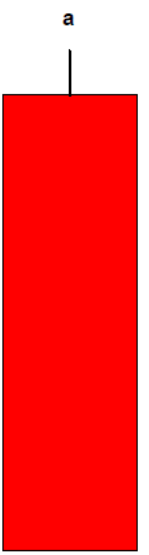

ST67 C

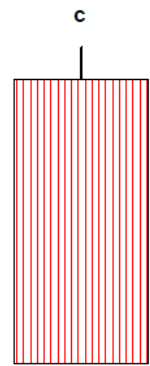

ST67।

Fig. 2.5. Índice de Volumen (IV, $\mathrm{cm}^{3}$ ) de los clones ALT, 149-82 (149) y ST67 al final del experimento 2009. C: control, I: inundado. Los datos fueron transformados a logaritmo decimal para satisfacer los requerimientos del ANOVA, pero se expresan en los valores sin transformar. Las medias con la misma letra no difieren significativamente $(p<0.05$ LSD).

parámetros. En condiciones control, el IV de ALT fue significativamente menor al de 149-82 y ST67, siendo su valor similar al de ST67 I. En condiciones de inundación, IV se redujo significativamente en 149-82 y ST67 (Fig. 2.5), pero no en ALT.

\subsubsection{Partición de materia seca}

En el experimento 2009 se evaluó la partición de materia seca. El peso seco total solo se redujo significativamente en 149-82 inundado, pero la inundación alteró la partición de materia seca en todos los clones (Fig. 2.6). La biomasa foliar solo disminuyó significativamente en las plantas inundadas de 149-82, mientras que la biomasa de tallo y la de raíces, se redujeron de manera significativa tanto en las plantas inundadas de 149-82 como las de ST67. Las plantas inundadas de ALT no mostraron variaciones significativas en ninguna de estas variables de crecimiento. Sin embargo, la menor 


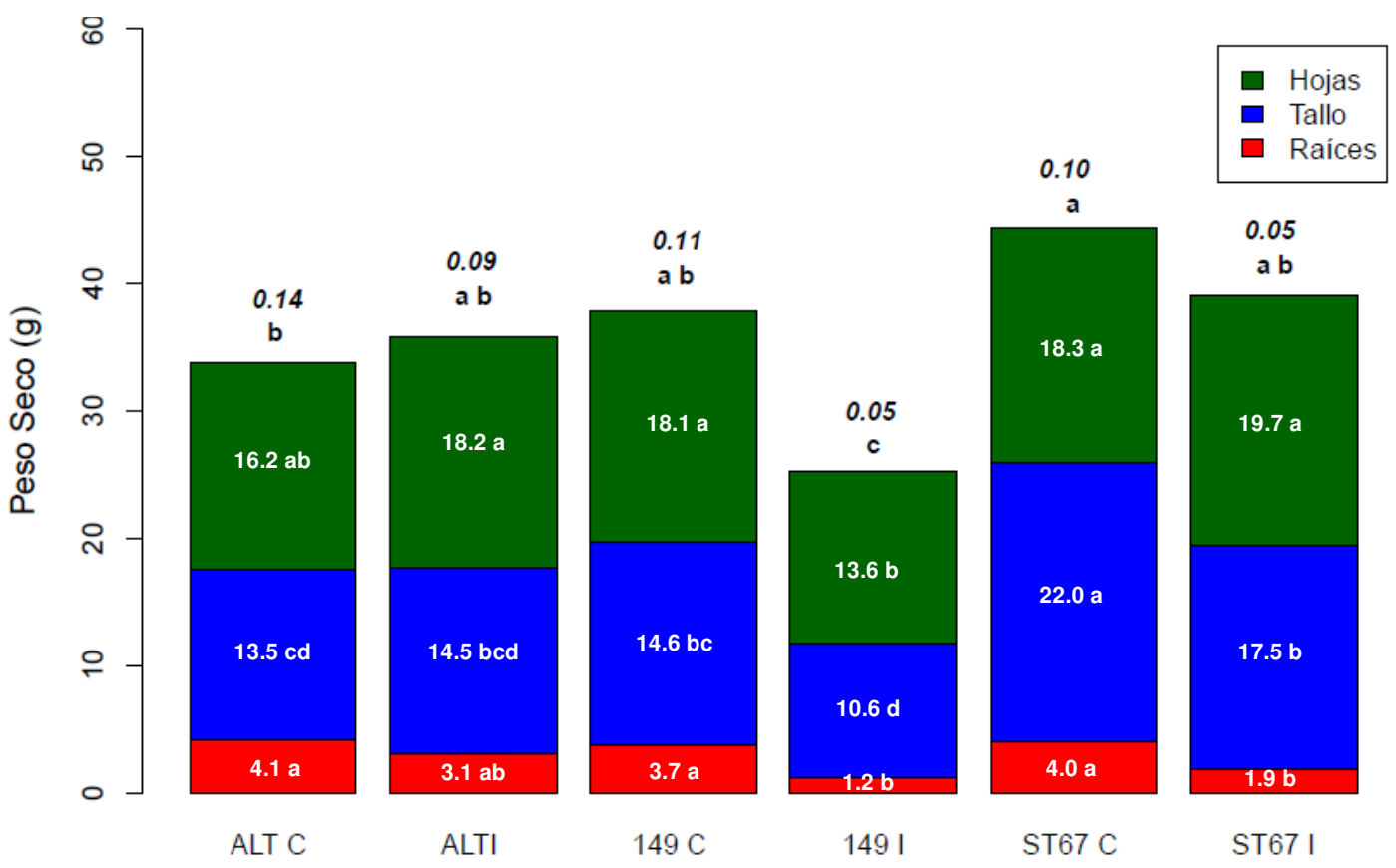

Fig. 2.6. Partición de materia seca entre raíces, tallo y hojas en los clones ALT, 149-82 y ST67, en el experimento 2009. C: control, I: inundado. En itálicas sobre las columnas se indica la relación raíz / vástago para cada clon y tratamiento. Dentro de las columnas se indican las medias de cada compartimento para cada clon y tratamiento. Las medias con la misma letra no difieren significativamente $(p<0.05$ LSD) entre el mismo compartimento para los distintos clones y tratamientos.

pérdida de biomasa radical en ALT inundado, provocó una menor disminución de esta relación. La biomasa radical de las plantas inundadas disminuyó un 25\%, 52\% y $66 \%$ con respecto a las plantas control para los clones ALT, ST67 y 149-82 respectivamente. Esta diferencia, sumada a las diferencias en el crecimiento de la parte aérea, provocaron las diferencias en la relación raíz / vástago (Fig. 2.6, en itálicas), siendo 35\% menor en las plantas inundadas de ALT con respecto a las control, 50\% menor en las de ST67 y 55\% en las de 149-82.

Las tablas 2.2 a y 2.2 b muestran la relación entre el área foliar total (Fig. 2.7), con respecto al índice de volumen del tallo (IV, Fig. 2.5) y a la biomasa de raíces (Fig. 2.6), al final del experimento 2009. Tanto para el tratamiento control como para el 
(a)

\begin{tabular}{|c|c|c|c|}
\hline Factores & $\boldsymbol{r}$ & $\boldsymbol{R}^{2}$ & $\boldsymbol{P}$ \\
\hline Todos C & 0,9114 & 0,8306 & $0,0000^{*}$ \\
\hline Todos I & 0,8396 & 0,7048 & $0,0000^{*}$ \\
\hline ALT C & 0,9071 & 0,8229 & $0,0019^{*}$ \\
\hline ALT I & 0,4063 & 0,1651 & 0,3179 \\
\hline $149-82$ C & 0,9613 & 0,9241 & $0,0001^{*}$ \\
\hline $149-82$ I & 0,7915 & 0,6265 & $0,0339^{*}$ \\
\hline ST67 C & 0,9350 & 0,8742 & $0,0007^{*}$ \\
\hline ST67 I & 0,9670 & 0,9350 & $0,0000^{*}$ \\
\hline
\end{tabular}

(b)

\begin{tabular}{|c|c|c|c|}
\hline Factores & $\boldsymbol{r}$ & $\boldsymbol{R}^{\mathbf{2}}$ & $\boldsymbol{P}$ \\
\hline Todos C & 0,5879 & 0,3457 & $0,0025^{*}$ \\
\hline Todos I & 0,4362 & 0,1903 & $0,0375^{*}$ \\
\hline ALT C & 0,5387 & 0,2902 & 0,1683 \\
\hline ALT I & 0,3844 & 0,1478 & 0,3471 \\
\hline $149-82$ C & 0,7502 & 0,5627 & $0,0321^{*}$ \\
\hline $149-82$ I & 0,7930 & 0,6288 & $0,0334^{*}$ \\
\hline ST67 C & 0,8606 & 0,7407 & $0,0061^{*}$ \\
\hline ST67 I & 0,8101 & 0,6562 & $0,0148^{*}$ \\
\hline
\end{tabular}

Tabla 2.2. Análisis de correlación: (a) área foliar total e índice de volumen y (b) área foliar total y biomasa de raíces, para los clones ALT, 149-82 y ST67 en el experimento 2009. Todos: todos los clones, C: control, I: inundado, r: coeficiente de correlación producto-momento, $\mathrm{R}^{2}$ : coeficiente de determinación, p: valor p. Los asteriscos indican resultados estadísticamente significativos $(p<0.05)$.

inundado, se observó una correlación positiva significativa en la relación entre el área foliar total y el IV, siendo menor para el tratamiento inundado (Todos C y Todos I, Tabla 2.2 a). 149-82 y ST67 mostraron correlaciones positivas significativas en ambos tratamientos (control e inundado), mientras que ALT solo mostró una correlación positiva significativa en el tratamiento control.

En cuanto al área foliar total y la biomasa de raíces, el análisis estadístico mostró correlaciones positivas significativas para los tratamientos control e inundado, siendo menor para el tratamiento inundado (Todos C y Todos I, Tabla 2.2 b). Los clones 149-82 y ST67 mostraron correlaciones positivas significativas tanto para el tratamiento control como para el inundado, mientras que en ALT la correlación no fue significativa en ninguno de los dos tratamientos. 

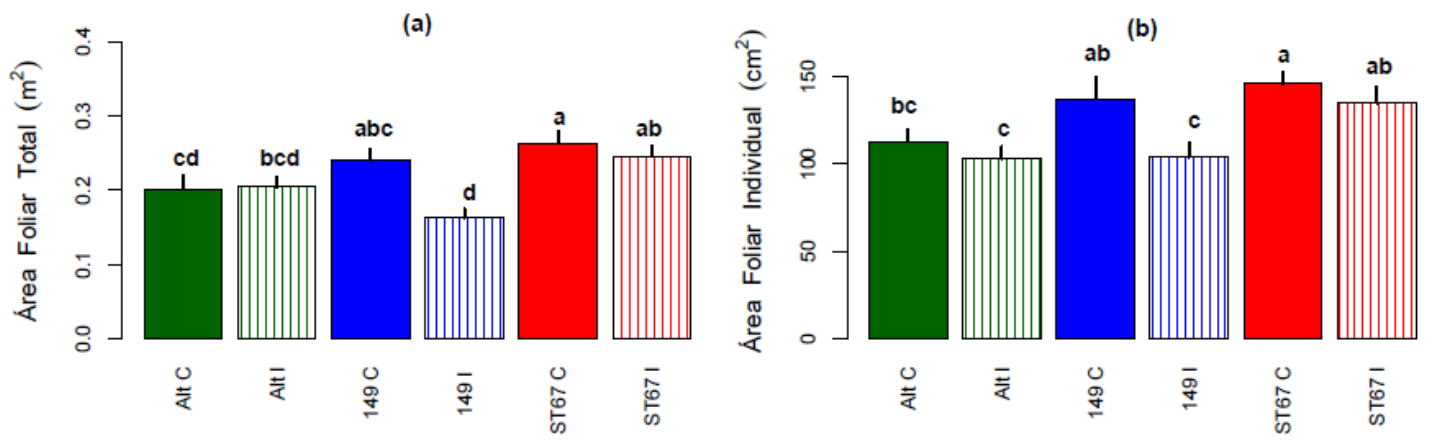

(c)
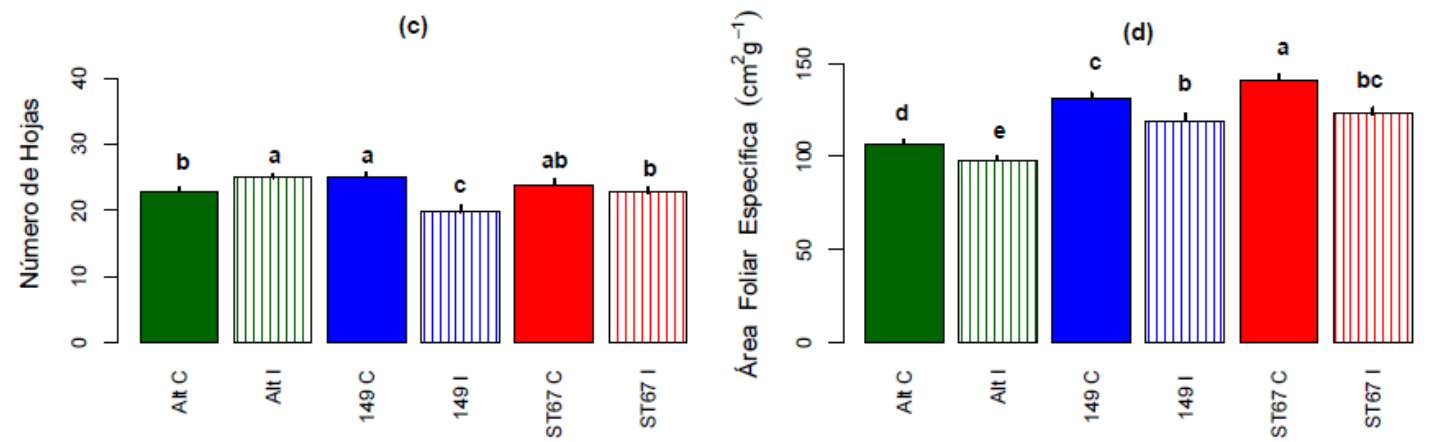

Fig. 2.7. Rasgos foliares en los clones ALT, 149-82 y ST67, en el experimento 2009. (a) Área foliar total; (b) área foliar individual; (c) número de hojas del tallo; (d) área foliar específica. C: control, I: inundado. Las medias con la misma letra no difieren significativamente $(p<0.05$ LSD) entre los dos tratamientos para un mismo clon. Las barras verticales indican el error estándar de la media.

\subsubsection{Características foliares}

En el experimento 2009 se evaluaron una variedad de rasgos foliares relacionados con la productividad en álamo (Rae et al., 2004). El área foliar total (Fig. 2.7, a) y el área foliar individual de la última hoja completamente expandida (Fig. 2.7, b) solo se redujeron significativamente en las plantas inundadas de 149-82. El número de hojas del tallo (Fig. 2.7, c) aumentó en las plantas inundadas de ALT con respecto a los controles, no se modificó en ST67 y se redujo en 149-82. El área foliar específica (Fig. 2.7, d) se redujo en las plantas inundadas de los tres clones. 

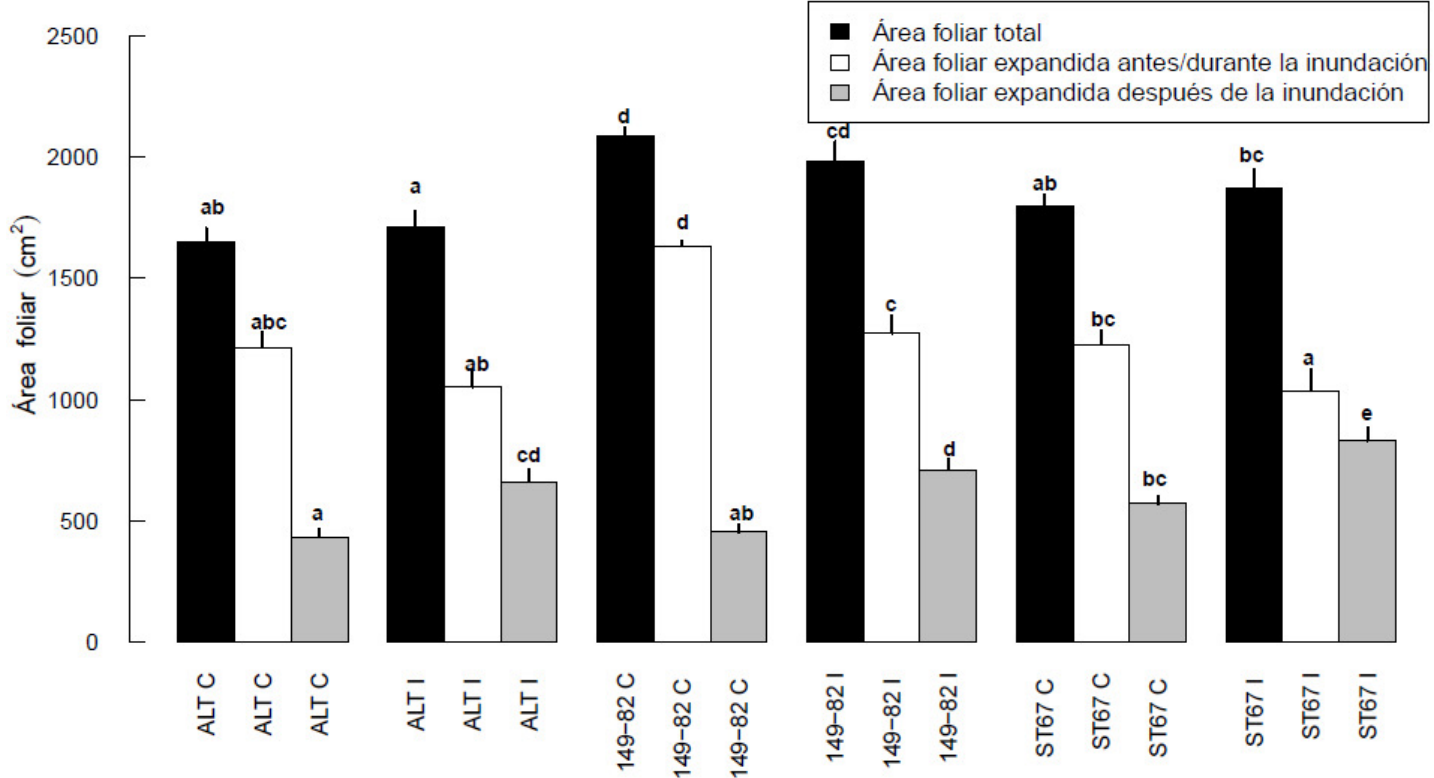

Fig. 2.8. Área foliar total, área foliar expandida antes-durante inundación y área foliar expandida pos inundación de los clones ALT, 149-82 y ST67, en el experimento 2011-A. C: control; I: inundado). Las medias con la misma letra no difieren significativamente $(p<0.05$ LSD) entre los dos tratamientos para un mismo clon. Las barras verticales indican el error estándar de la media.

El área foliar total fue determinada nuevamente en el experimento 2011-A, pero esta vez se discriminó entre el área desarrollada en el período pos inundación y el área desarrollada previamente (antes-durante inundación) (Fig. 2.8). Luego de 42 días de recuperación, no hubo diferencias significativas en el área foliar total entre las plantas control y las previamente inundadas, para ninguno de los clones; sin embargo, la contribución relativa de las hojas expandidas antes-durante inundación y las expandidas pos inundación, fue diferente entre los clones. No hubo diferencias significativas en el área foliar expandida antes-durante inundación entre los tratamientos control e inundado de ALT, pero si fue significativamente menor en las plantas previamente inundadas de ST67 y 149-82 con respecto a sus controles. El área foliar expandida pos inundación fue significativamente mayor en las plantas previamente inundadas con respecto a las plantas control en todos los clones. 


\begin{tabular}{|c|c|c|c|c|c|c|}
\hline & ALT C & ALT I & $149-82 C$ & $149-82$ I & ST67 C & ST67 I \\
\hline $\begin{array}{l}\text { Número de hojas antes- } \\
\text { durante inundación }\end{array}$ & $17 \mathrm{bc}$ & $14 \mathrm{a}$ & $17.7 \mathrm{c}$ & $13.3 \mathrm{a}$ & $15 a b$ & $11 \mathrm{~d}$ \\
\hline $\begin{array}{l}\text { Número de hojas pos } \\
\text { inundación }\end{array}$ & $8 a b$ & $8.2 a b$ & $6.7 c$ & $7 \mathrm{bc}$ & $8.8 \mathrm{a}$ & $9.2 \mathrm{a}$ \\
\hline Hojas totales & $25.0 \mathrm{c}$ & $22.2 \mathrm{ab}$ & $24.3 \mathrm{bc}$ & $20.3 \mathrm{a}$ & $23.9 \mathrm{bc}$ & $20.2 \mathrm{a}$ \\
\hline
\end{tabular}

Tabla 2.3. Recuento del número de hojas expandidas antes-durante inundación, pos inundación y totales, de los clones ALT, 149-82 y ST67 en el experimento 2011-A. C: control; I: inundado). Las medias con la misma letra no difieren significativamente $(p<0.05$ LSD) en la misma variable para todos los clones y tratamientos.

Al final del experimento 2011-A se realizó el recuento de hojas que se expandieron antes-durante la inundación y de las hojas expandidas pos inundación (Tabla 2.3). Los tres clones inundados mostraron un menor número de hojas en el período antes-durante inundación con respecto a sus controles, y no mostraron diferencias significativas en la expansión de hojas en el periodo pos inundación entre tratamientos. La disminución del número de hojas en las plantas inundadas durante el período antes-durante inundación se debió a la abscisión de las hojas basales, expandidas principalmente antes de iniciado el período de inundación.

En el experimento 2011-A se determinó el área foliar individual, el número de estomas y de células epidérmicas, el índice estomático (IE) y el grosor de hoja de las tres cohortes L1, L2 y L3 (Tabla 2.4). El área foliar individual no se redujo por la inundación en ninguno de los clones (Tabla 2.4).

La densidad estomática varía según el genotipo y las diferentes posiciones de las hojas en el canopeo (Al Afas et al., 2006), por lo que no sería sorprendente encontrar diferencias entre las tres cohortes analizadas, ya que cada una representa posiciones heterogéneas a los largo del tallo. Como consecuencia de esto, estos rasgos solo fueron 


\begin{tabular}{|c|c|c|c|c|c|c|}
\hline $\begin{array}{c}\text { Clon I } \\
\text { tratamiento }\end{array}$ & Cohorte & $\begin{array}{l}\text { Area } \\
\text { foliar }\end{array}$ & Estomas $/ \mathrm{mm}^{2}$ & Células $/ \mathrm{mm}^{2}$ & IE & $\begin{array}{c}\text { Grosor de } \\
\text { hoja }\end{array}$ \\
\hline ALT C & L1 & $66,3 \mathrm{a}$ & $168,5 \mathrm{a}$ & $1886,3 \mathrm{a}$ & $8,2 \mathrm{a}$ & $265 a$ \\
\hline $149-82 C$ & L1 & $89,3 \mathrm{~b}$ & $172,1 \mathrm{~b}$ & $2167,0 \mathrm{~b}$ & $9,0 \mathrm{~b}$ & $221 \mathrm{~b}$ \\
\hline ST67 C & L1 & $68,2 \mathrm{a}$ & $215,0 a$ & $1777,7 \mathrm{a}$ & $8,8 \mathrm{ab}$ & $221 \mathrm{~b}$ \\
\hline ALT C & L2 & $102,3 \mathrm{a}$ & $197,1 \mathrm{a}$ & $2041,9 a$ & $8,8 \mathrm{a}$ & $309 \mathrm{~b}$ \\
\hline ALT I & L2 & $98,1 \mathrm{a}$ & $193,1 \mathrm{a}$ & 1947,5 a & $9,0 \mathrm{a}$ & $315 \mathrm{~b}$ \\
\hline $149-82 \mathrm{C}$ & L2 & $106,8 \mathrm{a}$ & $213,4 a b$ & $2305,4 b$ & $8,5 \mathrm{a}$ & $278 a$ \\
\hline $149-82$ I & L2 & $98,5 \mathrm{a}$ & $239,6 \mathrm{c}$ & $2405,5 \mathrm{~b}$ & $8,9 a$ & $295 c$ \\
\hline ST67 C & L2 & $95,1 \mathrm{a}$ & 225,2 bc & 2068,3 a & $9,8 \mathrm{~b}$ & $272 a$ \\
\hline ST67 I & L2 & $103,1 \mathrm{a}$ & $193,1 \mathrm{a}$ & $2005,4 \mathrm{a}$ & $8,8 \mathrm{a}$ & $278 a$ \\
\hline ALT C & L3 & $78,9 \mathrm{c}$ & $193,1 \mathrm{ab}$ & 2308,4 bc & $7,7 \mathrm{a}$ & $310 \mathrm{~d}$ \\
\hline ALT I & L3 & $112,5 \mathrm{ab}$ & $188,1 \mathrm{ab}$ & $2099,5 \mathrm{ab}$ & $8,3 \mathrm{ab}$ & $323 b$ \\
\hline $149-82 \mathrm{C}$ & L3 & $102,8 \mathrm{ab}$ & $214,2 \mathrm{~b}$ & $2418,0 \mathrm{c}$ & $8,1 \mathrm{ab}$ & $297 a$ \\
\hline $149-82$ I & L3 & $116,2 \mathrm{a}$ & $173,6 \mathrm{a}$ & $2081,4 a$ & $7,7 \mathrm{a}$ & $326 \mathrm{~b}$ \\
\hline ST67 C & L3 & $87,9 \mathrm{c}$ & $251,8 \mathrm{C}$ & $2233,2 \mathrm{abc}$ & $10,1 \mathrm{c}$ & $277 a$ \\
\hline ST67 I & L3 & $127,6 \mathrm{~b}$ & $183,2 \mathrm{ab}$ & $1868,0 \mathrm{~d}$ & $8,9 \mathrm{~b}$ & $289 c$ \\
\hline
\end{tabular}

Tabla 2.4. Área foliar individual $\left(\mathrm{cm}^{2}\right)$, número de estomas por $\mathrm{mm}^{2}$, número de células epidérmicas por $\mathrm{mm}^{2}$, índice estomático (IE) y grosor de hojas $(\mu \mathrm{m})$, en tres cohortes de hojas de los clones ALT, 149-82 y ST67, en el experimento 2011-A. La primera cohorte (L1) completó su expansión antes del inicio de la inundación; la segunda cohorte (L2) se expandió durante el periodo de inundación; y la tercera cohorte (L3) se expandió luego de la finalización del tratamiento de estrés. C: control, I: inundado. Las medias con la misma letra no difieren significativamente $(p<0.05$ LSD) en la misma variable para todos los clones y tratamientos.

comparados entre las plantas control e inundadas de la misma cohorte (es decir, edad y posición similar en la planta).

En las hojas expandidas durante el período de inundación (L2), los resultados del número de estomas, número de células, IE y grosor de hoja, varían según el clon (Tabla 2.4). No hubo diferencias significativas entre las plantas control e inundadas de ALT en ninguna de las variables. En plantas de 149-82 inundadas, hubo un aumento de grosor de hoja y de la densidad estomática (Fig. 2.9), pero el número de células epidérmicas por 


\section{L2 (hojas expandidas durante inundación)}

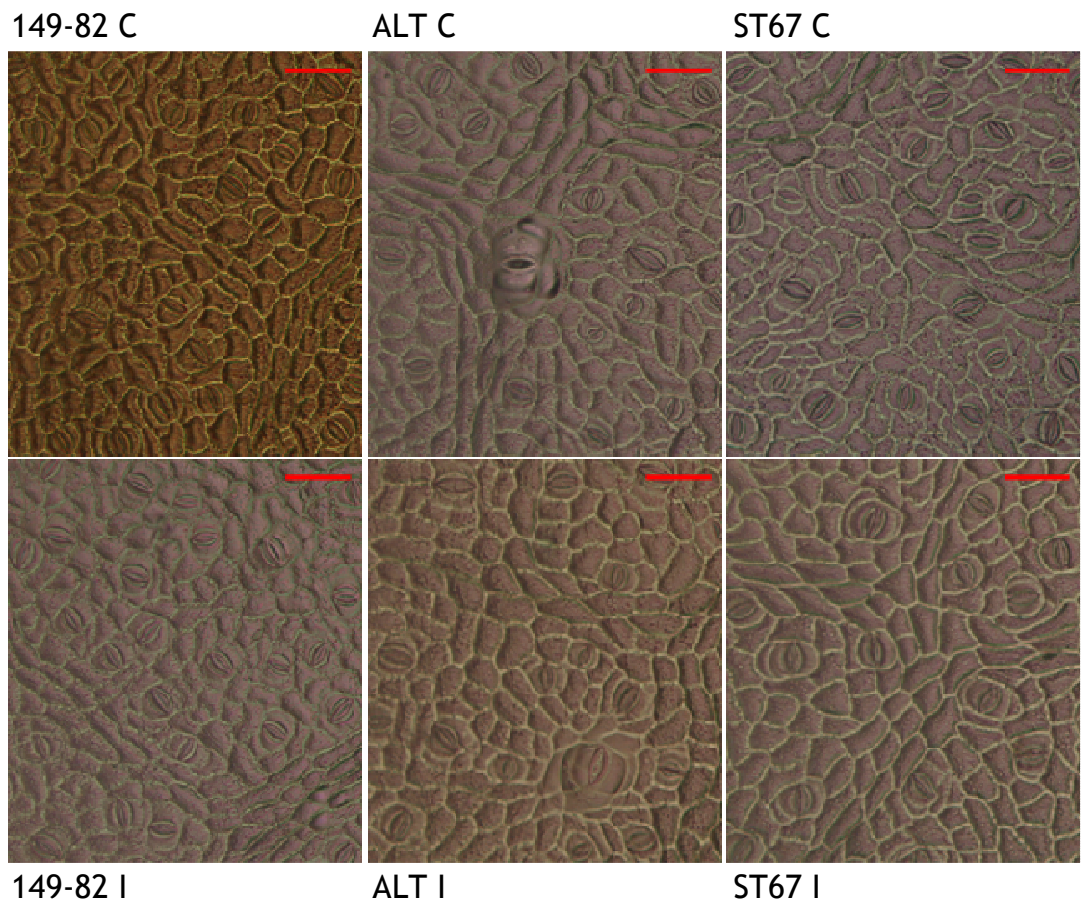

Fig. 2.9. Impresiones de la superficie abaxial de hojas de la cohorte L2 de los clones 149-82, ALT y ST67 en el experimento 2011-A. Las impresiones fueron observadas a 20x. Las fotos corresponden a un $22 \%$ del campo observado. C: control, I: inundado. Las barras de escala (en rojo), representan $50 \mu \mathrm{m}$.

$\mathrm{mm}^{2}$ y el IE no fueron afectados significativamente. En las plantas inundadas de ST67, el grosor de la hoja no resultó afectado, mientras que la densidad estomática se redujo (Fig. 2.9) y el número de células epidérmicas se mantuvo, provocando una reducción de IE estadísticamente significativa.

En la cohorte expandida en el periodo pos inundación (L3), el área foliar individual aumentó significativamente en ALT y ST67 previamente inundados, pero no en 149-82 (Tabla 2.4). El grosor de hoja aumentó en las plantas previamente inundadas, con respecto a los controles, en todos los clones (Fig. 2.10). 


\section{L3 (hojas expandidas pos inundación)}

$149-82 \mathrm{C}$
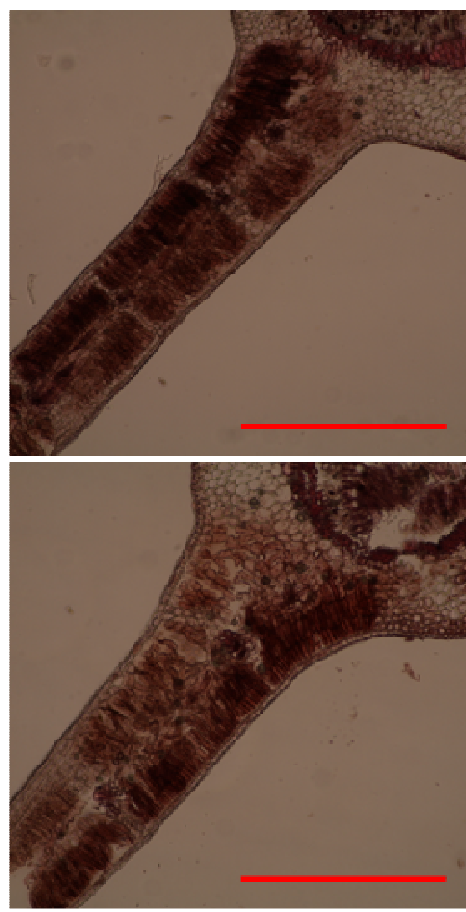

$149-82$ I
ALT C
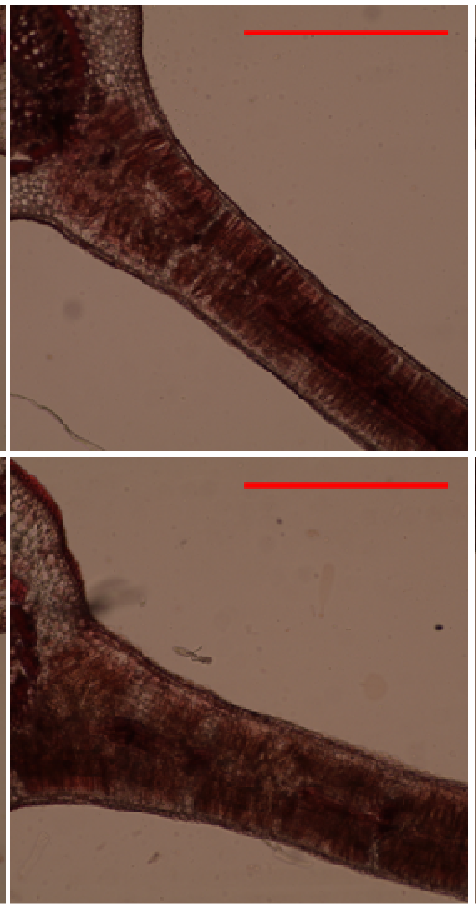

ALT I
ST67 C

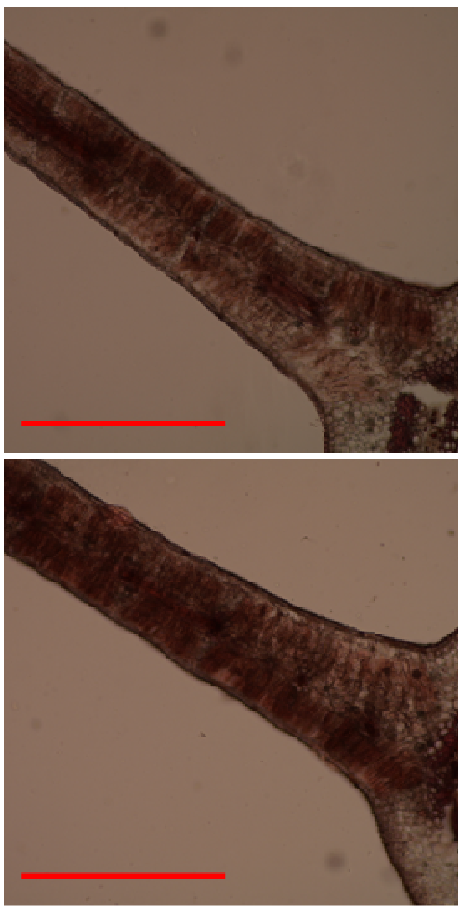

ST67 I

Fig. 2.10. Corte transversal de una porción de hoja rodeando a la vena principal de hojas de la cohorte L3 de los clones 149-82, ALT y ST67 en el experimento 2011-A. Las hojas fueron observadas a $10 \mathrm{x}$. Se realizaron mediciones a cada lado de la vena principal para determinar el grosor de lámina. C: control, I: inundado. Las barras de escala representan 0,5 mm.

En las plantas de ALT previamente inundadas no hubo cambios en la densidad estomática, número de células epidérmicas o IE (Tabla 2.4). En 149-82, la densidad estomática (Fig. 2.11) y el número de células epidérmicas por $\mathrm{mm}^{2}$ disminuyeron sin provocar cambios en IE (Tabla 2.4), mientras que en ST67 las tres variables se redujeron significativamente en las plantas previamente inundadas con respecto a los controles (Tabla 2.4; Fig. 2.11). 


\section{L3 (hojas expandidas pos inundación)}

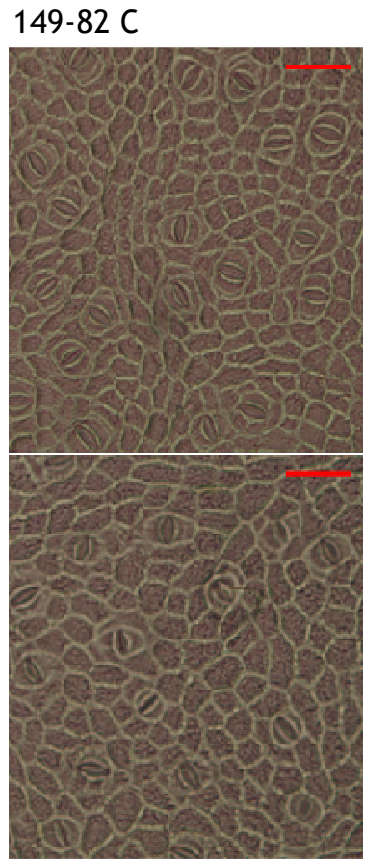

$149-82$ I
ALT C

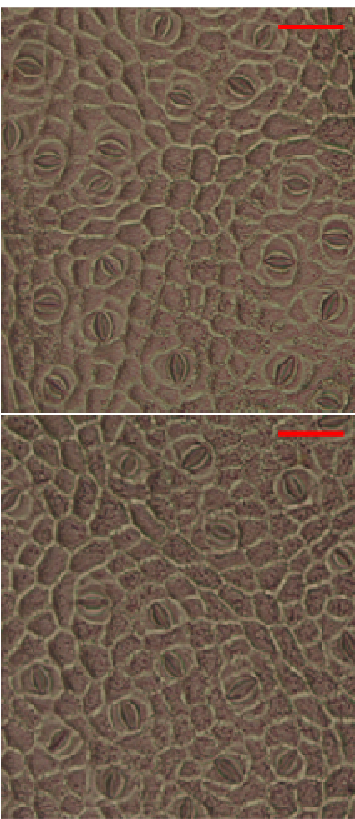

ALT I
ST67 C

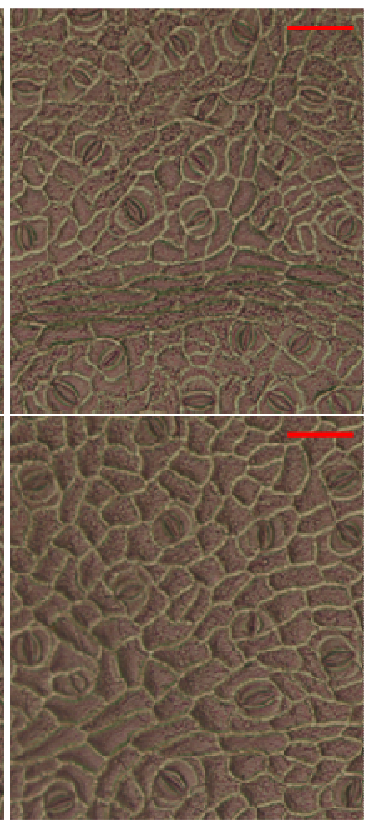

ST67 I

Fig. 2.11. Impresiones de la superficie abaxial de hojas de la cohorte L3 de los clones 149-82, ALT y ST67 en el experimento 2011-A. Las impresiones fueron observadas a 20x. Las fotos corresponden a un $22 \%$ del campo observado. C: control, I: inundado. Las barras de escala (en rojo), representan $50 \mu \mathrm{m}$.

\subsubsection{Lenticelas hipertrofiadas y raíces adventicias}

En el experimento 2009 se registró la aparición de raíces adventicias y el desarrollo de lenticelas hipertrofiadas. Luego de dos semanas de iniciada la inundación, las plantas de ALT y ST67 inundadas no produjeron raíces adventicias salientes de la parte sumergida del tallo, sino que, para ambos clones, se observó la emergencia de raíces desde la superficie del suelo hacia el agua (raíces ascendentes) (Fig. 2.12 a y b respectivamente). Todas las plantas de ALT inundadas mostraron la aparición de estas 


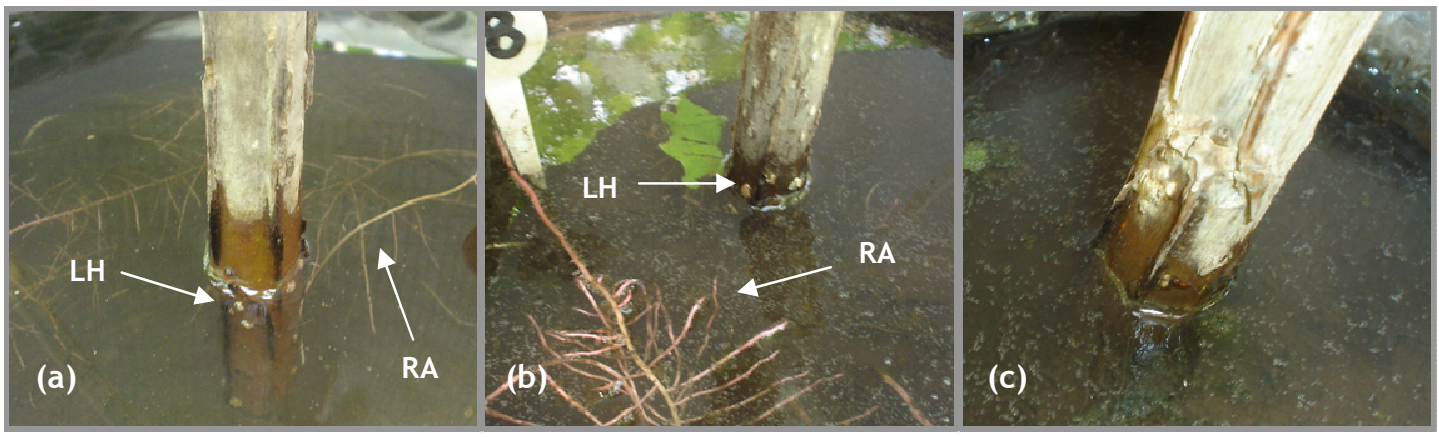

Fig. 2.12. Detalle de lenticelas hipertrofiadas $(\mathrm{LH})$ y raíces adventicias (RA) desarrolladas en respuesta a la inundación en el experimento 2009, en los clones ALT (a), ST67 (b) y 149-82 y (c). LH: lenticelas hipertrofiadas, RA: raíz ascendente. 149-82 no desarrolló lenticelas hipertrofiadas ni raíces adventicias.

raíces a las dos semanas de iniciado el periodo de inundación, mientras que las plantas inundadas de ST67 recién comenzaron a aparecer en la misma fecha. El desarrollo de lenticelas hipertrofiadas en estos dos clones, comenzó recién luego de tres semanas de iniciado el período de inundación. Las plantas de 149-82 inundadas no desarrollaron raíces adventicias en los 35 días que duró la inundación (Fig. 2.12, c), y sus lenticelas continuaron con su apariencia normal, sin desarrollar la estructura tipo callo, característico de las lenticelas hipertrofiadas.

\subsubsection{Aerénquima de raíz}

No fue posible realizar cortes de raíz de las plantas de 149-82 inundadas, ya que estas plantas tenían prácticamente toda la biomasa radical muerta, y las raíces vivas eran raíces maduras con desarrollo de estructura secundaria, haciéndolas incomparables con las muestras de raíces de las plantas control de este clon, y con las muestras controles e inundadas de los otros dos clones. 
ALT C

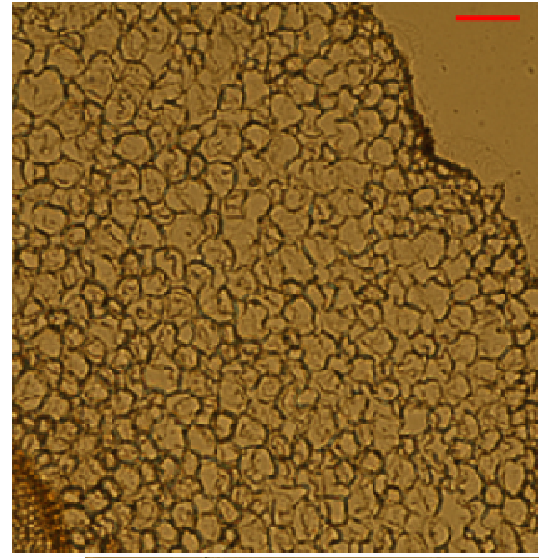

ST67 C

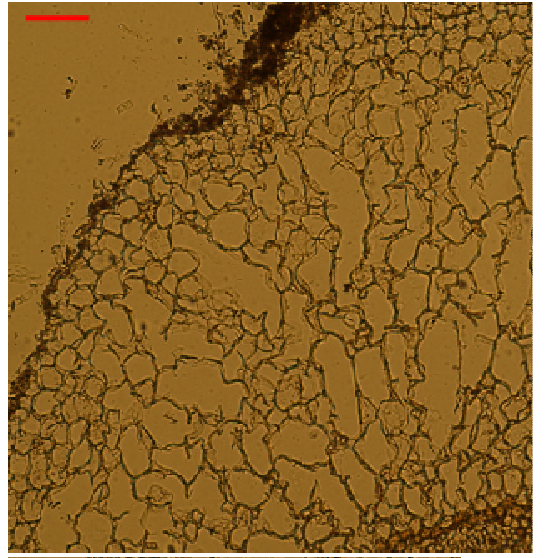

ALT I
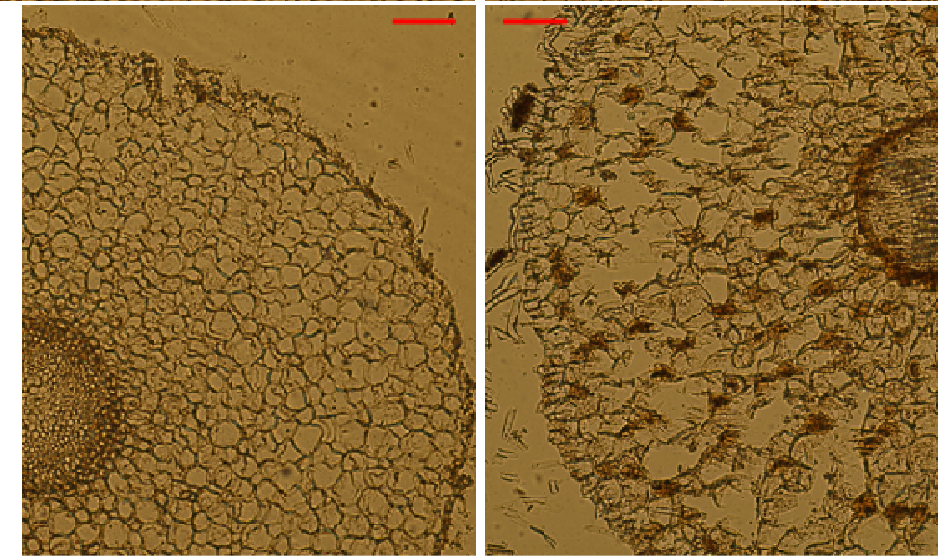

ST67 I

Fig. 2.13. Corte transversal de la región apical de raíz de los clones ALT y ST67 en el experimento 2009. Los cortes fueron observados a $10 \mathrm{x}$. C: control, I: inundado. Las barras de escala representan $100 \mu \mathrm{m}$.

Tanto las plantas de ALT como de ST67 inundadas mostraron desarrollo de lagunas aerenquimáticas, no observadas en las plantas control de estos clones (Fig. 2.13). No es claro el tipo de arreglo espacial del aerénquima formado en estos clones, pero la formación de las lagunas pareciera darse por el colapso de células alineadas radialmente en el córtex, separadas por filas de células intactas o paredes celulares remanentes, como ocurre en gramíneas (Fig. 2.2). 


\subsection{DISCUSIÓN}

\subsubsection{Respuestas de los álamos a un período de inundación}

La tasa de difusión de oxígeno (ODR) es una medida de la movilidad del oxígeno en el suelo, característica importante en la disponibilidad del gas para las raíces. El método consiste en la medición de la corriente eléctrica ocasionada por la reducción de todo el oxígeno disponible en la superficie de un electrodo que simula ser una raíz (McIntyre, 1970), permitiendo obtener un valor del gas disponible en el suelo para las raíces. La inundación redujo dramáticamente la tasa de difusión de oxígeno, siendo el valor promedio de ODR de las plantas inundadas unas 10 veces menor que el de las plantas control; esto concuerda con el hecho de que el exceso de agua en los poros del suelo limita la entrada de oxígeno a la raíces debido a que su difusión en agua es 10.000 veces menor que en aire (Armstrong, 1979).

Las respuestas de crecimiento bajo estrés por inundación, consistentes en ambos experimentos realizados, y similares a resultados obtenidos previamente (Luquez et al., 2012), fueron diferentes en los tres clones utilizados. Como consecuencia, se decidió explorar que mecanismos podrían explicar las variaciones de respuesta de los distintos clones bajo inundación.

En $P$. deltoides y otras especies, la inundación ocasiona la muerte del sistema radical (Kozlowski, 1997). En los tres clones se observó la misma respuesta, la relación raíz / vástago disminuyó en las plantas inundadas con respecto a las control. Sin embargo, ALT inundado, conservó mayor biomasa radical que los otros dos clones inundados. Esta diferencia se reflejó en la relación raíz / vástago, que en las plantas inundadas de 149-82 y ST67 se redujo a la mitad del tratamiento control, mientras que en ALT inundado la reducción fue menor. La reducción de la biomasa radical sumado a 
una mayor resistencia de la raíz al flujo de agua, puede ocasionar la disminución del ingreso de agua hacia el interior de la planta. En álamo, la resistencia al flujo de agua a través de las raíces aumenta con bajos niveles de $\mathrm{O}_{2}$ y elevados de $\mathrm{CO}_{2}$ como consecuencia de la inundación (Smit y Stachowiak, 1988). El déficit hídrico foliar generado, resultante del menor ingreso de agua a la planta, puede inducir cierre estomático y reducción de la tasa de crecimiento de las hojas (Smit y Stachowiack, 1988; Smit et al., 1989), por lo que resulta importante el mantenimiento biomasa radical viva para mantener el adecuado suministro de agua y asegurar la supervivencia de la planta en condiciones hipóxicas.

Los análisis de correlación entre el área foliar total y el IV del tallo, y entre el área foliar total y la biomasa de raíces (Tablas 2.2 a y b, respectivamente), mostraron relaciones positivas entre estas variables, siendo de menor significancia estadística en el tratamiento inundado frente al control. Esta disminución se debe principalmente al clon ALT, que solo muestra una correlación positiva significativa entre el área foliar total y el IV del tallo en el tratamiento control. Este clon es el menos afectado por la inundación tanto en el crecimiento de la parte aérea como de la radical y además, es el de menor crecimiento en condiciones control.

Un hecho importante, que favorecería la mayor disponibilidad de fotoasimilados y por lo tanto el crecimiento sostenido, es el mantenimiento del área foliar. En álamo, el área foliar total, el número de hojas del tallo principal y el área foliar individual correlacionan con frecuencia con la acumulación de biomasa (Rae et al., 2004; Monclus et al., 2005; Marron et al., 2005). Todos estos atributos se redujeron por la inundación en el clon más sensible, 149-82, pero no fueron afectados en ALT y ST67 inundados (Fig. 2.7, a, b y c), mientras que el área foliar especifica se redujo por la inundación en todos los clones (Fig. 2.7, d). Esta disminución pudo deberse a una disminución en el área foliar individual o quizás, como consecuencia de una alteración en el grosor de la 
hoja. Como en el experimento 2009 el área foliar solo disminuyó significativamente en 149-82, se midió el grosor de hoja en el experimento 2011-A. En la cohorte L2 (expandida durante el período de inundación), que se corresponde con la hoja individual evaluada en el experimento 2009 , solo $149-82$ inundado tuvo un incremento significativo en el grosor de lámina (Tabla 2.4), y aunque la disminución del área foliar individual no haya sido significativa en este experimento, 149-82 inundado tuvo hojas de menor tamaño y más gruesas como consecuencia de la inundación.

Especies de Populus han mostrado desarrollo de lenticelas hipertrofiadas, raíces adventicias y aerénquima cuando son expuestos a condiciones de anoxia por inundación (Pereira y Kozlowski, 1977; Harrington, 1987; Smit y Stachowiak, 1988; Cao y Conner, 1999). Los distintos clones evaluados mostraron diferentes respuestas en el desarrollo de raíces adventicias y lenticelas hipertrofiadas (Fig. 2.12). ALT y ST67 inundados produjeron lenticelas hipertrofiadas y mostraron raíces ascendentes emergiendo desde la superficie del suelo hacia el agua, mientras que 149-82 no mostró ninguna de estas respuestas, ni el desarrollo de raíces adventicias desde la parte del tallo sumergida.

Tanto ALT como ST67 inundados, produjeron desarrollo de lagunas aerenquimáticas en las raíces de reemplazo producidas en respuesta a la anoxia, mientras que 149-82 no mostró desarrollo de nuevas raíces. Estas estructuras contribuyen al intercambio gaseoso en las partes sumergidas de las plantas, permitiendo la difusión de oxígeno desde la atmosfera a las raíces, y la salida de compuestos volátiles que pueden acumularse en las raíces de plantas inundadas (Kozlowski, 1997; Vartapetian y Jackson, 1997). Además, las raíces adventicias, o ascendentes en este caso, serían necesarias para mantener la captación adecuada de agua y nutrientes. Es por ello, que no es sorprendente que $149-82$, un clon que no produce ninguna de estas estructuras, sea tan afectado y posea un pobre desempeño en condiciones de inundación. ALT inundado casi no fue afectado por la inundación en el crecimiento de 
su parte aérea (Fig. 2.4), produjo lenticelas hipertrofiadas, raíces ascendentes (Fig. 2.12), aerénquima (Fig. 2.13), y mantuvo el desarrollo de una mayor biomasa radical (Fig. 2.6) durante la inundación, permitiéndole sobrellevar la falta de oxígeno mejor que los otros clones.

\subsubsection{Respuestas de los álamos durante el período de recuperación posterior a un episodio de inundación}

Los resultados obtenidos en el período de inundación resultaron en el planteamiento de si otras características foliares relacionadas con la productividad son alteradas por la inundación, y si éstas influencian la recuperación del crecimiento luego del final de la inundación.

Las respuestas del crecimiento durante el período pos inundación difirieron entre los distintos clones (Fig. 2.4, d, e y f). La TCR aumentó significativamente en las plantas de ALT previamente inundadas (TCRpi, Fig. 2.4 d) sin embargo, al final del experimento, no hubo diferencias significativas en el crecimiento en altura entre plantas control e inundadas. Luego de 20 días de recuperación, las plantas de 149-82 previamente inundadas continuaban siendo significativamente menores que las plantas control, mientras que las de ST67 previamente inundadas alcanzaron los valores de altura de las plantas control. Esto se refleja en los valores de TCRpi, que se mantuvieron similares a los de las plantas control en 149-82 previamente inundado, pero aumentaron significativamente en las plantas de ST67 previamente inundadas, (TCRpi, Fig. 2.4 e y f, respectivamente). La lenta recuperación de 149-82 previamente inundado, probablemente pueda ser explicada en parte, por la masiva muerte de la biomasa radical (Fig. 2.6) y la mayor pérdida de área foliar en condiciones de inundación (Fig. 2.7). 
A pesar del aumento del área foliar expandida pos inundación (Fig. 2.8), el área foliar total no fue significativamente diferente entre las plantas control y las previamente inundadas en ninguno de los clones. El área expandida antes-durante inundación fue menor en las plantas previamente inundadas debido a la abscisión de hojas basales en este período (Tabla 2.3, número de hojas antes-durante inundación), principalmente en ST67 y 149-82 donde se observaron mayores diferencias. Las hojas basales, de menor tamaño, pueden haber sufrido por el sombreado generado por las hojas apicales, y su abscisión puede haber sido una respuesta conveniente para reciclar nutrientes para la formación de nuevas hojas que se encuentren menos sombreadas y que tengan mayor capacidad asimilatoria. La reducción del área foliar debida al estrés por inundación, no fue compensada por un aumento en el número de hojas desarrolladas, sino por la expansión de nuevas hojas de mayor tamaño en el período de recuperación; como consecuencia, a pesar del menor número de hojas en las plantas inundadas con respecto a las control al finalizar el ensayo, el área foliar total fue similar entre ambos tratamientos para cada clon. Así, el aumento en el área foliar total desarrollada en el periodo pos inundación es producto de una mayor área foliar individual (L3, Tabla 2.4). Además, en L3, el grosor de hoja aumento significativamente en todos los clones, pudiendo ser una consecuencia del incremento en el tamaño de la hoja (hojas con mayor área y más gruesas). El aumento del área foliar individual de L3, puede haberse debido a un aumento en el tamaño de las células epidérmicas, sin un incremento de su número (Tabla 2.4). El tamaño celular no fue analizado en este trabajo, y algunos autores sugieren que es el número de células epidérmicas el que posee una buena correlación con el tamaño foliar y no el área de estas células (Rae et al., 2004; Bunn et al., 2004), por lo que el comportamiento de estos rasgos foliares deberían ser profundizados en futuros trabajos.

Las características estomáticas están relacionadas con la productividad en álamo, y son alteradas por distintas condiciones ambientales, como hipoxia de la raíz 
(Smit et al., 1989) y aumento de la concentración de $\mathrm{CO}_{2}$ (Ceulemans et al., 1995). También hay diferencias entre distintos genotipos, lado de la hoja y posición de la hoja en el canopeo (Al Afas et al., 2006; Dillen et al., 2008). Se ha demostrado que una mayor densidad estomática puede aumentar la capacidad fotosintética en Arabidopsis (Tanaka et al., 2013). En el clon ALT, la densidad estomática, el número de células epidérmicas y el IE no variaron a lo largo de todo el experimento (inundación seguida de recuperación) entre los dos tratamientos, pero en los otros clones hubo variaciones. La densidad estomática aumentó en la hoja completamente expandida durante la inundación (L2) de 149-82 inundado y disminuyó en la misma hoja de ST67 (Tabla 2.4), sin variaciones significativas del número de células epidérmicas. En la hoja expandida durante el periodo pos inundación (L3), tanto la densidad estomática como la celular disminuyeron significativamente las plantas inundadas de ambos clones. El IE solo fue afectado significativamente en las plantas inundadas de ST67, tanto en L2 como en L3, principalmente debido a una disminución en el número de estomas.

La difusión de $\mathrm{CO}_{2}$ dentro de la hoja durante la fotosíntesis y la difusión de vapor de agua, son dos procesos controlados por la apertura y cierre estomático. Un aumento en la densidad estomática, les permitiría a plantas con buena disponibilidad hídrica, aumentar la conductancia para intercambio de gases en la superficie de la hoja y así, evitar limitaciones fotosintéticas por suministro reducido de $\mathrm{CO}_{2}$ (Schluter et al., 2003). La anatomía foliar y la organización interna de la hoja también impactarían fuertemente en el intercambio de gases, especialmente en la fotosíntesis. El aumento de grosor de la hoja puede conducir a un aumento de la fotosíntesis debido a un mayor número de cloroplastos o, contrariamente, a una disminución de la asimilación de $\mathrm{CO}_{2}$ debido a rutas de difusión más largas (Ceulemans et al., 1984).

En el caso de 149-82 inundado, la densidad estomática aumenta en las hojas L2 y esto probablemente haya sido la razón de la mayor conductancia estomática en esta hoja en el periodo pos inundación (Fig. 4.2, capítulo 3). No es claro como un aumento 
de la densidad estomática podría ser ventajoso para este clon como respuesta a la inundación, ya que tanto la conductancia estomática (gs) como la fotosíntesis neta (A) disminuyeron considerablemente durante la inundación (Fig. 4.2, capítulo 3). A pesar del aumento de la densidad estomática, 149-82 inundado no mostró variación en el IE. Esto fue debido a que, a pesar de no ser estadísticamente significativo, el número de células epidérmicas también aumentó, por lo que el aumento de la densidad estomas en realidad no implica un aumento de su relación con respecto al número total de células (IE). En este caso, la alteración de la densidad estomática, y también de las células epidérmicas, podría ser consecuencia de una reducción en la expansión celular, que lleve además a una menor área foliar. En el caso de ST67 inundado, la reducción de la densidad estomática con respecto al número de células epidérmicas implica la disminución del IE. En la hoja L3, expandida en el periodo pos inundación, tanto la densidad estomática como la de células epidérmicas disminuyeron en 149-82 y ST67 previamente inundados (Fig. 2.11). Sin embargo, la variación en la densidad de estos tipos de células solo provocó un menor IE de las plantas de ST67 inundadas con respecto a las control. La reducción del IE observada en ST67 inundado, podría ser una respuesta a la inundación que contribuya a la reducción de la conductancia estomática y el mantenimiento del estado hídrico de la planta. Se ha propuesto que clones con menor densidad de estomas, y de mayor tamaño, podrían regular la resistencia de la difusión estomática, y consecuentemente parte del transporte de agua, más eficientemente que aquellos con mayor número de estomas y de menor tamaño (Al Afas et al., 2006). 


\subsection{CONCLUSIONES}

El grado de tolerancia a la inundación parece estar relacionado con la capacidad de retener una mayor área foliar y biomasa de raíces durante el episodio de estrés. La retención de mayor biomasa radical y el rápido desarrollo de nuevas raíces en ALT inundado, le asegurarían un rápido restablecimiento del suministro de agua y nutrientes una vez finalizado el estrés.

En el clon ALT inundado, a pesar del aumento de área y grosor de hoja, no hubo cambios en la densidad celular o estomática. La estabilidad de la mayoría de las características foliares en ALT coincide con el hecho de que el crecimiento de la parte aérea es muy poco afectado por la inundación, mientras que lo opuesto ocurre con ST67 y 149-82 inundados, que si tienen crecimiento reducido. Las respuestas no son tan claras con estos dos clones. La estrategia de 149-82 inundado podría ser la inversión en un intento de aumento de la capacidad fotosintética de las hojas que mantiene, a través del aumento en el número de estomas y del grosor de la hoja. En cambio ST67 inundado parece tener una estrategia más reservada, manteniendo el grosor de la hoja y disminuyendo el número de estomas para reducir la conductancia estomática y mantener el estado hídrico de la planta durante el estrés.

Si se analizan las respuestas de los clones a la inundación en términos de productividad relativa (Índice de Volumen), ALT fue el menos afectado por la inundación y 149-82 el más afectado. Sin embargo, es importante destacar que, en términos absolutos, las plantas de ST67 inundadas fueron tan productivas como las de ALT control, y más aún en condiciones a capacidad de campo, donde ST67 supera ampliamente en crecimiento a ALT, tanto en Índice de volumen como en altura del tallo. 
CAPÍTULO 3

\section{FORMACIÓN DE AERÉNQUIMA INICIADA POR ETILENO EN RAÍCES SOMETIDAS A HIPOXIA DE UN CLON DE P. DELTOIDES}

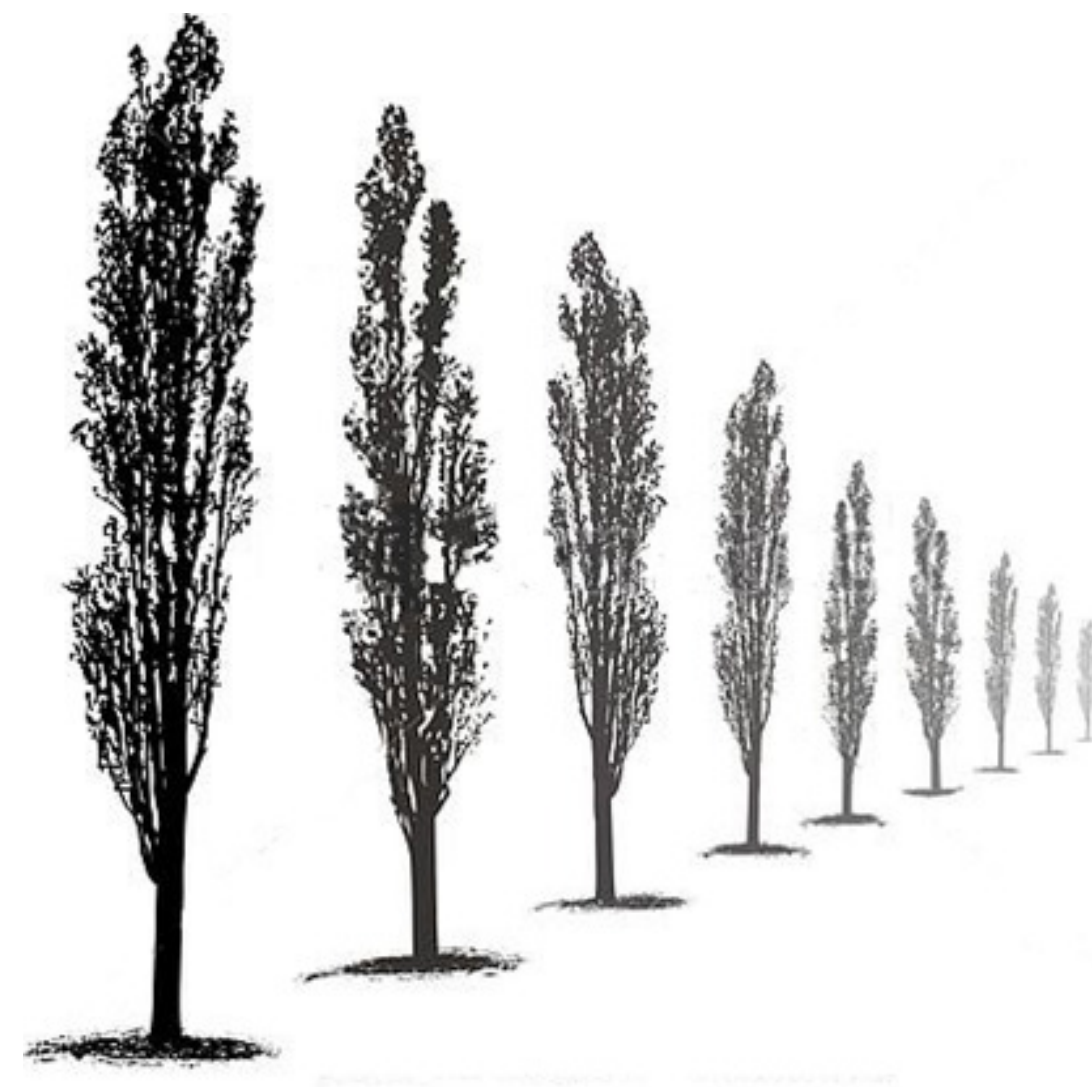




\subsection{INTRODUCCIÓN}

La difusión de gases es importante para las plantas; la llegada de $\mathrm{CO}_{2}$ a los cloroplastos es necesaria para la fotosíntesis y la rápida difusión del oxígeno a las mitocondrias permite la respiración. Además, la regulación de la concentración endógena del etileno depende mucho de la tasa de difusión hacia el exterior. La rápida difusión de estos gases se dificulta severamente durante un período de inundación, siendo menor en cuatro ordenes de magnitud en agua que en aire (Visser y Voesenek, 2004; Colmer y Voesenek, 2009). La lenta difusión de los gases en suelos saturados de agua provoca también el aumento de $\mathrm{CO}_{2}$ y metano. Como consecuencia los niveles de oxígeno disminuyen, mientras que los de etileno aumentan en tejidos sumergidos (Colmer y Voesenek, 2009).

La hipoxia o anoxia son los principales factores que alteran el metabolismo en las raíces de plantas sometidas a inundación (Agarwal y Grover, 2006). Aquellas raíces cuyo metabolismo aeróbico depende totalmente del oxígeno del suelo, cesan su crecimiento y pueden eventualmente morir (Visser y Voesenek, 2004). Para contrarrestar este efecto algunas especies desarrollan aerénquima, lenticelas hipertrofiadas y raíces adventicias (Kozlowski, 1997; Braendle y Crawford, 1999; Bailey-Serres y Voesenek, 2008). La formación de estas estructuras permite un aumento de la difusión de oxígeno hacia las raíces, y por lo tanto, el desarrollo del metabolismo aeróbico que es mucho más eficiente en la producción de energía que la fermentación (Bailey Serres y Voesenek, 2008).

La formación de aerénquima permite el transporte de oxígeno hacia el ápice de las raíces y la rizósfera, y la movilización de gases, como el $\mathrm{CO}_{2}$, el etileno y el metano, desde la raíz y el suelo hacia la atmósfera (Armstrong, 1979; Evans, 2003; Colmer, 2003 a). El movimiento interno del oxígeno desde los tallos hasta las raíces, gracias a la ruta 
de baja resistencia que provee el aerénquima, es crucial para la tolerancia de las plantas a la inundación de suelos (Colmer y Voesenek, 2009).

\subsubsection{Tipos de aerénquima}

Han sido reconocidos tres tipos de aerénquima (Seago et al., 2005): expansígeno, esquizógeno y lisígeno (Fig. 3.1). En el aerénquima expansígeno, las lagunas aerenquimáticas se forman a partir de la división y agrandamiento celular, sin separación de paredes o muerte celular. Este tipo de aerénquima se caracteriza por una apariencia de panal de abejas en secciones transversales de raíz y es llamada tipo Rumex (Fig. 2.2 d, capítulo 2; Fig. 3.1 a) (Seago et al., 2005; Striker, 2012).El aerénquima esquizógeno es formado por separación de células a lo largo de sectores radiales, sin involucrar muerte celular (Fig. 3.1 b), durante estadios de desarrollo temprano. Este origen generalmente precede a la lisis celular (lisigenia) que incrementa el tamaño de las lagunas y, solo en muy pocos casos aparece como el único proceso de formación de aerénquima (Seago et al., 2005; Striker, 2012).

La formación de aerénquima lisígeno, que involucra la muerte celular, es la forma más común encontrada; células formadas durante el desarrollo de la planta mueren y son removidas, dejando espacios gaseosos. Dentro de este tipo de origen, se distinguen dos patrones diferentes. En la lisigenia radial, las lagunas se generan por el colapso de células alineadas radialmente en el córtex, separadas por filas de células intactas (o paredes celulares remanentes). La supervivencia de algunas células en la estructura es importante para la integridad estructural de la raíz y para el transporte apoplástico y simplástico de nutrientes (Evans, 2003). Este tipo de aerénquima es típico de gramíneas y es similar a la forma de una rueda de bicicleta (Fig 2.2 a, capítulo 2;

Fig. 3.1 c). En la lisigenia tangencial se produce separación y colapso de células en zonas tangenciales del córtex radical con filas radiales de células intactas, dando como 
(a)

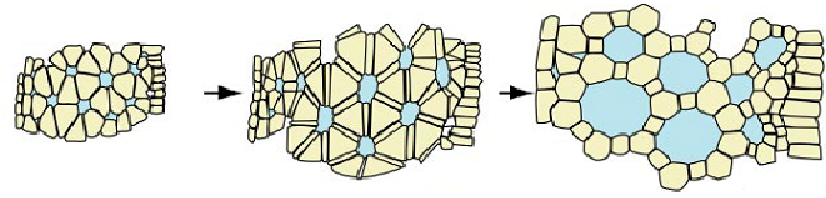

(b)

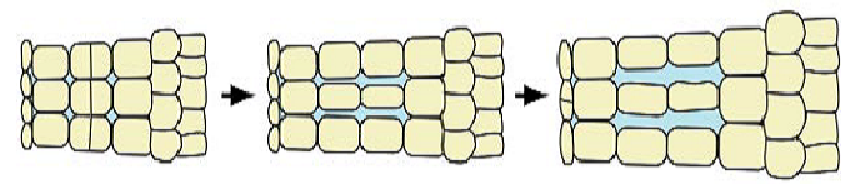

(c)

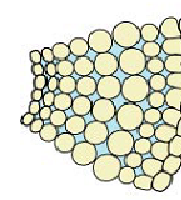

(d)

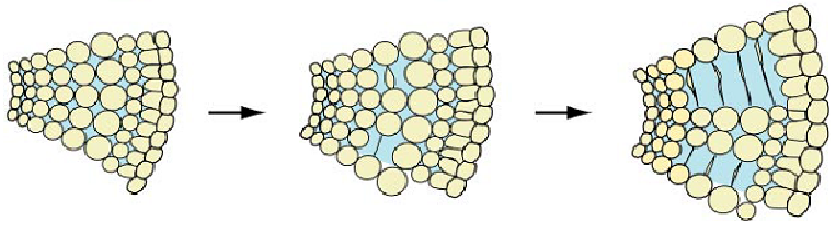

Fig. 3.1. Representación de la formación de los distintos tipos de aerénquima. (a) expansigenia tipo panal de abejas; (b) esquizogenia; (c) lisigenia radial; y (d) lisigenia tangencial. La endodermis es la capa de células de la izquierda y la exodermis la de la derecha. En celeste, espacios intercelulares y lagunas aerenquimáticas. Modificado de Seago et al. (2005).

resultado una forma similar a una tela de araña. Este tipo de aerénquima es típico de las Ciperáceas (Fig. 2.2 b, capítulo 2; Fig. 3.1 d). A veces la generación de aerénquima por lisigenia no presenta un patrón regular y organizado, como ocurre en especies como Apium (Fig. 2.2 c, capítulo 2) (Seago et al., 2005; Striker, 2012). Algunas especies forman aerénquima exquizógeno y lisígeno en diferentes tejidos y también se encuentran formas intermedias (Evans, 2003; Visser y Voesenek, 2004).

\subsubsection{Hipoxia, etileno y desarrollo de aerénquima}

La lisis y muerte celular que llevan al desarrollo de aerénquima, son atribuidas a la hipoxia y la acumulación de etileno (Evans, 2003; Visser y Bögemann, 2006) (Fig. 3.2). El etileno se forma a partir de S-adenosil metionina en un proceso que involucra a las enzimas 1-aminociclopropano-1-carboxilato (ACC) sintasa y ACC oxidasa. La formación 


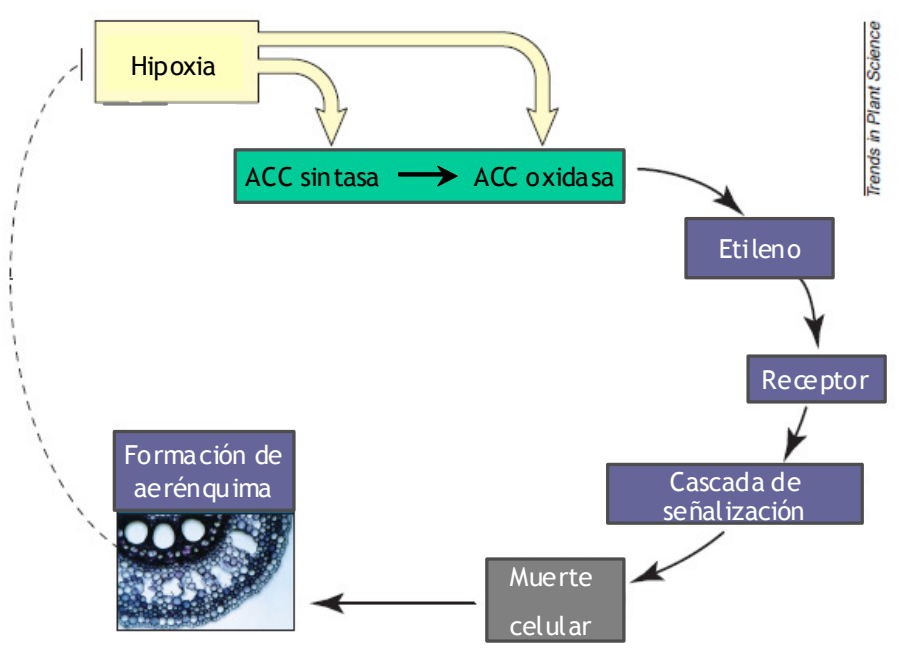

Fig. 3.2. Modelo de inducción de muerte celular programada por hipoxia en células corticales de raíz, que lleva a la formación de aerénquima. El suministro de oxígeno permitido por el aerénquima ayuda a mantener el metabolismo aeróbico y el crecimiento. Modificado de Drew et al. (2000).

de ACC sintasa es inducida por hipoxia en unas pocas horas de tratamiento (He et al., 1996). Una vez liberado, el etileno sería detectado por un receptor en las células corticales que mueren para formar los espacios gaseosos (Evans, 2003) (Fig. 3.2). En Rumex, la inundación provoca un rápido aumento de la síntesis del receptor de etileno (Vriezen et al., 1997).

El etileno induce la formación de aerénquima en muchas especies cuando es producido endógenamente o aplicado exógenamente (Drew et al., 1981; Jackson y Armstrong, 1999; Gunawardena et al., 2001) El desarrollo de aerénquima puede ser promovido idénticamente por la aplicación de etileno o por crecimiento en condiciones de hipoxia (Gunawardena et al., 2001; Evans, 2003). Además, el desarrollo de aerénquima se produce por impedancia mecánica y deficiencia de nutrientes, en donde el etileno también está involucrado, lo que sugiere que la muerte celular programada que genera aerénquima puede ser disparada por una variedad de estímulos (Evans, 2003).

Frente a condiciones de inundación, el aerénquima lisígeno se desarrolla en órganos ya existentes, o de manera concomitante con el crecimiento de nuevas raíces 
adventicias (Colmer y Voesenek, 2009). Algunas especies como el arroz forman aerénquima de forma constitutiva, mostrando mayor formación cuando son sometidas a inundación del suelo (Das y Jat, 1977) o limitación de $\mathrm{O}_{2}$ (Colmer et al., 1998; Colmer, 2003 a). En otras especies, como el maíz, la formación de aerénquima lisígeno ocurre durante la inundación inducido por la hormona etileno (Drew et al., 2000). El aerénquima lisígeno inducido se forma a medida que se desarrolla la hipoxia en el suelo, siendo las bajas presiones de oxígeno el disparador del desarrollo y el etileno que se acumula dentro del tejido, el principal iniciador interno. En anoxia sin embargo, el proceso es detenido y el tejido permanece intacto hasta que ocurre la muerte por necrosis (Evans, 2003; Visser y Voesenek, 2004). 


\subsection{OBJETIVO E HIPÓTESIS}

Objetivo general. Determinar si la hormona etileno está involucrada en el desarrollo de aerénquima en respuesta a hipoxia en Populus deltoides.

Hipótesis general. La hormona etileno está involucrada en la formación de aerénquima en álamos con raíces en condiciones de hipoxia.

\section{Objetivos particulares.}

1. Determinar si las condiciones de hipoxia causadas por la inundación del sistema radicular inducen la formación de aerénquima en álamo.

2. Determinar si la aplicación exógena de etileno (en forma del regulador etefón) induce la formación de aerénquima en raíces aisladas de álamo.

3. Determinar si la aplicación de etefón induce la formación de aerénquima en raíces de plantas enteras de álamo cultivadas en hidroponía. 


\subsection{MATERIALES Y MÉTODOS}

En base a los resultados obtenidos en experimentos realizados en los años 2009 y 2011, se seleccionó el clon ALT, el cual desarrolla aerénquima en respuesta a la inundación. En el año 2012 se realizaron una serie de experimentos con el fin de determinar si la hormona etileno está involucrada en el desarrollo de aerénquima en respuesta a hipoxia en este clon.

\subsubsection{Material vegetal y cultivo de las plantas}

Estacas de 1 año de edad, de $20 \mathrm{~cm}$ de longitud, se obtuvieron de un estaquero y se almacenaron a $4^{\circ} \mathrm{C}$ hasta el momento de su plantación, que comenzó el 9 de agosto, y se extendió durante 1 mes debido a que las estacas fueron plantadas en grupos de 10 cada 7 días para permitir una serie de experimentos sucesivos con plantas de la misma edad. Todas las estacas fueron tratadas con fungicidas como se describe en el capítulo 2. A continuación fueron plantadas en macetas de $1 \mathrm{~L}$ rellenas con arena. Las macetas fueron colocadas en invernáculo y se regaron a capacidad de campo hasta el inicio de cada experimento. Todas las plantas fueron podadas a una única guía. Las plantas fueron fertilizadas semanalmente con $20 \mathrm{ml}$ de solución de Hoagland completa (Legget y Frere, 1971).

\subsubsection{Determinación de la porosidad de raíz}

En todos los experimentos se determinó la porosidad de raíz (POR), una medida del porcentaje de espacios aéreos en la raíces (Li et al., 2006). Porciones de raíces de entre 0,4 y $0,6 \mathrm{~g}$ de peso fresco, fueron cortadas de zonas de nuevo crecimiento y se realizaron mediciones con picnómetro de $50 \mathrm{ml}$ como se describe en Li et al. (2006). El 
picnómetro fue inicialmente llenado con agua y pesado. Las raíces fueron pesadas y colocadas en el picnómetro lleno de agua, y luego se pesó. A continuación, las raíces fueron extraídas del picnómetro y molidas a una pasta con mortero y pilón. La molienda fue colocada en el picnómetro y se pesó nuevamente. POR fue determinado como:

$$
\begin{aligned}
& \operatorname{POR}(\%)=\underline{(\mathrm{Pmr}-\mathrm{Pr})} * 100 \\
& (\mathrm{R}+\mathrm{P}-\mathrm{Pr})
\end{aligned}
$$

donde Pmr es la masa del picnómetro con agua y la molienda de raíces, Pr es la masa del picnómetro con agua y las raíces, $\mathrm{R}$ es la masa de las raíces y $\mathrm{P}$ es la masa del picnómetro con agua.

\subsubsection{Cortes histológicos de la raíz}

Se tomaron muestras de las regiones apicales de raíces nuevas al inicio y al final del período de inundación, para determinar si se produce formación de aerénquima. Tres muestras de 3 plantas distintas de cada tratamiento fueron fijadas en FAA (formol: ácido acético glacial : alcohol etílico una relación 10 : 5 : 50; D`ambrogio de Argueso, 1986). Las muestras fueron deshidratadas en serie alcohólica e incluidas en parafina. Cortes de aproximadamente 15 micrones fueron obtenidos con un micrótomo rotativo Leitz 1512, y observados a 10 x y fotografiados con una cámara digital Olympus Evolt E330.

\subsubsection{Diseño experimental}

Se llevaron a cabo distintos experimentos, cuyos objetivos particulares y metodología se describen a continuación. 


\section{Experimento 2012-A.}

El objetivo fue determinar si las condiciones de hipoxia causadas por la inundación del sistema radicular inducen la formación de aerénquima en álamo.

En este experimento, 18 plantas fueron transferidas a macetas de 2,5 L rellenas con una mezcla 1:1 de tierra - arena. El día 0 se muestrearon 4 plantas control para determinar POR y realizar cortes histológicos. De las plantas restantes, 7 fueron inundadas y 7 se mantuvieron regadas a capacidad de campo, durante 28 días. Al final del período de inundación, se tomaron muestras de raíz para determinar POR y realizar cortes histológicos.

\section{Experimento 2012-B.}

El objetivo fue determinar si la aplicación exógena de etileno (en forma del regulador etefón) induce la formación de aerénquima en raíces aisladas de álamo.

Se cortaron los extremos apicales $(5 \mathrm{~cm})$ de raíces nuevas de 9 plantas y se colocó una muestra de cada una en distintas placas de Petri. Se realizaron 3 tratamientos: control (aplicación de agua), aplicación de etefón (Tifon, Gleba SA) $10^{-5} \mathrm{M}$ y etefón $10^{-3} \mathrm{M}$, por duplicado. El etefón se hidroliza espontáneamente a etileno a pH mayor a 5. El día 0 se evaluó la porosidad de raíz (POR) en muestras control. Las muestras fueron embebidas en agua (tratamiento control) y en las dos dosis de etefón. POR fue evaluada en mezclas de raíces de las distintas plantas, por triplicado para cada uno de los tratamientos a los días 1 y 3 de iniciado el tratamiento. 


\section{Experimento 2012-C.}

El objetivo fue determinar si la aplicación de etefón induce la formación de aerénquima en raíces de plantas enteras de álamo cultivadas en hidroponía.

En este experimento 18 plantas fueron colocadas en hidroponía aireada con solución de Hoagland diluida durante 3 días. A 6 plantas se les aplicó etefón $10^{-3} \mathrm{M}$ en la solución nutritiva y las 6 restantes fueron mantenidas como control, en solución nutritiva sin aplicación de etefón. Se realizaron muestreos de 4 plantas control al inicio, y 6 de cada tratamiento al final del experimento, para determinar POR.

\subsubsection{Análisis estadístico}

El análisis estadístico fue llevado a cabo con el programa STATISTICA versión 7.1 (StatSoft, Inc., 2005). Se realizaron análisis de varianza (ANOVA) y comparación de medias. 


\subsection{RESULTADOS}

\subsubsection{Experimento de inundación}

El experimento 2012-A se llevó a cabo con una metodología similar a los experimentos fisiológicos y bioquímicos descriptos en los capítulos previos de la tesis. Se tomaron muestras de raíz para establecer los valores de POR y relacionarlos con la presencia o ausencia de aerénquima, determinada a través de cortes histológicos. Los valores de POR de las plantas de ALT inundadas, al finalizar el experimento, fueron significativamente mayores a los de las plantas control (Tabla 3.1). Esto se correlacionó con la presencia de aerénquima en esa fecha (Fig. 3.3), el cual no se observa en las muestras control.

\subsubsection{Experimentos de aplicación exógena de etileno}

Una vez que se confirmó la relación entre la presencia de aerénquima y los valores de POR estimados con el picnómetro, se procedió a realizar una serie de experimentos para intentar reproducir los efectos de la hipoxia generada por la inundación en las raíces de ALT.

Para evaluar si en plantas de álamo se requiere etileno para la formación de aerénquima en respuesta a hipoxia como ocurre en maíz (Drew et al., 2000; Ram et al., 2002), es necesario evaluar como las plantas responden a tratamientos exógenos con etileno (etefón), ACC (precursor del etileno) y 1-MCP (1-metilciclopropeno), un inhibidor irreversible de la acción del etileno por su unión al receptor. Si el etileno está involucrado en la formación de aerénquima en álamo, el 1-MCP debería inhibir el proceso, mientras que la aplicación de ACC o etefón debería favorecer la formación, 


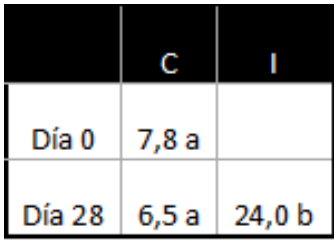

Tabla 3.1. Porcentaje de porosidad de raíz (POR) a los días 0 y 28 , en plantas control (C) e inundadas por 28 días (I) del experimento 2012-A. Las medias con la misma letra no difieren significativamente $(p<0.05$ LSD) entre tratamientos para cada fecha.

Fig. 3.3. Corte transversal de la región apical de raíz del clon ALT en el experimento 2012-A. Los cortes fueron observados a $10 \mathrm{x}$. C: control, I: inundado. Las barras de escala representan $100 \mu \mathrm{m}$.

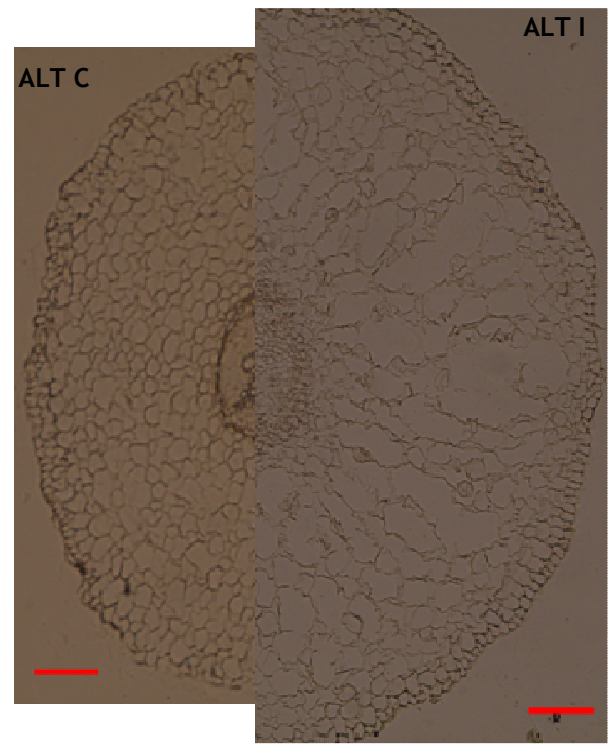

incluso en ausencia de una situación de hipoxia. Debido a que el 1-MCP se aplica de manera gaseosa, se procedió a evaluar un enfoque experimental, distinto al del crecimiento en maceta, que facilitara su aplicación. Para ello se tomaron fragmentos de raíz y se les aplicó etefón para verificar si se forma aerénquima en presencia de etileno. Además se realizó un experimento combinando hidroponía y aplicación de etefón.

En el experimento 2012-B, se cortaron raíces de varias plantas y se trataron exógenamente con 2 dosis de etefón en placa de Petri. No se observaron diferencias significativas en los valores de POR entre las raíces control y las tratadas con la menor dosis de etefón $\left(10^{-5} \mathrm{M}\right)$ ni al día 1 , ni al día 3 de iniciado el tratamiento. Las raíces tratadas con la dosis $10^{-3} \mathrm{M}$ de etefón, disminuyeron significativamente su porosidad con respecto a las raíces control, tanto al día 1 como al día 3 (Tabla 3.2). 
2012-B

\begin{tabular}{|c|c|c|c|}
\hline & $\mathrm{C}$ & $\mathrm{E} 10^{-5} \mathrm{M}$ & $\mathrm{E} 10^{-3} \mathrm{M}$ \\
\hline Día 0 & $13,7 \mathrm{a}$ & & \\
\hline Día 1 & $13,9 \mathrm{a}$ & $12,2 \mathrm{ab}$ & $10,1 \mathrm{bc}$ \\
\hline Día 3 & $11,7 \mathrm{ab}$ & $8,8 \mathrm{bc}$ & $7,4 \mathrm{c}$ \\
\hline
\end{tabular}

2012-C

\begin{tabular}{|c|c|c|}
\hline & $\mathrm{C}$ & $\mathrm{E} 10^{-3} \mathrm{M}$ \\
\hline Día 0 & $18,8 \mathrm{a}$ & \\
\hline Día 3 & $18,8 \mathrm{a}$ & $2,9 \mathrm{~b}$ \\
\hline
\end{tabular}

Tabla 3.2. $P O R$ en los experimentos 2012-B y 2012-C. C, control, $E$, etefón. Las medias con la misma letra no difieren significativamente $(p<0.05$ LSD) entre tratamientos para cada fecha.

En el experimento 2012-C el tratamiento con etefón afectó tanto a las plantas tratadas que a los 3 días los valores de POR disminuyeron al 10\% de las control (Tabla 3.2). En estas plantas se observó epinastia, un efecto causado por la hormona etileno (Taiz y Zeiger, 2002). 


\subsection{DISCUSIÓN}

En el experimento de inundación realizado en maceta (2012- A) se observó la formación de aerénquima, generada por la hipoxia en la zona radical, al igual que lo observado en ensayos anteriores. El arreglo espacial del aerénquima formado en ALT inundado, parece ser por el colapso de células alineadas radialmente en el córtex, separadas por células intactas o paredes celulares remanentes, como ocurre en la lisigenia radial en gramíneas (Fig. 2.2, capítulo 2; Fig. 3.1).

La presencia de aerénquima en las plantas inundadas, fue asociada a un aumento en la porosidad de las raíces (POR), determinada con picnómetro, con respecto plantas mantenidas a capacidad de campo. Estos resultados muestran que el aerénquima se forma como consecuencia del tratamiento de inundación en álamo.

Este sistema de cultivo de las plantas no puede usarse para evaluar aplicaciones exógenas de la hormona etileno, de su precursor el ACC y del inhibidor específico del receptor del etileno 1-MCP sobre las raíces. Por ese motivo, se probaron dos sistemas alternativos para llevar a cabo estos experimentos: un sistema con raíces aisladas y otro con plantas creciendo en hidroponia. Estos sistemas no solo facilitan los tratamientos con ACC y 1-MCP, sino que además son más eficientes en cuanto a tiempos y espacio, en comparación con los experimentos realizados en invernáculo.

Los efectos generados por la inundación no pudieron ser reproducidos en ninguno de los 2 experimentos intentados. Tanto en el experimento 2012-B como en el experimento 2012-C, no solo no aumentó la porosidad de las raíces, sino que al contrario de lo esperado, POR disminuyó significativamente en esas raíces. Estos resultados son opuestos a lo encontrado en el experimento con plantas creciendo en maceta con tierra arena 1:1 como sustrato (experimento 2012-A), experimento metodológicamente similar a aquellos donde se llevaron a cabo las demás mediciones fisiológicas y bioquímicas de esta tesis. 
De acuerdo al enfoque planteado, para evaluar si las plantas de ALT requieren etileno para la formación de aerénquima en respuesta a hipoxia, era necesario reproducir este efecto mediante la aplicación de etileno exógeno, antes de analizar la respuesta de estas plantas frente a aplicaciones de ACC o 1-MCP. Debido a los resultados obtenidos, no pudo determinarse si el etileno es o no el iniciador interno de la formación de aerénquima en raíces de álamo sometidas a hipoxia por inundación, y se considera que la aproximación experimental adoptada para evaluarlo no fue la adecuada, por lo que deberían considerarse otras alternativas. En experimentos donde la homeostasis del etileno es manipulada artificialmente de algún modo (como mediante el enfoque farmacológico utilizado) es probable que la concentración o compartimentalización de la hormona sea anormal, y no prueben su función en condiciones naturales (Love et al., 2009). Una alternativa ideal sería disponer de plantas transgénicas de $P$. deltoides que sean insensibles al etileno endógeno, bloqueando su percepción. La percepción del etileno se produce por una familia de receptores unidos a membrana, siendo ETR1 (Ethylene response 1) el primer receptor identificado en Arabidopsis; en el mutante etr1, la unión del etileno a su receptor se encuentra bloqueada, generando plantas insensibles a etileno (Bleecker et al., 1988). Love et al., 2009 generaron y seleccionaron árboles de $P$. tremula $\mathrm{X}$ tremuloides con sensibilidad reducida a etileno, expresando un alelo mutante, etr1-1. La obtención de transgénicos $P$. deltoides de este tipo permitirían continuar con el enfoque general seleccionado para el marco de esta tesis, en donde las plantas se cultivan en macetas con tierra y arena, y la hipoxia en sus raíces es generada cuando son sometidas a inundación. No se dispone de estos mutantes, ni de un protocolo por el que se pueda transformar $P$. deltoides, por lo que no es posible llevar a cabo este enfoque. 


\subsection{CONCLUSIONES}

A través de los experimentos 2009 y 2012-A, se pudo determinar que la inundación induce la formación de aerénquima en raíces sumergidas del clon ALT; sin embargo, mediante la metodología aplicada, no fue posible poner a prueba el objetivo general de este capítulo. Se concluye que, con el enfoque experimental planteado y los resultados obtenidos, no puede determinarse si el etileno está involucrado en el desarrollo de aerénquima en raíces de álamo sometidas a condiciones de hipoxia por un episodio de inundación. 


\section{CAPÍTULO 4}

RESPUESTAS FISIOLÓGICAS DE TRES CLONES DE $P$.

DELTOIDES FRENTE A UN EPISODIO DE ESTRÉS POR

INUNDACIÓN Y SU POSTERIOR RECUPERACIÓN

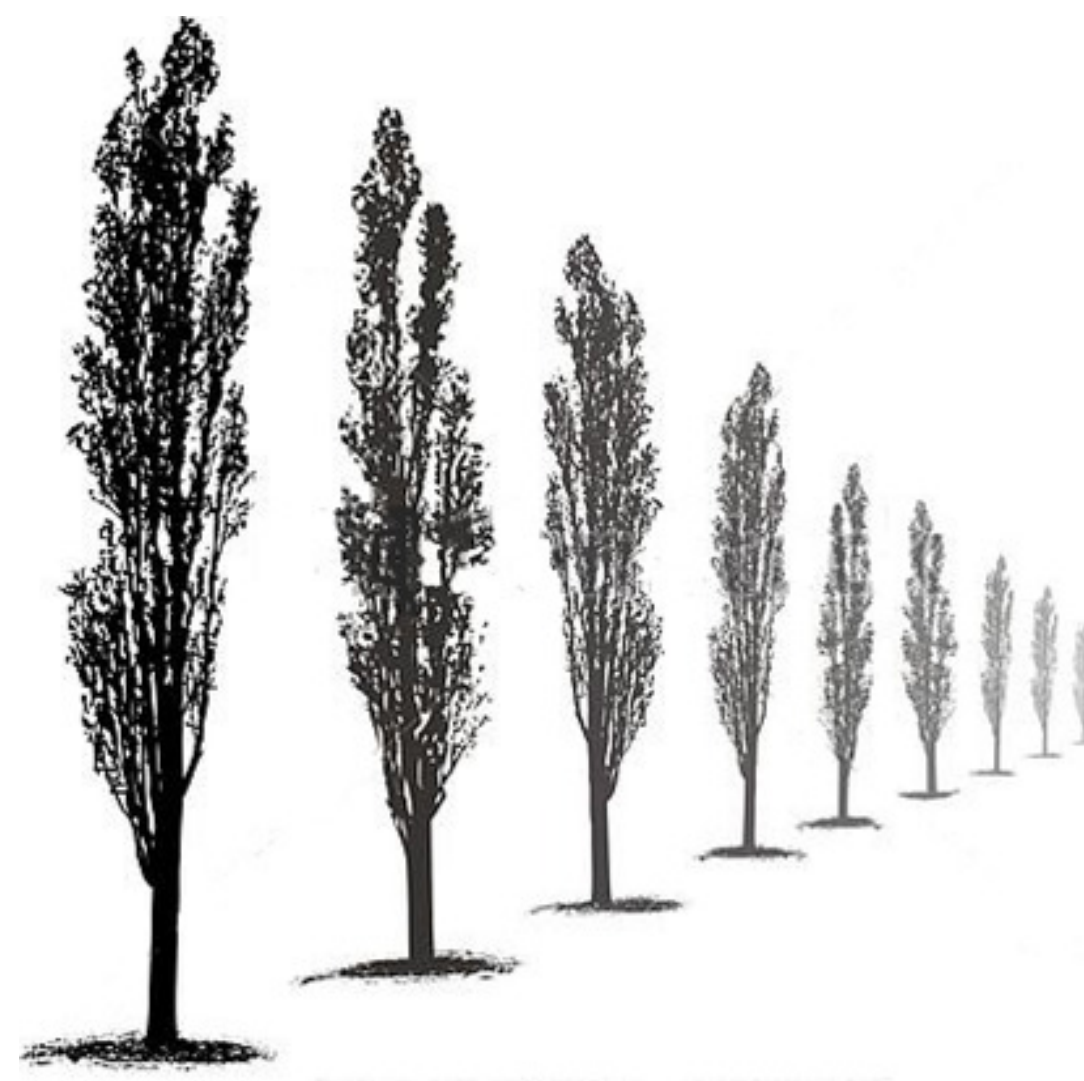




\subsection{INTRODUCCIÓN}

\subsubsection{Respuestas fisiológicas a la inundación}

A nivel fisiológico, las plantas inundadas sufren modificaciones en las relaciones hídricas y en la fijación de carbono. El cierre de estomas, con o sin deshidratación foliar, la reducción de la transpiración y la inhibición de la fotosíntesis, son respuestas que pueden ocurrir en horas o días después de iniciada la inundación, dependiendo de la tolerancia a la inundación de cada especie (Regehr et al., 1975; Bradford y Hsiao, 1982; Pezeshki y Chambers, 1985 a; Else et al., 1996; Verma et al., 2013).

La inundación del suelo en general induce una disminución relativamente rápida en la tasa de fotosíntesis en muchas especies de angiospermas, incluyendo Populus deltoides y otras especies de Populus (Regehr et al., 1975; Liu y Dickmann, 1993). Gran parte de la reducción temprana en la tasa de fotosíntesis de las plantas inundadas se correlaciona con el cierre de estomas, lo que resulta en una disminución de la absorción de $\mathrm{CO}_{2}$ por las hojas (Pezeshki et al., 1996). El cierre de estomas durante un episodio de inundación ha sido demostrado en muchas especies (por ejemplo, Regehr et al., 1975; Sena Gomes y Kozlowski, 1980a y 1980b; Pezeshki y Chambers 1985 a y 1985 b; Gong et al., 2007; Guo et al., 2011, entre otros). En P. deltoides, la inundación induce el cierre estomático tanto en la superficie adaxial como la abaxial de las hojas (Pereira y Kozlowski, 1977). El momento y grado de cierre de los estomas depende de la duración de la inundación y de la especie o clon de álamo (Regehr et al., 1975; Harrington, 1987; Neuman et al., 1996).

Históricamente, el cierre estomático inducido por inundación ha sido atribuido a una disminución en la conductividad hidráulica de la raíz, seguido de la reducción del potencial hídrico de las hojas, que a su vez, ocasiona el cierre estomático (Andersen et al., 1984; Syvertsen et al., 1983). Aunque la inundación causaría una reducción de la 
conductividad hidráulica de la raíz en álamos, hay pocos indicios de cualquier disminución significativa asociada en el potencial hídrico foliar (Harrington, 1987; Smit y Stachowiak, 1988; Smit et al., 1990; Liu y Dickmann, 1992). En muchas especies, el cierre de estomas inducido por inundación no se asocia con una reducción del potencial hídrico foliar. En hojas de $P$. deltoides, la inundación induce un rápido cierre estomático, pero la turgencia de las hojas se mantiene durante el período de inundación (Regehr et al., 1975). Esto sugiere que el cierre estomático disminuye la transpiración previniendo la deshidratación foliar durante el estrés (Bradford y Hsiao, 1982). El cierre de estomas que no responde a una regulación hidráulica, puede ser consecuencia de una señal hormonal. El ácido abscísico (ABA) ha sido implicado en el cierre de estomas de plantas creciendo en suelos anegados (Davies y Kozlowski, 1975; Jackson et al., 2003; Else et al., 1996).

La reducción temprana en la tasa de fotosíntesis de muchas plantas inundadas está muy correlacionada con el cierre de estomas, mientras que en inundaciones prolongadas, la tasa de fotosíntesis se reduce de manera progresiva, principalmente por efectos inhibitorios sobre el proceso de fotosíntesis. La inhibición no estomática puede atribuirse a un menor contenido de clorofila, una actividad reducida o un menor contenido de las enzimas de carboxilación, y un daño en el fotosistema II (PSII) por especies activas de oxígeno (EAO) (Bradford, 1983; Davies y Flore, 1986; Liao y Lin, 1994; Vu y Yelenosky, 2001; Yordanova y Popova, 2001; Yordanova et al., 2004; Verma et al., 2013).

Los efectos negativos de la inundación en la fotosíntesis a nivel de la hoja, pueden traducirse en una baja tasa de crecimiento a nivel de planta. Esta reducción implica una baja demanda de triosas fosfato para la biosíntesis de sacarosa, así como una desaceleración de su transporte en el floema. En consecuencia, el almidón empieza a acumularse en los cloroplastos y esto podría resultar en la reducción de la tasa de fotosíntesis (Wample y Davies, 1983; Liao y Lin, 1994; Liao y Lin, 2001; Pezeshki, 2001). 
Además, la senescencia prematura de las hojas y la reducción en el área foliar ocasionadas por la inundación (Cao y Conner, 1999; Rae et al., 2004; Marron et al., 2005; Monclus et al., 2005), pueden también conducir a una disminución de la fijación de carbono a nivel de planta. En consecuencia, el nivel de carbohidratos de reserva puede ser crucial en la determinación de la tolerancia a las inundaciones a largo plazo (Striker, 2012). 
Capítulo 4: Respuestas fisiológicas de tres clones de P. deltoides frente a un episodio de inundación y su posterior recuperación

\subsection{OBJETIVO E HIPÓTESIS}

Objetivo. Analizar las respuestas fisiológicas a nivel de hoja durante un episodio de estrés por inundación y el posterior período de recuperación, en tres clones de Populus deltoides con distinto grado de susceptibilidad a la inundación.

Hipótesis. Los clones más tolerantes a la inundación mantienen una mayor apertura estomática y actividad fotosintética que los clones más susceptibles. 


\subsection{MATERIALES Y MÉTODOS}

\subsubsection{Material vegetal, diseño experimental y tratamiento de estrés \\ Detallados en el inciso 2.3.1 del capítulo 2.}

\subsubsection{Actividad fotosintética}

Rendimiento cuántico (Fv/Fm). En el ensayo 2009, el rendimiento cuántico máximo del PSII (Fv/Fm) fue medido con un medidor de fluorescencia de pulso modulado Hansatech FMS2, en la última hoja completamente expandida adaptada a oscuridad durante 20 minutos.

Fotosíntesis (A). En el experimento 2011-A, la actividad fotosintética fue medida periódicamente en la última hoja completamente expandida, con un IRGA CIRAS II, PP Systems. Las mediciones se realizaron entre las 10:00 hs y las 15:00 hs La temperatura ambiental promedio fue de $25^{\circ} \mathrm{C}$ en el período de inundación y de $31^{\circ} \mathrm{C}$ en el período de recuperación. La cámara de medición se seteó a una irradiancia de 1500 $\mu$ moles $\mathrm{m}^{-2} \mathrm{~s}^{-1}$, una presión de vapor de agua del aire de $5 \mathrm{mbar}$, una temperatura de 25 ${ }^{\circ} \mathrm{C}$, una concentración de $\mathrm{CO}_{2}$ de $360 \mathrm{ppm}$ y una velocidad de flujo de aire de $191 \mathrm{ml}$ $\min ^{-1}$. Luego de cerrar la cámara sobre una hoja, se esperó que la hoja se ajuste a las condiciones de la cámara y se estabilicen los valores del diferencial de $\mathrm{CO}_{2}$, durante 20 3 minutos dependiendo de las condiciones diarias..

\subsubsection{Conductancia estomática}

En el experimento 2009, la conductancia estomática (gs) se midió con un porómetro Decagon SC1 en la cara abaxial de la última hoja completamente expandida. 


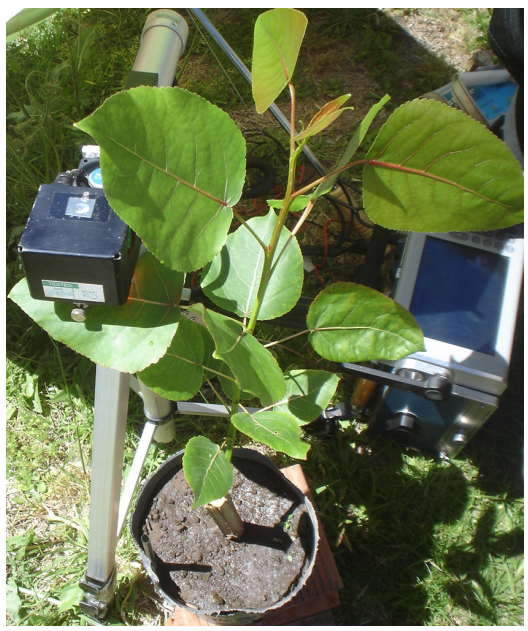

Fig. 4.1. Vista de la medición de fotosíntesis y conductancia estomática con un IRGA CIRAS II, PP Systems, en una planta control del experimento 2011-A.

Las mediciones se llevaron a cabo entre las $11: 30$ hs y $13: 30$ hs y la irradiancia promedio fue de $928 \mu$ moles $\mathrm{m}^{-2} \mathrm{~s}^{-1}$.

En el experimento 2011-A gs fue medida con un IRGA CIRAS II, PP Systems (Fig. 4.1). Las mediciones se realizaron periódicamente en la última hoja completamente expandida, en las mismas condiciones en las que se midió fotosíntesis.

\subsubsection{Contenido de Clorofila}

En el experimento 2009 el contenido de clorofila fue monitoreado regularmente en la zona basal de la última hoja completamente expandida con un SPAD Minolta.

En el experimento 2011-A, un disco de $5 \mathrm{~mm}$ de diámetro, de la zona basal de la última hoja completamente expandida, fue congelado en nitrógeno liquido y almacenado a $-80^{\circ} \mathrm{C}$ hasta la determinación del contenido de clorofila usando $\mathrm{N}, \mathrm{N}$ Dimetilformamida según Inskeep y Bloom (1985). 


\subsubsection{Contenido de RuBisCO}

En el experimento 2011-A, 2 discos, de $10 \mathrm{~mm}$ de diámetro, de la zona basal de la hoja fueron congelados en nitrógeno líquido, y almacenados a $-80^{\circ} \mathrm{C}$ hasta la determinación del contenido de la enzima Ribulosa 1,5-bifosfato carboxilasa-oxigenasa, RuBisCO, por SDS-PAGE según Laemmli (1970). Los 2 discos de hoja fueron homogeneizados en sample buffer $1 \mathrm{X}(62,5 \mathrm{mM}$ Tris $\mathrm{pH} 6.8 ; 5 \% \mathrm{w} / \mathrm{v} \mathrm{SDS}, 5 \% \mathrm{v} / \mathrm{v}$ glicerol, $5 \%$ v/v B-mercaptoetanol) y centrifugados a $10000 \mathrm{rpm}$ por $8 \mathrm{~min}$ a $4^{\circ} \mathrm{C}$. Para el análisis por SDS-PAGE, las proteínas del sobrenadante fueron separadas en minigeles de acrilamida $12 \%$ de $1,5 \mathrm{~mm}$ de grosor de acuerdo a Laemmli (1970). En cada calle se sembró un volumen equivalente a $2,62 \mathrm{~mm}^{2}$ de área de hoja. Las proteínas fueron visualizadas por tinción con Coomassie Brilliant Blue R-250. Los geles fueron digitalizados y la intensidad de las bandas fue analizada utilizando el programa Image $\mathrm{J}$ (http://rsbweb.nih.gov/ij/). Se analizaron 3 o 4 réplicas por tratamiento. La cantidad de la subunidad mayor de RuBisCO (LSU) fue calculada como porcentaje del contenido correspondiente al inicio del tratamiento de estrés.

\subsubsection{Análisis estadístico}

El análisis estadístico fue llevado a cabo con los programas STATISTICA versión 7.1 (StatSoft, Inc., 2005) y R versión 2.8.1 (R Development Core Team, 2010). Se realizaron análisis de medias y de varianza (ANOVA de una vía), utilizando el paquete agricolae $R$. Los análisis de correlación de variables fueron realizados con el STATISTICA. 


\subsection{RESULTADOS}

\subsubsection{Actividad fotosintética}

En el experimento 2009 se midió el rendimiento cuántico máximo del PSII (Fv/Fm); solo se redujo significativamente en las plantas inundadas del clon 149-82 (Tabla 4.1), y 3 días después de finalizado el período de inundación aun no se había recuperado.

En el experimento 2011-A, la fotosíntesis neta (A) y la conductancia estomática (gs) fueron medidas semanalmente, durante un período de 28 días de inundación y un posterior período de recuperación de 42 días. A disminuyó significativamente por la inundación en los tres clones (Fig. $4.2 \mathrm{a}, \mathrm{b}$ y c), pero en menor medida en las plantas de ALT inundado. Una vez finalizado el período de estrés, A se recuperó en las plantas previamente inundadas de todos los clones, alcanzando los mismos niveles que las plantas control.

\subsubsection{Conductancia estomática}

La conductancia estomática (gs), un indicador de la apertura estomática, fue medida en la superficie abaxial de la última hoja completamente expandida en ambos experimentos, pero utilizando distinta metodología; en el experimento 2009 se midió con un porómetro Decagón SC1 y en el experimento 2011-A se utilizó un IRGA CIRAS II, PP Systems. En ambos experimentos se obtuvieron los mismos resultados, gs disminuyó por la inundación en los tres clones, pero ALT inundado experimentó una reducción menos severa (Fig. 4.2, d, e y f). Una semana después de finalizado el período de inundación gs no se había recuperado en ninguno de los tres clones, pero a los 10 días pos inundación, las diferencias entre las plantas control y las previamente inundadas de 


\begin{tabular}{|ccc|}
\hline Clon / tratamiento & FV/Fm, día 33 de inundación & FV/Fm, dia 3 de recuperación \\
\hline ALT C & $0.79 \mathrm{a}$ & $0.80 \mathrm{a}$ \\
ALT I & $0.78 \mathrm{a}$ & $0.78 \mathrm{a}$ \\
$149-82 \mathrm{C}$ & $0.79 \mathrm{a}$ & $0.79 \mathrm{a}$ \\
$149-82 \mathrm{I}$ & $0.75 \mathrm{~b}$ & $0.72 \mathrm{~b}$ \\
ST67 C & $0.81 \mathrm{a}$ & $0.79 \mathrm{a}$ \\
ST67 I & $0.80 \mathrm{a}$ & $0.78 \mathrm{a}$ \\
\hline
\end{tabular}

Tabla 4.1. Rendimiento cuántico máximo del fotosistema II (Fv/Fm) en hojas adaptadas a la oscuridad durante 20 minutos, de los clones ALT, 149-82 y ST67, en el experimento 2009. C: control, I: inundado. Las mediciones fueron hechas en la última hoja completamente expandida. Las medias con la misma letra no difieren significativamente $(p<0.05$ LSD) entre clones y tratamientos para cada fecha.
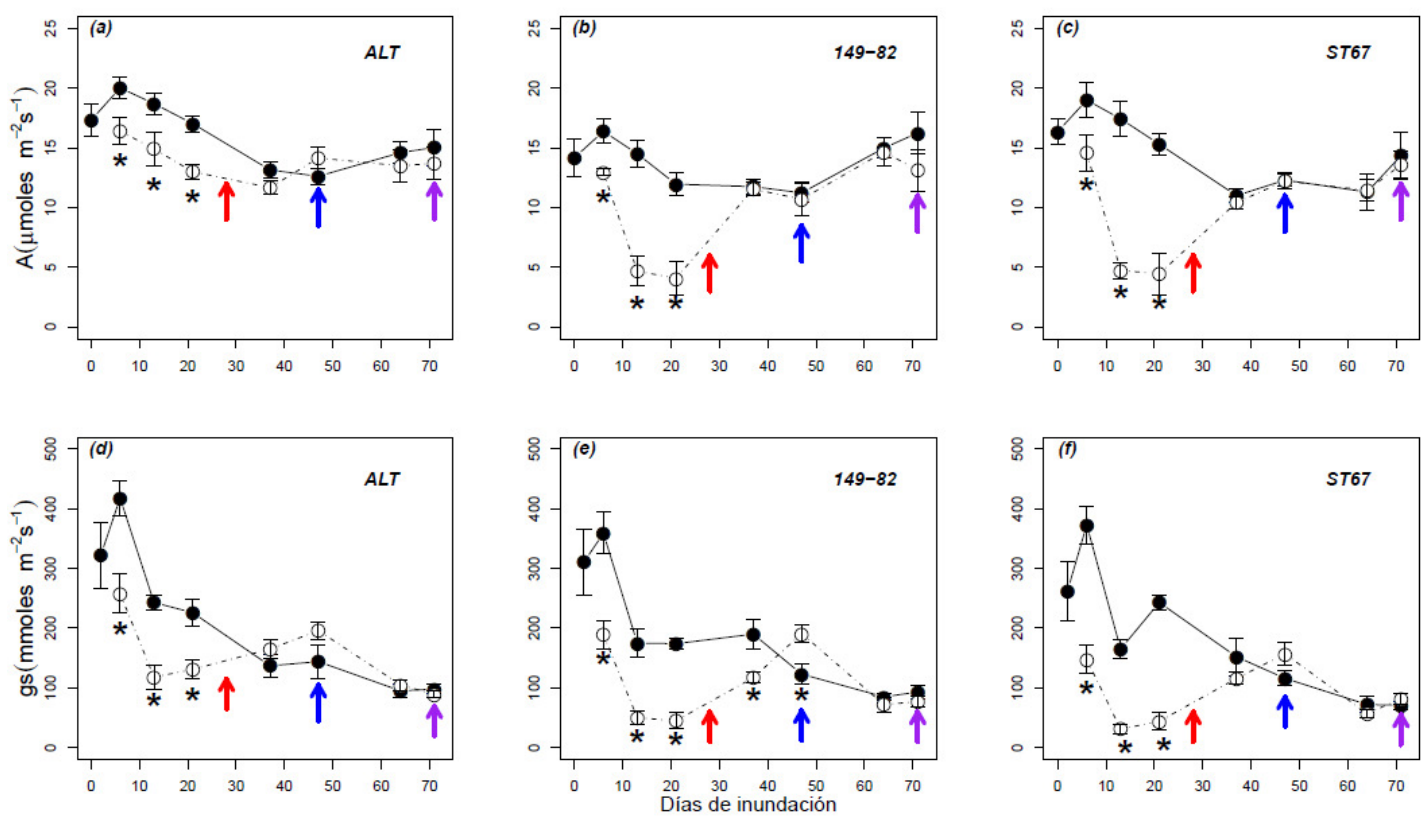

Fig. 4.2. Tasa de fotosíntesis ( $\mathrm{A} ; \mathrm{a}$, b y c) y conductancia estomática ( $\mathrm{gs}$; $\mathrm{d}$, e y f) de los clones ALT, 149-82 y ST67, en el experimento 2011-A. Los tratamientos fueron control (círculos negros) e inundación (círculos blancos). La flecha roja indica el final del tratamiento de inundación. La flecha azul señala la fecha en la que las variables fueron medidas para la cohorte L2 (ver materiales y métodos capítulo 2a) y la flecha lila la fecha en la que se midieron para la cohorte L3. Los asteriscos indican diferencias estadísticamente significativas $(p<0.05$ LSD) entre los controles e inundados de un mismo clon. 
(a)

\begin{tabular}{|c|c|c|c|}
\hline Factores & $\boldsymbol{r}$ & $\boldsymbol{R}^{2}$ & $\boldsymbol{p}$ \\
\hline Todos C & 0,5800 & 0,3363 & $0,0000^{*}$ \\
\hline Todos I & 0,8470 & 0,7167 & $0,0000^{*}$ \\
\hline ALT C & 0,5956 & 0,3548 & $0,0034^{*}$ \\
\hline ALT I & 0,7570 & 0,5731 & $0,0003^{*}$ \\
\hline $149-82$ C & 0,5980 & 0,3571 & $0,0042^{*}$ \\
\hline $149-82$ I & 0,9127 & 0,8330 & $0,0000^{*}$ \\
\hline ST67 C & 0,6322 & 0,4000 & $0,0050^{*}$ \\
\hline ST67 I & 0,9470 & 0,8960 & $0,0000^{*}$ \\
\hline
\end{tabular}

(b)

\begin{tabular}{|c|c|c|c|}
\hline Factores & $\boldsymbol{r}$ & $\boldsymbol{R}^{2}$ & $\boldsymbol{p}$ \\
\hline Todos C & 0,0420 & 0,0018 & 0,7652 \\
\hline Todos PI & 0,2051 & 0,0421 & 0,1294 \\
\hline ALT C & 0,2133 & 0,0455 & 0,4306 \\
\hline ALT PI & 0,2500 & 0,0625 & 0,2877 \\
\hline $149-82$ C & 0,0290 & 0,0008 & 0,9181 \\
\hline $149-82$ PI & 0,0200 & 0,0004 & 0,9400 \\
\hline ST67 C & 0,2192 & 0,0480 & 0,4325 \\
\hline ST67 PI & 0,2251 & 0,0507 & 0,3542 \\
\hline
\end{tabular}

Tabla 4.2. Análisis de correlación entre fotosíntesis y conductancia estomática durante: (a) período de inundación y (b) período pos inundación, para los clones ALT, 149-82 y ST67 en el experimento 2011-A. Todos: todos los clones, C: control, I: inundado, PI: previamente inundado, r: coeficiente de correlación producto-momento, $\mathrm{R}^{2}$ : coeficiente de determinación, $\mathrm{p}$ : valor $\mathrm{p}$. Los asteriscos indican resultados estadísticamente significativos $(p<0.05)$.

ALT y ST67 disminuyeron, siendo no significativas estadísticamente (Fig. 4.2, d y f). En la primer fecha luego de terminada la inundación, 149-82 previamente inundado mantenía aún una gs significativamente menor, pero en la segunda fecha pos inundación aumentó, volviéndose significativamente mayor que la de las plantas control (Fig. 4.2, e, flecha azul). En las fechas siguientes no hubo diferencias significativas entre ambos tratamientos de 149-82.

En la tabla 4.2 se muestra la relación entre las variables fotosíntesis y conductancia estomática, durante el período de inundación (Tabla 4.2 a), y el pos inundación (Tabla 4.2 b), en el experimento 2011-A. En el período de inundación, la 


\begin{tabular}{|cccccc|}
\hline Clon / tratamiento & Cohorte & Clorofila a & Clorofila $\mathrm{b}$ & Clorofila total & LSU Rubisco \\
\hline ALT C & L1 & $31.6 \mathrm{a}$ & $11.6 \mathrm{a}$ & $44.5 \mathrm{a}$ & 100 \\
149-82 C & L1 & $29.7 \mathrm{a}$ & $11.6 \mathrm{a}$ & $41.3 \mathrm{a}$ & 100 \\
ST67 C & L1 & $32.5 \mathrm{a}$ & $33.4 \mathrm{a}$ & $44.5 \mathrm{a}$ & 100 \\
& & & & & \\
ALT C & L2 & $25.2 \mathrm{ab}$ & $10.1 \mathrm{ab}$ & $35.2 \mathrm{ab}$ & $73 \mathrm{a}$ \\
ALT I & L2 & $26.5 \mathrm{a}$ & $10.3 \mathrm{a}$ & $36.8 \mathrm{a}$ & $82 \mathrm{a}$ \\
149-82 C & L2 & $24.8 \mathrm{ab}$ & $9.9 \mathrm{ab}$ & $34.8 \mathrm{ab}$ & $88 \mathrm{a}$ \\
149-82 I & L2 & $26.6 \mathrm{a}$ & $10.4 \mathrm{a}$ & $37.0 \mathrm{a}$ & $91 \mathrm{a}$ \\
ST67 C & L2 & $23.5 \mathrm{bc}$ & $9.9 \mathrm{ab}$ & $33.3 \mathrm{bc}$ & $72 \mathrm{a}$ \\
ST67 I & L2 & $21.4 \mathrm{C}$ & $9.4 \mathrm{~b}$ & $30.8 \mathrm{c}$ & $66 \mathrm{a}$ \\
Alton C & L3 & $27.1 \mathrm{ab}$ & $10.8 \mathrm{ab}$ & $37.9 \mathrm{ab}$ & $82 \mathrm{a}$ \\
Alton F & L3 & $27.1 \mathrm{ab}$ & $10.9 \mathrm{ab}$ & $38.0 \mathrm{ab}$ & $76 \mathrm{a}$ \\
149-82 C & L3 & $28.7 \mathrm{bc}$ & $11.2 \mathrm{bc}$ & $39.4 \mathrm{bc}$ & $100 \mathrm{a}$ \\
149-82 F & L3 & $30.2 \mathrm{c}$ & $11.8 \mathrm{c}$ & $42.0 \mathrm{c}$ & $108 \mathrm{a}$ \\
ST67 C & L3 & $25.0 \mathrm{a}$ & $10.3 \mathrm{a}$ & $35.3 \mathrm{a}$ & $85 \mathrm{a}$ \\
ST67 F & L3 & $27.4 \mathrm{ab}$ & $11.3 \mathrm{bc}$ & $38.7 \mathrm{abc}$ & $87 \mathrm{a}$ \\
\hline
\end{tabular}

Tabla 4.3. Contenido de clorofila $\left(\mu \mathrm{g} \mathrm{cm}^{-2}\right.$ ) y RuBisCO (como porcentaje del contenido inicial) en tres cohortes de hojas de los clones ALT, 149-82 y ST67, en el experimento 2011-A. La primer cohorte (L1) completó su expansión antes de el inicio de la inundación, la segunda cohorte (L2) se expandió durante el período de inundación, y la tercera (L3) durante el período pos inundación. C: control, I: inundado. Las medias con la misma letra no difieren significativamente $(p<0.05$ LSD) entre clones y tratamientos para cada variable en cada cohorte.

correlación fue positiva y significativa estadísticamente, tanto para el tratamiento control como para el inundado, siendo mayor para el tratamiento inundado (Todos C y Todos I, Tabla 4.2 a). 149-82 y ST67 mostraron un mayor aumento de la correlación en el tratamiento inundado con respecto al control, que el clon ALT. En el período pos inundación, la correlación significativa entre las variables desaparece, tanto en las plantas control como en las previamente inundadas. 


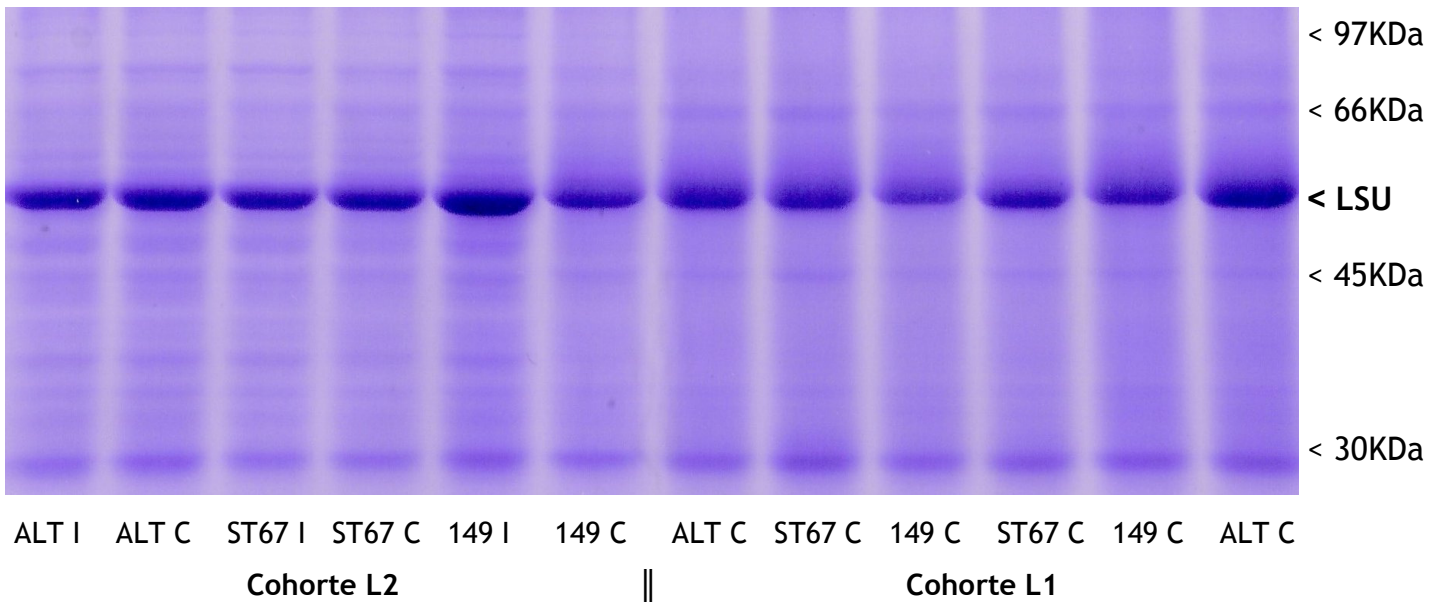

Fig. 4.3. SDS-PAGE de proteínas foliares de la última hoja completamente expandida, cohortes L1 y L2, de los clones ALT, 149-82 (149) y ST67, en el experimento 2011-A. Las muestras fueron cargadas en base al área. C: control, I: inundado. Las flechas indican los marcadores de peso molecular y la subunidad grande de RuBisCO (LSU, de Large SubUnit).

\subsubsection{Contenido de clorofila}

El contenido de clorofila fue medido en la última hoja completamente expandida en ambos experimentos. En la tabla 4.3 se muestran los resultados en el experimento 2011-A. No se observaron diferencias significativas entre las plantas control e inundadas en ninguno de los clones con ninguno de los dos métodos.

\subsubsection{Contenido de RuBisCO}

En el experimento 2011-A, se cuantificó el contenido de la enzima RuBisCO en las tres cohortes de hojas (Tabla 4.3, Fig. 4.3). No se observaron diferencias significativas entre las plantas control e inundadas en ninguno de los clones para ninguna de las tres cohortes. 


\subsection{DISCUSIÓN}

\subsubsection{Actividad fotosintética}

Dos efectos de la inundación en álamo muy documentados que dan lugar a una disminución de la fijación de carbono, y por lo tanto el crecimiento, son el cierre estomático y la reducción de la actividad fotosintética (Regehr et al., 1975, Liu y Dickmann, 1993 y 1996). La fluorescencia de la clorofila es una herramienta útil para detectar cambios en el funcionamiento del aparato fotosintético durante la inundación (Mielke et al., 2003; Pociecha et al., 2008; Verma et al., 2013). La relación Fv/Fm refleja el rendimiento cuántico máximo potencial del PSII y es utilizada como indicador del rendimiento fotosintético de las plantas, con valores óptimos de alrededor de 0,8. Valores menores son observados cuando una planta ha sido expuesta a un estrés, indicando particularmente el fenómeno de fotoinhibición (Maxwell y Johnson, 2000). Fv/Fm solo se redujo significativamente por la inundación en 149-82 en el experimento 2009 (Tabla 4.1), indicando daño en el aparato fotosintético de este clon. El daño ocasionado por la inundación en el aparato fotosintético, sumado al daño radical que sufre este clon, puede ser el causante de la lenta recuperación del crecimiento en el período pos inundación (Fig. 2.4 e, capítulo 2).

Los resultados del experimento 2011-A mostraron reducción de A en todos los clones sometidos a inundación, pero en menor medida en ALT. La explicación probablemente radique en el hecho de que ALT mantiene una mayor cantidad de raíces funcionales, lo que le asegura un adecuado suministro de agua, que a su vez contribuye a mantener una mayor fotosíntesis neta durante el período de estrés (Fig. 4.2). Probablemente, el cierre estomático sea la causa principal de la disminución de la fotosíntesis en las plantas inundadas de ALT y ST67. El análisis de correlación entre A y 
gs indica una mayor relación entre estas variables en el tratamiento de inundación con respecto al control (Tabla 4.2 a), indicando una probable mayor dependencia de A con respecto a la apertura estomática.

Los cambios en las características estomáticas no parecen afectar la actividad fotosintética en las hojas correspondientes a la cohorte L3 (Fig. 4.2, flecha lila), ya que no se observaron diferencias significativas entre las plantas control e inundadas en ninguno de los clones. Sin embargo, esta relación debe ser analizada con cuidado; tanto la fotosíntesis neta como la conductancia estomática son mediciones instantáneas, y pueden experimentar cambios a lo largo del día, y la densidad estomática influencia principalmente la máxima conductancia estomática posible, pero otros factores pueden afectar la apertura estomática y la tasa fotosintética.

\subsubsection{Conductancia estomática}

La reducción de la biomasa radical en las plantas inundadas, y la probable mayor resistencia de la raíz, debida al daño ocasionado por las condiciones de hipoxia, puede causar la disminución del flujo de agua hacia el interior de la planta. En álamos, el menor flujo de agua no parece tener impacto en el estado hídrico del tallo, probablemente porque la disminución de la conductancia estomática previene la perdida excesiva de agua, contribuyendo así a mantener el estado hídrico del tallo (Regehr et al., 1975; Smit y Stachowiak, 1988; Liu y Dickmann, 1993; Cao y Conner, 1999). La reducción de la conductancia estomática en las plantas inundadas en todos los clones (Fig. 4.2), podría explicarse como un ajuste en respuesta al menor transporte de agua hacia la parte aérea, siendo el cierre estomático más marcado en 149-82 inundado, el clon con su biomasa radical más afectada (Fig. 2.6, capítulo 2). 
En el período de inundación, ST67 reduce la densidad estomática en las hojas correspondientes a la cohorte L2. Esto, sumado a la mayor reducción de la biomasa radical, puede ser uno de los motivos por el que gs cae en mayor medida en ST67 que en ALT inundado, y por el que su recuperación a niveles de las plantas control una vez finalizada la inundación, es más lenta en este clon. En el caso de 149-82 inundado, la densidad estomática aumenta en las hojas L2, y es probable que esto ocasione el aumento de gs en esa hoja al principio de la recuperación (Fig. 4.2, e, flecha azul).

En el periodo pos inundación, se observa la desaparición de la significancia estadística en la correlación entre la fotosíntesis y la conductancia. La correlación de las variables desaparece tanto para las plantas previamente inundadas como para las control, lo que sugiere que las plantas se encuentran afectadas por factores externos a los tratamientos aplicados. Hacia el final del ensayo la temperatura diaria aumentó varios grados, y probablemente la humedad relativa del ambiente haya disminuido, en relación a la época del año (meses de diciembre y enero), por lo que es probable que esto haya afectado la apertura estomática y el intercambio gaseoso foliar.

\subsubsection{Contenido de clorofila y RuBisCO}

En el experimento 2011-A, no se encontró ninguna alteración significativa ocasionada por la inundación en el contenido de RuBisCO o clorofila, por unidad de área foliar, en ninguno de los clones inundados (Tabla 4.3); tampoco se encontraron diferencias en el contenido de clorofila monitoreado semanalmente con SPAD en la última hoja completamente expandida a lo largo del experimento 2009. Los cambios en el tamaño celular o grosor de la hoja producidos a lo largo del ensayo (inundación más recuperación) (Tabla 2.4, capítulo 2), no afectaron el contenido de clorofila y RuBisCO por unidad de área. Estos resultados, sumados a la mayor correlación positiva entre gs y 
A en los clones inundados, apoyan la idea de que la disminución de la fotosíntesis en las plantas inundadas de ALT y ST67, se debió principalmente al cierre estomático y no a efectos inhibitorios ocasionados por un menor contenido de clorofila y/o de RuBisCO, ni por daño ocasionado en el PSII. Las diferencias entre ambos clones pueden estar dadas por un menor número de estomas y un mayor cierre estomático en ST67 inundado, el cual retuvo una menor biomasa radical (Fig. 2.6, capítulo 2). En el caso de 149-82, además la disminución de Fv/Fm que muestra que hay daño en el PSII, ocurre una gran disminución de gs (a pesar del aumento en la densidad estomática; Tabla 2.4, capítulo 2); esto sumado a la gran pérdida de biomasa radical y a la menor área foliar (Fig. 2.6 y 2.7, capítulo 2), podrían explicar la lenta recuperación de este clon en el período pos inundación. 


\subsection{CONCLUSIONES}

Los datos sugieren que las inundaciones episódicas del suelo promueven el cierre de estomas y la consecuente disminución de la fotosíntesis neta en todos los clones, y perturban el funcionamiento del aparato fotosintético en las plantas de 149-82 en términos de rendimiento cuántico máximo potencial, Fv / Fm, de PSII. Estos efectos parecen ser reversibles después de finalizado el estrés.

La disminución de la apertura de estomas y la limitación estomática de la fotosíntesis, sumado a la disminución de la biomasa radical y del área foliar individual, son los principales factores que contribuyen a la reducción de la asimilación de carbono y acumulación de biomasa de toda la planta en los clones inundados. Las plantas de ALT mantuvieron mayores niveles de gs y A que ST67 y 149-82 durante el período de inundación, y fueron capaces de mantener gran cantidad de biomasa radical y foliar, lo que se refleja en el mantenimiento del crecimiento en este clon.

La capacidad de mantener una mayor apertura estomática, y por lo tanto de la fotosíntesis neta, por parte de ALT al ser sometido a un mes de inundación en invernáculo, lo hace parecer el más apto a sobrevivir a inundaciones periódicas en la región del Delta del Paraná. 
CAPÍTULO 5

CARACTERIZACIÓN DE LA RESPUESTA ANTIOXIDANTE EN DOS CLONES DE P. DELTOIDES CON DISTINTA SUSCEPTIBILIDAD A LA INUNDACIÓN

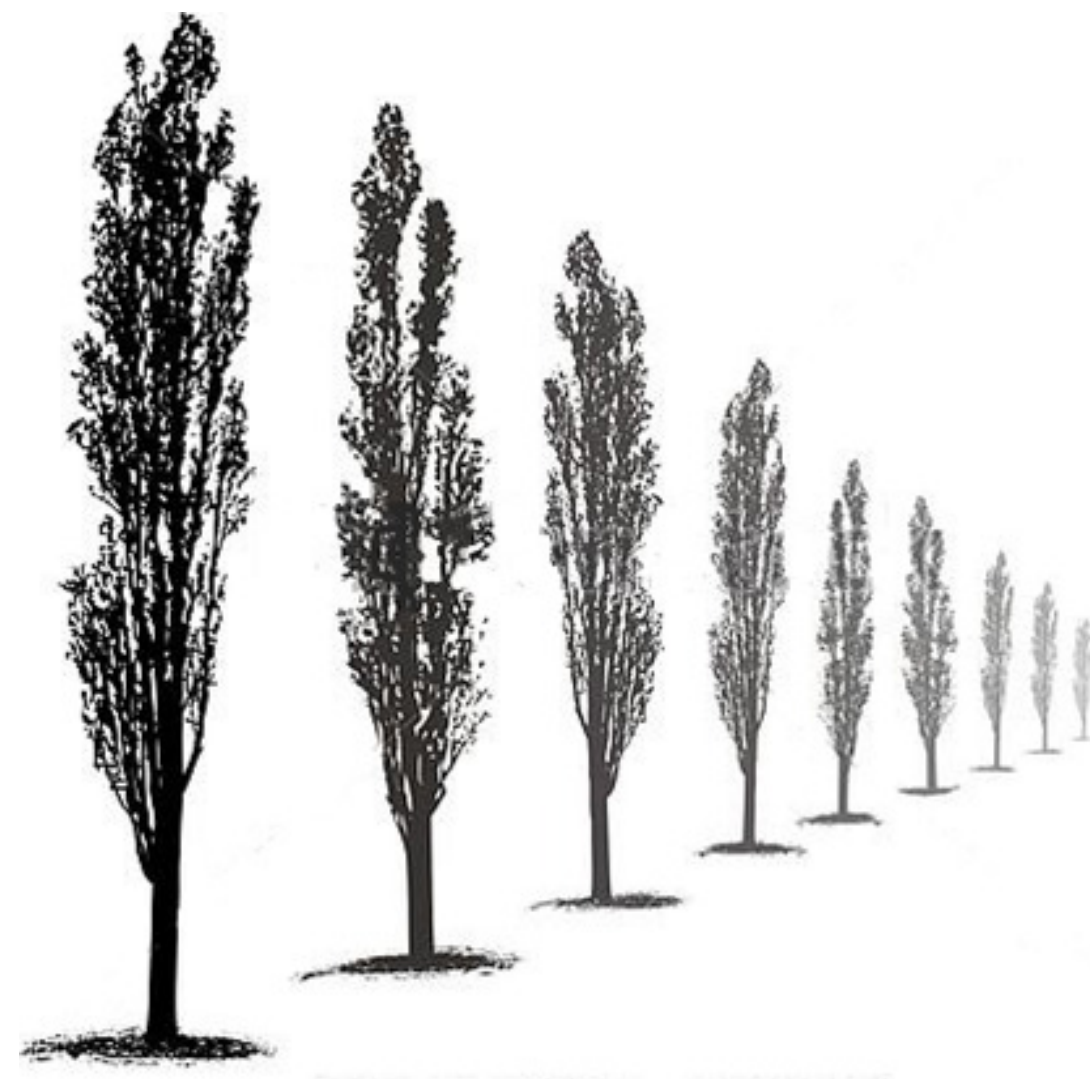




\subsection{INTRODUCCIÓN}

\subsubsection{Especies Activas del Oxígeno (EAO) en plantas}

Las Especies Activas del Oxígeno, EAO, son formas parcialmente reducidas del oxígeno, que se producen como resultado de la transferencia de uno, dos o tres electrones al $\mathrm{O}_{2}$ para formar el radical superóxido $\left(\mathrm{O}_{2}{ }^{\circ}\right)$, peróxido de hidrógeno $\left(\mathrm{H}_{2} \mathrm{O}_{2}\right) \mathrm{O}$ el radical hidroxilo $\left(\mathrm{HO}^{-}\right)$, respectivamente (Mittler, 2002). Las EAO son capaces de oxidar diferentes componentes celulares y provocar severo daño oxidativo cuando las defensas antioxidantes son sobrepasadas (Asada, 1999), fenómeno conocido como estrés oxidativo (Blokhina et al., 2003; Foyer y Noctor, 2011).

Existen muchas fuentes potenciales de generación de EAO en plantas (Tabla 5.1), produciéndose, directa o indirectamente, en numerosas reacciones y en casi todos los compartimentos celulares. Una fuente importante es la mitocondria, en la que los electrones transportados a través del complejo III (Ubiquinona-Citocromo C reductasa) de la cadena de transporte de electrones en condiciones de anoxia, son donados al $\mathrm{O}_{2}$ durante la re-aireación (Colmer y Voesenek, 2009). En órganos fotosintéticos, la generación de EAO en mitocondrias es despreciable en comparación con la de cloroplastos y peroxisomas, sin embargo en órganos no fotosintéticos, son la fuente más importante (Navrot et al., 2007). A pesar de no ser el sitio de mayor producción de EAO en hojas, las mitocondrias son un blanco de daño primario, ya que algunas EAO difunden libremente dentro de los compartimentos celulares (Bartoli et al., 2004).

En órganos fotosintéticos, la principal fuente de EAO son los cloroplastos, en los

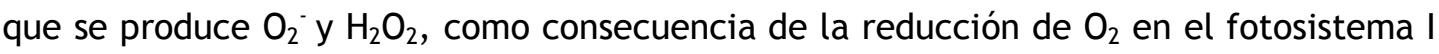
(PSI), y $\mathrm{O}_{2}{ }^{1}$ (oxígeno singulete) por modificación en el spin del electrón en presencia de moléculas de clorofila excitadas en el fotosistema II (PSII), donde la disipación del exceso de energía por carotenoides es menos efectiva (Asada, 2006; Galvez-Valdivieso y 


\begin{tabular}{|c|c|c|c|}
\hline Mecanismo de Producción & Localización & EAO & Referencias \\
\hline Fotosíntesis (PSI y PSII) & Cloroplasto & $\mathrm{O}_{2}^{-}$ & Asada y Takahashi, 1987; Asada, 1999 \\
\hline $\begin{array}{l}\text { Cadena de transporte de } \\
\text { electrones respiratoria }\end{array}$ & Mitocondria & $\mathrm{O}_{2}^{-}$ & Grant y Loake, 2000; Maxwell et al., 1999 \\
\hline Glicolato oxidasa & Peroxisoma & $\mathrm{H}_{2} \mathrm{O}_{2}$ & Corpas et al., 2001 \\
\hline Clorofila excitada & Cloroplasto & $\mathrm{O}_{2}{ }^{1}$ & Asada y Takahashi, 1987 \\
\hline NADPH oxidasa & $\begin{array}{l}\text { Membrana } \\
\text { Plasmática }\end{array}$ & $\mathrm{O}_{2}^{-}$ & $\begin{array}{l}\text { Hammond-Kosack y Jones, 1996; Grant y } \\
\text { Loake, } 2000\end{array}$ \\
\hline B-oxidación de ácidos grasos & Peroxisoma & $\mathrm{H}_{2} \mathrm{O}_{2}$ & Corpas et al., 2001 \\
\hline Oxalato oxidasa & Apoplasto & $\mathrm{H}_{2} \mathrm{O}_{2}$ & Dat et al., 2000 \\
\hline Xantina oxidasa & Peroxisoma & $\mathrm{O}_{2}^{-}$ & Corpas et al., 2001 \\
\hline Peroxidasas, $\mathrm{Mn}^{2+}$ y NADH & Pared celular & $\mathrm{H}_{2} \mathrm{O}_{2}, \mathrm{O}_{2}^{-}$ & $\begin{array}{l}\text { Hammond-Kosack y Jones, 1996; Grant y } \\
\text { Loake, } 2000\end{array}$ \\
\hline Amino oxidasa & Apoplasto & $\mathrm{H}_{2} \mathrm{O}_{2}$ & Allan y Fluhr, 1997 \\
\hline
\end{tabular}

Tabla 5.1. Mecanismos y sitio de producción de Especies Activas de Oxígeno (EAO) en las plantas. Modificado de Mittler (2002).

Mullineaux, 2009). La fotorrespiración es una gran fuente de $\mathrm{H}_{2} \mathrm{O}_{2}$. El glicolato, producto de la actividad oxigenasa de RuBisCO, es exportado desde los cloroplastos a peroxisomas, y metabolizado a $\mathrm{H}_{2} \mathrm{O}_{2}$ entre otros productos (Foyer y Noctor, 2009).

El estrés producido por falta de oxígeno incluye tres estados consecutivos y transitorios, hipoxia, anoxia y reoxigenación, caracterizados por las diferencias en la concentración de oxígeno. La generación de EAO es característica de la hipoxia y especialmente de la reoxigenación (Blokhina et al., 2003). La exposición súbita a oxígeno de tejidos previamente sometidos a un período de anoxia, constituye situación estresante debido a la generación de EAO que provocan daños por estrés oxidativo (“post-anoxic injury”, Monk et al., 1987 a; Ram et al., 2002; Blokhina et al., 2003; Goggin y Colmer, 2005). Entre los componentes celulares más susceptibles a daño se encuentran lípidos, proteínas, carbohidratos y ácidos nucleicos, que pueden ser modificados oxidativamente por las EAO (Blokhina et al., 2003). 


\subsubsection{Sistemas antioxidantes en plantas}

Para evitar el daño por EAO, las plantas disponen de sistemas de antioxidantes enzimáticos y no enzimáticos en todas sus células (Blokhina et al., 2003; Foyer et al., 1994 a; Foyer y Noctor, 2005). El término antioxidante describe a cualquier compuesto capaz de inactivar o remover EAO, sin sufrir en sí mismo modificaciones que lo conviertan en un radical destructivo (Noctor y Foyer, 1998). Las enzimas antioxidantes catalizan reacciones entre antioxidantes y EAO, o participan directamente en el procesamiento de EAO (Noctor y Foyer, 1998). Así, los antioxidantes y las enzimas antioxidantes funcionan como interruptores de cascadas de reacciones oxidativas descontroladas provocadas por las EAO. En la tabla 5.2 se resumen los principales sistemas antioxidantes en plantas, su localización y las EAO sobre las que actúan.

Las vías más importantes de eliminación de EAO en plantas incluyen a la enzima Superoxido Dismutasa (SOD) en casi todos los compartimentos celulares, el ciclo ascorbato-glutatión en cloroplastos, citosol, mitocondrias y peroxisomas, y las enzimas Glutatión Peroxidasa (GPX) y Catalasa (CAT) en peroxisomas (Fig. 5.1). El hecho de que el ciclo celular ascorbato-glutatión se encuentre en casi todos los compartimentos examinados ,y la elevada afinidad de la enzima ascorbato peroxidada (APX) por el $\mathrm{H}_{2} \mathrm{O}_{2}$, sugieren que este ciclo es crucial en el control de las EAO (Mittler, 2002).

\subsubsection{Antioxidantes}

El ácido ascórbico y el glutatión, son antioxidantes hidrosolubles, de bajo peso molecular (Smirnoff, 2000; Blokhina et al., 2000; Blokhina et al., 2003; Foyer y Noctor, 2011), que se encuentran en elevadas concentraciones en cloroplastos y otros compartimentos celulares, y son esenciales para la defensa de las plantas contra el estrés oxidativo (Noctor y Foyer, 1998; Smirnoff, 2000). 


\begin{tabular}{|c|c|c|c|}
\hline Sistema antioxidante & Localización & EAO & Referencias \\
\hline Superoxido dismutasa & $\begin{array}{l}\text { Cloroplasto, Citosol, Mitocondria, } \\
\text { Peroxisoma, Apoplasto }\end{array}$ & $\mathrm{O}_{2}^{-}$ & Bowler et al., 1992 \\
\hline Ascorbato peroxidasa & $\begin{array}{l}\text { Cloroplasto, Citosol, Mitocondria, } \\
\text { Peroxisoma, Apoplasto }\end{array}$ & $\mathrm{H}_{2} \mathrm{O}_{2}$ & $\begin{array}{l}\text { Asada y Takahashi, 1987; } \\
\text { Asada, } 1999\end{array}$ \\
\hline Catalasa & Peroxisoma & $\mathrm{H}_{2} \mathrm{O}_{2}$ & Willekens et al., 1997 \\
\hline Glutatión peroxidada & Citosol & $\mathrm{H}_{2} \mathrm{O}_{2}, \mathrm{ROOH}$ & Dixon et al., 1998 \\
\hline Peroxidasas & Pared celular, Citosol, Vacuola & $\mathrm{H}_{2} \mathrm{O}_{2}$ & Asada y Takahashi, 1987 \\
\hline Tioredoxina peroxidada & Cloroplasto, Citosol, Mitocondria & $\mathrm{H}_{2} \mathrm{O}_{2}$ & Baier y Dietz, 1996 \\
\hline Ácido ascórbico & $\begin{array}{c}\text { Cloroplasto, Citosol, Mitocondria, } \\
\text { Peroxisoma, Apoplasto }\end{array}$ & $\mathrm{H}_{2} \mathrm{O}_{2}, \mathrm{O}_{2}^{-}$ & $\begin{array}{c}\text { Asada, 1999; Noctor y Foyer, } \\
1998\end{array}$ \\
\hline Glutatión & $\begin{array}{c}\text { Cloroplasto, Citosol, Mitocondria, } \\
\text { Peroxisoma, Apoplasto }\end{array}$ & $\mathrm{H}_{2} \mathrm{O}_{2}$ & $\begin{array}{c}\text { Asada, 1999; Noctor y Foyer, } \\
1998\end{array}$ \\
\hline A-tocoferol & Membranas & $\mathrm{ROOH}, \mathrm{O}_{2}{ }^{1}$ & Asada y Takahashi, 1987 \\
\hline Carotenoides & Cloroplastos & $\mathrm{O}_{2}^{1}$ & Asada y Takahashi, 1987 \\
\hline
\end{tabular}

Tabla 5.2. Mecanismos de eliminación de Especies Activas de Oxígeno (EAO) en las plantas. Modificado de Mittler (2002).

El mantenimiento de una elevada relación de las formas reducido / oxidado de ácido ascórbico y glutatión, es esencial para la apropiada eliminación de EAO. Esta relación es mantenida por las enzimas glutatión reductasa (GR), monodehidroascorbato reductasa (MDAR) y dehidroascorbato reductasa (DHAR) (Fig. 5.1) (Noctor y Foyer 1998; Asada, 1999; Blokhina et al., 2000; Mittler, 2002).

El Ascorbato y el glutatión se distinguen de la mayoría de estos compuestos porque (1) enzimas especificas los acoplan al metabolismo del $\mathrm{H}_{2} \mathrm{O}_{2}$, (2) sus formas oxidadas son relativamente estables, y (3) sus formas oxidadas se reciclan a sus compuestos reducidos mediante un eficiente sistema de enzimas que dependen del NAD(P)H (Foyer y Noctor, 2011). Estos compuestos son parte de un complejo e intrincado sistema antioxidante, actuando junto a catalasas en vías de procesamiento de $\mathrm{H}_{2} \mathrm{O}_{2}$ (Mittler, 2002; Foyer y Noctor, 2011). 


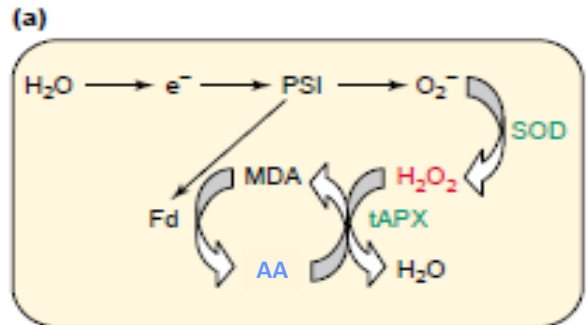

(b)

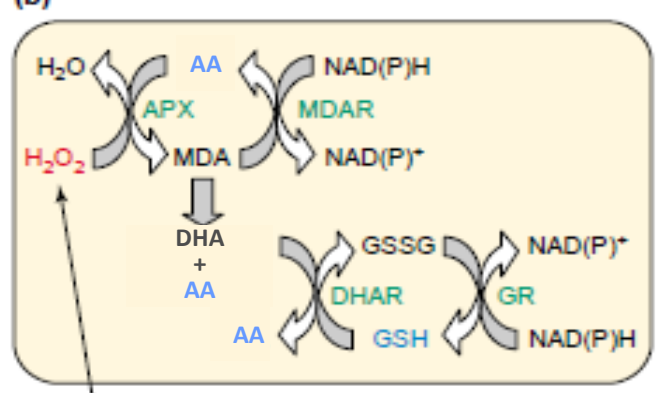

(c)

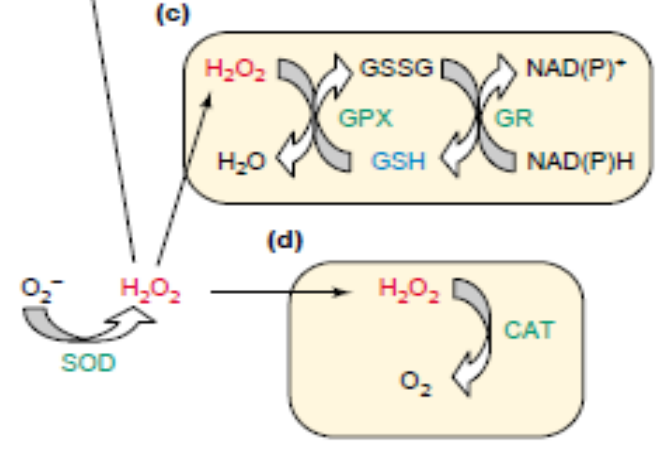

Fig. 5.1. Vías de eliminación de Especies Activas de Oxígeno (EAO) en plantas. (a) Ciclo agua - agua. (b) Ciclo ascorbato - glutatión. (c) Ciclo glutatión peroxidasa (GPX). (d) Catalasa (CAT).

La superoxido dismutasa (SOD) actúa como primera línea de defensa, convirtiendo $\mathrm{O}_{2}{ }^{-}$en $\mathrm{H}_{2} \mathrm{O}_{2}$. Luego, las ascorbato peroxidasas (APX), GPX y CAT detoxifican el $\mathrm{H}_{2} \mathrm{O}_{2}$.

A diferencia de CAT (d), APX y GPX, ascorbato (AA) o glutatión (GSH) (a-c) requieren de un ciclo de regeneración. Estos ciclos utilizan electrones provenientes del aparato fotosintético (a) o $\mathrm{NAD}(\mathrm{P}) \mathrm{H}$ (b y c) como poder reductor.

En rojo: EAO; en azul: antioxidantes; en verde: enzimas antioxidantes

Abreviaturas: DHA, dehidroascórbico; DHAR, DHA reductasa; Fd, ferredoxina; GR, glutatión reductasa; GSSG, glutatión oxidado; MDA, ácido monodehidroascórbico; MDAR, MDA reductasa; PSI, fotosistema I; tAPX, APX unida a tilacoide. Modificado de Mittler (2002).

Ácido ascórbico. El ácido ascórbico $(\mathrm{AA})$ es el metabolito central en la defensa antixoidante de células vegetales, encontrándose en todos los compartimentos celulares (Smirnoff, 2000). Tiene la capacidad de eliminar una amplia gama de EAO, como $\mathrm{O}_{2}{ }^{-}, \mathrm{O}_{2}{ }^{1}$ y, fundamentalmente, $\mathrm{H}_{2} \mathrm{O}_{2}$ (Foyer et al., 1994 a; Blokhina et al., 2000). Trabaja en cooperación con el glutatión (ciclo ascorbato-glutatión), y mantiene la regeneración del antioxidante lipofílico a-tocoferol, proporcionando una protección sinérgica de las membranas lipídicas (Thomas et al., 1992). Además, participa en la regulación del ciclo celular influenciando la progresión de la fase $\mathrm{G} 1$ a la $\mathrm{S}$, y se ha implicado en la regulación de la elongación celular (Smirnoff, 1996; Liso et al., 1998).

La oxidación del AA por las EAO ocurre en dos pasos secuenciales, produciéndose 
primero monodehidroascorbato (MDA) y posteriormente dehidroascorbato (DHA) (Fig. 5.1 , b). La regeneración del AA está dada por las enzimas monodehidroascorbato reductasa (MDAR), que utiliza $\mathrm{NAD}(\mathrm{P}) \mathrm{H}$ para regenerar AA directamente a partir de MDA, y dehidroascorbato reductasa (DHAR) (Fig. 5.1, b) (Smirnoff, 1996; Noctor y Foyer, 1998; Asada, 1999). Además, el MDHA es un eficiente aceptor de electrones (Foyer y Lelandais, 1993), y es reducido directamente a AA usando electrones derivados de la cadena de transporte de electrones fotosintética (Fig. 5.1, b).

Glutatión. El glutatión en su forma reducida $(\mathrm{GSH})$ es el principal tiol de bajo peso molecular en la mayoría de las plantas (Rennenberg, 1982). Actúa como forma de almacenamiento y transporte de azufre reducido (Rennenberg, 1982; May et al., 1998), y está implicado en la regulación de la expresión génica en respuesta a estrés ambiental y ataque de patógenos (Dron et al., 1988; Wingate et al., 1988).

El GSH actúa como compuesto de defensa contra el estrés oxidativo reaccionando no enzimaticamente con $\mathrm{O}_{2}{ }^{1}, \mathrm{HO}^{-}$y $\mathrm{O}_{2}{ }^{-}$, removiendo enzimaticamente $\mathrm{H}_{2} \mathrm{O}_{2}$, y protegiendo los grupos tiol de enzimas (Larson, 1988; Foyer et al., 1994 a; Blokhina et al., 2003). También participa en la regeneración de AA a partir de DHA, en una reacción catalizada por la enzima DHAR (Fig. 5.1, b), donde el GSH, dador de electrones, se oxida a disulfuro de glutatión (GSSG). GSH se regenera mediante la acción de la enzima glutatión reductasa $(G R)$ en una reacción dependiente de NADPH (Fig. 5.1, b) (Foyer et al., 1994 a; Blokhina et al., 2000).

Antocianinas como antioxidantes. La absorción de luz solar por tejidos verdes, puede ser peligrosa cuando la captación de energía se produce a una tasa más rápida que el transporte de electrones, y su utilización en la reducción de $\mathrm{CO}_{2}$, haciendo que el exceso de excitación del aparato fotosintético sea una amenaza constante. La sobreexcitación se manifiesta como una represión de la fotosíntesis, o fotoinhibición 
(Long et al., 1994). Las condiciones fotoinhibitorias pueden conducir a la formación de EAO, que a su vez ocasionan perturbación del metabolismo celular (Foyer et al., 1994 b). La fotoinhibición crónica puede reducir significativamente la productividad y tener un efecto negativo en la supervivencia (Ball et al., 1991).

Las antocianinas modifican significativamente la cantidad y calidad de luz que incide sobre los cloroplastos (Krol et al., 1995); estas absorben preferentemente luz verde y UV, y luz azul en menor proporción. La absorción de luz azul-verde reduce la luz disponible para la clorofila (Smillie y Hetherington, 1999; Steyn et al., 2002). La acumulación de antocianinas coincide generalmente con períodos de elevada presión de excitación y aumento de potencial daño fotooxidativo debido al desequilibrio entre la captura de luz, la asimilación de $\mathrm{CO}_{2}$ y la utilización de carbohidratos. La atenuación de la luz incidente por parte de las antocianinas, puede ayudar a restablecer este equilibrio, y reducir la presión de excitación y el riesgo de daño fotooxidativo (Steyn et al., 2002) que se genera en órganos afectados por un estrés ambiental.

\subsubsection{Enzimas antioxidantes}

Las enzimas antioxidantes son imprescindibles para la vida en una atmósfera con oxígeno; incluyen la SOD, APX y otras peroxidasas (PX), enzimas implicadas en la síntesis y regeneración de las formas reducidas de los antioxidantes, y CAT (Foyer et al., 1994 a). La eficiente destrucción de $\mathrm{O}_{2}$ y $\mathrm{H}_{2} \mathrm{O}_{2}$ requiere de la acción de estas enzimas $\mathrm{s}$ actuando en sincronía (Fig. 5.1) (Noctor y Foyer, 1998).

El $\mathrm{O}_{2}{ }^{-}$producido en diferentes compartimentos celulares se convierte rápidamente en $\mathrm{H}_{2} \mathrm{O}_{2}$ por la acción de la SOD. Como el $\mathrm{H}_{2} \mathrm{O}_{2}$ es un oxidante fuerte que oxida rápidamente grupos tiol, no se puede permitir su acumulación en exceso en organelas, como por ejemplo en los cloroplastos, donde la fotosíntesis depende de enzimas reguladas por grupos tiol (Kaiser, 1979; Noctor y Foyer, 1998). 
La CAT convierte $\mathrm{H}_{2} \mathrm{O}_{2}$ en $\mathrm{H}_{2} \mathrm{O}$ y $\mathrm{O}_{2}$. Esta enzima, que sólo se encuentra en peroxisomas, tiene elevada velocidad catalítica pero baja afinidad de sustrato, porque requiere el acceso simultáneo de dos moléculas de $\mathrm{H}_{2} \mathrm{O}_{2}$ al sitio activo (Willkens et al., 1995). Una alternativa de destrucción de $\mathrm{H}_{2} \mathrm{O}_{2}$ es a través de peroxidasas, que se encuentran en toda la célula y tienen mayor afinidad por el $\mathrm{H}_{2} \mathrm{O}_{2}$ que CAT.

En células vegetales, el sustrato reductor más importante para la detoxificación de $\mathrm{H}_{2} \mathrm{O}_{2}$, es el AA (Willekens et al., 1995; Mehlhorn et al., 1996). APX, que posee isoenzimas en distintas organelas, utiliza dos moléculas de $A A$ para reducir $\mathrm{H}_{2} \mathrm{O}_{2}$ a $\mathrm{H}_{2} \mathrm{O}$, con la generación concomitante de dos moléculas de MDA (Noctor y Foyer, 1998).

\subsubsection{Inundación y estrés oxidativo}

La baja utilización de fotones por plantas inundadas, podría dar lugar a la producción de EAO que induzcan estrés oxidativo y generen daño oxidativo en las proteínas del aparato fotosintético (Asada y Takahashi, 1987; Yordanova et al., 2004) (Fig. 5.2); además, los tejidos previamente sometidos a un período de anoxia, también sufren la generación de EAO durante la reoxigenación (Monk et al., 1987 a y 1987 b; Ram et al., 2002; Blokhina et al., 2003; Goggin y Colmer, 2005). Bajo estrés por inundación, la capacidad de eliminación de las EAO puede ser superada debido a su rápida producción (Yordanova et al., 2004). Los síntomas de daño ocasionados cuando las plantas son sometidas a hipoxia o anoxia, y en el período pos anóxico, son disminución de la integridad de membrana, medida como pérdida de electrolitos, cambios en el contenido y composición de lípidos, y activación de la peroxidación lipídica (Hetherington et al., 1982; Crawford y Braendle, 1996; Yordanova et al., 2003).

En algunos estudios comparativos de especies o variedades con diferente grado de tolerancia a inundación y anoxia, la mayor tolerancia se asociada a un mayor contenido de antioxidantes. Esto ocurre en especies como arroz (Ram et al., 2002) y 


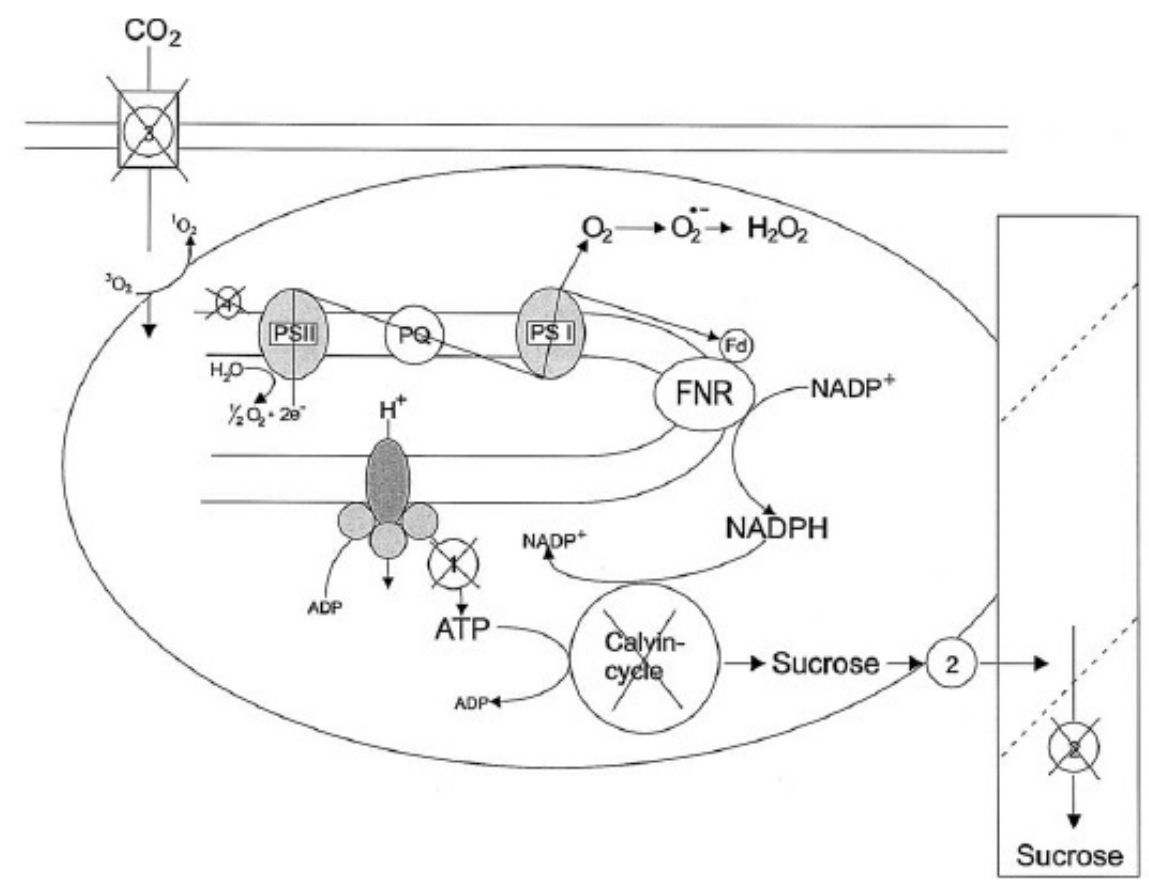

Fig. 5.2. Formación de $E A O$ en plantas bajo estrés debido a la inhibición del ciclo de Calvin por (4) inhibición del transporte de electrones por daño en el PSII, (3) cierre estomático, (2) bloqueo de carga y, transporte hacia las raíces, de sacarosa en el floema que provoca acumulación de almidón en cloroplastos, o (1) transporte de electrones desacoplado que conduce a deficiencia de ATP. Luego de que el ciclo de Calvin es bloqueado, la oxidación del $\mathrm{NAD}(\mathrm{P}) \mathrm{H}$ disminuye y aumenta la probabilidad de que los electrones sean transferidos al $\mathrm{O}_{2}$ llevando a la formación de $\mathrm{O}_{2}{ }^{-}$en el PSI, $\mathrm{O}_{2}{ }^{1}$ en el PSII. Fd: ferredoxina; FNR: NADPH-ferredoxina oxidorreductasa; PQ: plastoquinona. Modificado de Grassmann et al. (2002)

citrus (Arbona et al., 2007), mientras que en otros casos no parece haber una relación directa (Blokhina et al., 2000). Estas diferencias en los resultados se deben en gran parte a la variabilidad genética inter e intraespecífica, pero también a los diferentes métodos experimentales utilizados para inducir la situación de anoxia y a la duración del estrés (Blokhina et al., 2003). No hay información disponible acerca del impacto del daño post-anóxico en la recuperación de plantas de Populus luego de un episodio de inundación, ni tampoco si el grado de susceptibilidad está relacionado con el contenido de antioxidantes. 


\subsection{OBJETIVO E HIPOTESIS}

Objetivo. Caracterizar la respuesta del sistema antioxidante, principalmente a través del contenido de ácido ascórbico y glutatión, durante un período de inundación y el posterior período de recuperación, en dos clones de Populus deltoides con diferente grado de susceptibilidad a la inundación.

Hipótesis. La recuperación de los clones luego de un episodio de inundación, está determinada por su capacidad de detoxificar especies activas del oxígeno (EAO), reduciendo el impacto del daño pos anóxico causado por la vuelta a condiciones aeróbicas luego de un período de anoxia-hipoxia. La mayor capacidad de reiniciar el crecimiento luego de la inundación se relaciona con un mayor nivel de defensas contra el estrés oxidativo. Estas mayores defensas pueden ser inducidas en mayor medida por la inundación o la reoxigenación en los clones menos susceptibles, o ser mayores en estos clones incluso en condiciones no estresantes. 


\subsection{MATERIALES Y MÉTODOS}

\subsubsection{Material vegetal, diseño experimental y tratamiento de estrés}

Experimento 2011-B. En este experimento se utilizaron los clones de Populus deltoides ALT y ST67. 149-82 tuvo que ser descartado ya que la reducción de la biomasa radical fue tan grande por su susceptibilidad a la inundación, que no fue posible conseguir material suficiente para los muestreos.

El material de ALT y ST67 utilizado en este experimento fue plantado, regado y fertilizado como el material del experimento 2011-A. Las macetas fueron colocadas en invernáculo en un diseño totalmente aleatorizado con 35 replicas por cada clon y tratamiento.

La inundación duró 28 días y fue impuesta como se describió anteriormente, iniciando el tratamiento de estrés el 7 de noviembre de 2011. Luego, las plantas previamente inundadas, fueron removidas de las macetas selladas permitiendo el drenaje del agua durante 1 día para evaluar respuestas inmediatas de la recuperación. A los días 0 y 28 del período de inundación, y a 1 y 24 hs de iniciada la recuperación, se tomaron muestras, de hoja y de raíz, de 6 plantas por clon por tratamiento para las distintas determinaciones.

\subsubsection{Antioxidantes}

El contenido de ácido ascórbico y de glutatión fue determinado en muestras de hoja y raíz tomadas a los días 0 y 28 del período de inundación, y a 1 h y 24 h de comenzado el período de recuperación, en el experimento 2011-B. 
Contenido de ácido ascórbico. La técnica corresponde a la utilizada por Gómez et al. (2008). Las muestras fueron congeladas en nitrógeno líquido y almacenadas en freezer a $-80^{\circ} \mathrm{C}$ hasta su procesamiento. Para la determinación en hojas, $1 \mathrm{~g}$ de peso fresco de muestra fue homogeneizado en $5 \mathrm{ml}$ de ácido trifluoroacetico (TFA) al 3\% V/V con mortero y pilón. En el caso de las raíces, $1 \mathrm{~g}$ de peso fresco fue homogeneizado en $3,5 \mathrm{ml}$ de TFA $3 \%$. El homogenato fue centrifugado a $16.000 \mathrm{~g}$ por 10 minutos, se trasvasó el sobrenadante a nuevos tubos y se conservó en hielo. Se sembraron $500 \mu \mathrm{l}$ de sobrenadante en una columna de elusión (Eluted Bond C18 Varian ${ }^{\mathrm{TM}}$ ) previamente equilibrada con $1 \mathrm{ml}$ de buffer fosfato de potasio $100 \mathrm{mM} \mathrm{pH} 7$. A continuación se sembraron $500 \mu \mathrm{l}$ del buffer y se descartó el volumen de elución de la columna. Luego, se cargó $1,5 \mathrm{ml}$ del buffer y el volumen de elución se colectó en un eppendorf, obteniéndose así la muestra filtrada.

Se tomaron $240 \mu \mathrm{l}$ de la muestra filtrada y se le agregaron $240 \mu \mathrm{l}$ de solución de $\mathrm{K}_{2} \mathrm{HPO}_{4} 100 \mathrm{mM}, 15 \mu \mathrm{l}$ de agua y $50 \mu \mathrm{l}$ de TFA $10 \% \mathrm{v} / \mathrm{v}$. Las muestras se filtraron e inyectaron con jeringa en el HPLC. El buffer de corrida utilizado fue buffer fosfato de potasio $100 \mathrm{mM} \mathrm{pH} 3$ y el caudal de trabajo fue de $0,5 \mathrm{ml} \mathrm{min}^{-1}$.

Para la determinación del AA total se utilizó ditiotreitol (DTT) como agente reductor del DHA. Se mezclaron $240 \mu \mathrm{l}$ de muestra, $240 \mu \mathrm{l}$ de una solución de $\mathrm{K}_{2} \mathrm{HPO}_{4}$ 100 mM, $15 \mu \mathrm{l}$ de DTT 100 mM. Se agitó y se dejó reaccionar a temperatura ambiente por el término de 5 minutos. Para detener la reacción se agregó al medio $50 \mu$ de TFA al 10\%. Se filtraron las muestras y se procedió a la medición por HPLC.

El AA fue cuantificado con un equipo de HPLC Shimadzu LC-10ATvp solvent delivery module, con una columna C-18 (Varian Chromsep $100 \mathrm{~mm}$ x 4,6mm) y detectado a 265 nm (Shimadzu Co. UV-vis Detector SPD-10Avp, Japón) como se describe en Bartoli et al. (2006). El contenido de DHA fue estimado como la diferencia entre el contenido de las formas total (AAT) y reducido (AA). 
Contenido de glutatión. La técnica se basa en el trabajo de Griffith (1980) con algunas modificaciones. La concentración de glutatión se determinó en extractos ácidos solubles usando un ensayo cinético en el cual se cuantifica la reducción del ácido 5, 5' dithiobis-2-nitrobenzoico (DTNB) por reacción con tioles a 5-tio-2nitrobenzoato (TNB) de acuerdo a las siguientes reacciones (Tietze, 1969).

$$
\begin{aligned}
& 2 \mathrm{GSH}+\mathrm{DTNB} \quad \rightarrow \quad \mathrm{GSSG}+2 \mathrm{TNB} \\
& \mathrm{GSSG}+\mathrm{NADPH}+\mathrm{H}^{+} \rightarrow 2 \mathrm{GSH}+\mathrm{NADP}^{+}
\end{aligned}
$$

$$
\mathrm{NADPH}+\mathrm{H}^{+}+\mathrm{DTNB} \rightarrow 2 \mathrm{TNB}+\mathrm{NADP}^{+}
$$

La ecuación 1 es de naturaleza no enzimática, mientras que la ecuación 2 está catalizada por la enzima glutatión reductasa (GR).

La determinación de glutatión total y GSSG, se realizó en las mismas muestras en las que se determinó el contenido de AA y DHA en hoja y raíz. Para determinar el glutatión total en hojas, volúmenes de $25 \mu \mathrm{l}$ y $50 \mu \mathrm{l}$ de la muestra en medio ácido obtenida de la columna de elusión fueron agregados a $440 \mu$ y $415 \mu \mathrm{l}$, respectivamente, de la siguiente mezcla de reacción: Buffer fosfato de postasio $100 \mathrm{mM} \mathrm{pH} \mathrm{7,5,} \mathrm{EDTA} 5$ mM; DTNB 0,5 mM; NADPH 0,2 mM; GR 0,5 U/ml

La formación de TNB fue seguida espectrofotométricamente a una longitud de onda de $\lambda=412 \mathrm{~nm}$. Para cuantificar sólo GSSG, a $200 \mu \mathrm{l}$ de la muestra en medio ácido obtenida de la columna de elusión, se le adicionaron $4 \mu \mathrm{l}$ de vinilpiridina (Vinylpyridine $(\mathrm{PM}=105,1,95 \%)$, se vortexeó vigorosamente y se dejó a $25^{\circ} \mathrm{C}$ por el término de 20 minutos. Se centrifugó a $16.000 \mathrm{~g}$ por 5 minutos y se tomó el sobrenadante para cuantificar espectrofotométricamente de la misma forma que para determinar el glutatión total. La vinilpiridina secuestra el GSH, quedando solo el GSSG en la muestra. 
En raíces se siguió el mismo protocolo, utilizando 50 y $100 \mu \mathrm{l}$ de muestra para cuantificar el glutatión total, y $200 \mu$ l para GSSG.

Contenido de antocianinas. El contenido de antocianinas se determinó por espectrofotometría a una longitud de onda de $525 \mathrm{~nm}$ en muestras de raíces. La muestra se obtuvo eluyendo la columna bond elut donde se purificó el extracto para medir $\mathrm{AA}$ con $1 \mathrm{ml}$ de $\mathrm{CH}_{4} \mathrm{O}: \mathrm{HCL}(19: 1)$.

\subsubsection{Enzimas antioxidantes}

Debido la probabilidad de que el sistema radical sufra estrés pos anóxico por la reoxigenación al finalizar el período de inundación, se intentó profundizar más en la respuesta del sistema antioxidante, evaluando el comportamiento de algunas enzimas.

Muestras de raíz se congelaron en nitrógeno líquido y se guardaron a $-80{ }^{\circ} \mathrm{C}$ hasta la determinación de las enzimas. La extracción se realizó con mortero y pilón en hielo, en buffer fosfato de potasio $50 \mathrm{mM}$ pH 7, EDTA $1 \mathrm{mM}$, glicerol $10 \%$, PMSF $1 \mathrm{mM}$, PVPP Sigma-Aldrich (15 mg $1 \mathrm{ml}^{-1}$ ). La proporción volumen de buffer a g de peso fresco de muestra fue de $1 \mathrm{ml}: 0,5 \mathrm{~g}$. Se centrifugó a $7000 \mathrm{~g}$ por $12 \mathrm{~min}$ y se recuperó el sobrenadante, que se fraccionó, congeló en nitrógeno líquido y almacenó a - $80{ }^{\circ} \mathrm{C}$ hasta su posterior utilización.

Peroxidasas totales (PX). La actividad de peroxidasas se determinó utilizando pirogalol como dador de hidrógeno, que por acción enzimática origina purpurogalina:

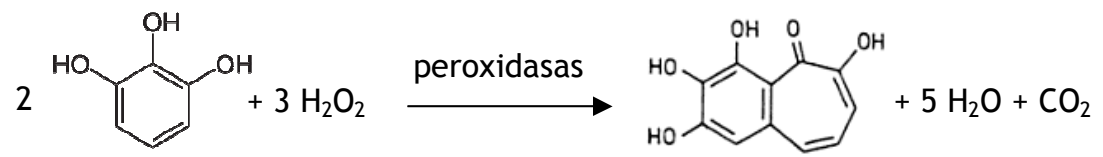


El medio de reacción consistió en buffer fosfato de potasio $50 \mathrm{mM} \mathrm{pH} \mathrm{6,5,} \mathrm{H}_{2} \mathrm{O}_{2} 8$ $\mathrm{mM}$, pirogalol $45 \mathrm{mM}$ y una alícuota de muestra conteniendo $25 \mathrm{mg}$ de peso fresco de raíz. La lectura espectrofotométrica fue realizada a una longitud de onda de $430 \mathrm{~nm}$ $\left(\varepsilon=2,47 \mathrm{mM}^{-1} \mathrm{~cm}^{-1}\right)$ (Puntarulo et al., 1988). La actividad es expresada en mmol de purpurogalina $\min ^{-1} \mathrm{mg}^{-1}$ peso fresco raíz.

Ascorbato peroxidasas totales (APX). La actividad de esta enzima se determinó según Nakano y Asada (1981). El método consiste en la medición espectrofotométrica de la velocidad de oxidación del ácido ascórbico realizada a una longitud de onda de $290 \mathrm{~nm}\left(\varepsilon=2,8 \mathrm{mM}^{-1} \mathrm{~cm}^{-1}\right)$.

El medio de reacción consistió en buffer fosfato de potasio $50 \mathrm{mM} \mathrm{pH} \mathrm{7,} \mathrm{EDTA} \mathrm{0,1}$ $\mathrm{mM}, \mathrm{H}_{2} \mathrm{O}_{2}$ 0,1 mM, AA 0,5 mM y una alícuota de muestra conteniendo $25 \mathrm{mg}$ de peso fresco de raíz. La actividad es expresada en mmol DHA min $^{-1} \mathrm{mg}^{-1}$ Peso fresco raíz.

\subsubsection{Análisis estadístico}

El análisis estadístico fue llevado a cabo con el programa STATISTICA versión 7.1 (StatSoft, Inc., 2005). Se realizaron análisis de medias y de varianza (ANOVA) y se analizó si las diferencias entre las medias fueron significativas utilizando el test LSD. Los datos fueron transformados para satisfacer los requerimientos del ANOVA cuando fue necesario. En caso de transformación de datos se indica en el gráfico o tabla correspondiente a la variable transformada. 


\subsection{RESULTADOS}

\subsubsection{Contenido de AA y DHA en las hojas}

No hubo diferencias en el contenido de AA y DHA foliar entre los tratamientos control de ambos clones. El pool de ascorbato $(\mathrm{AA}+\mathrm{DHA})$ se encuentra dominado por la forma reducida AA (un $87 \%$ del total) en ambos clones.

En ALT no se observó ninguna variación significativa de AA y DHA entre plantas control e inundadas, en ninguna de la fechas analizadas (Fig. 5.3). Tampoco hubo variaciones en el contenido total del pool de ácido ascórbico (Fig. 5.3 en itálicas).

En las plantas de ST67 previamente inundadas, el contenido de DHA aumentó $1 \mathrm{~h}$ después de finalizada la inundación (Fig. 5.3), siendo un 69\% mayor que el contenido en las plantas control; a las $24 \mathrm{~h}$ de finalizado el período de estrés, el DHA de las plantas previamente inundadas volvió a valores similares a los de las plantas control, mientras que el AA aumentó en un 18\%. En el período pos inundación, no solo aumentó el DHA, y luego el AA, de las plantas de ST67 previamente inundadas, sino que también aumentó el total del pool de ácido ascórbico (Fig. 5.3, en itálicas color verde).

\subsubsection{Contenido de GSH y GSGG en las hojas}

El contenido de GSGG no fue detectable en ninguna de las fechas analizadas, para ninguno de los dos clones. A pesar de algunas variaciones al final del período de inundación y al inicio de la recuperación, el contenido de glutatión total fue similar entre las plantas control de ambos clones. No se observaron variaciones significativas en el contenido de glutatión total entre plantas inundadas y control de ninguno de los dos clones en ninguna de las fechas (Fig. 5.4). 


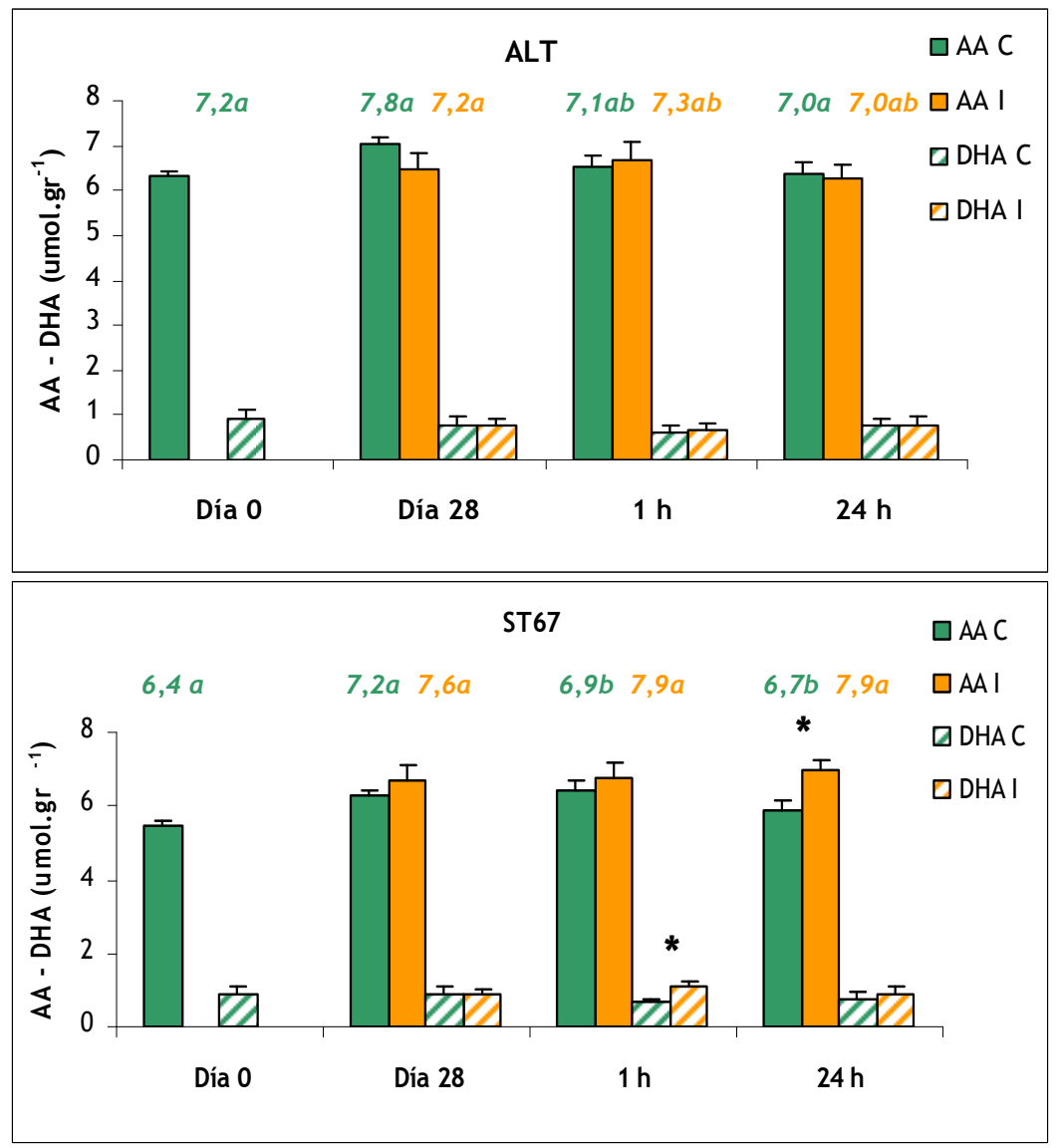

FIG. 5.3. Contenido de AA (barras sólidas) y DHA (barras rayadas) de la última hoja completamente expandida de los clones ALT y ST67, a los días 0 y 28 del período de inundación, y a 1 h y 24 h de iniciada la recuperación, en el experimento 2011-B. Verde: control, Naranja: inundado. Los datos están expresados con respecto al peso fresco de la muestra. Los asteriscos señalan diferencias estadísticamente significativas ( $<<0.05$ LSD) entre las plantas control e inundadas. Barras verticales: error estándar de la media. En itálicas se indica el contenido total del pool (AA + DHA) por fecha, para cada clon y tratamiento (las medias con la misma letra no difieren significativamente, $p<0.05$ LSD).

\subsubsection{Contenido de AA y DHA en la raíz}

El contenido total del pool de ácido ascórbico en las raíces de las plantas control fue menor que el observado en las hojas en ambos clones. En ALT, el pool fue hojas, el pool de ácido ascórbico de las plantas control, no se encuentra dominado por 


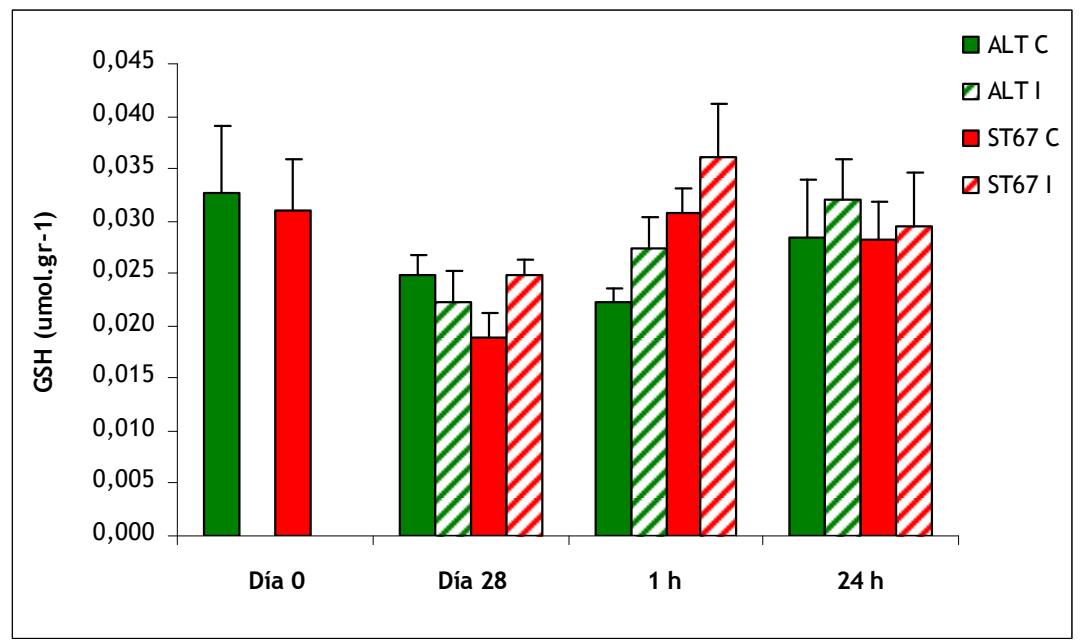

Fig. 5.4. Contenido de glutatión de la última hoja completamente expandida de los clones ALT (verde) y ST67 (rojo), a los días 0 y 28 del período de inundación, y a 1 h y $24 \mathrm{~h}$ de iniciada la recuperación, en el experimento 2011-B. C: control (barras sólidas), I: inundado (barras rayadas). Los datos están expresados con respecto al peso fresco de la muestra. Los datos de $1 \mathrm{~h}$ fueron transformados a logaritmo natural para satisfacer los requerimientos del ANOVA, pero se expresan en los valores sin transformar. Barras verticales: error estándar de la media.

de alrededor de un $5 \%$ del contenido en las hojas y en ST67 del $8 \%$. Al contrario de las la forma $\mathrm{AA}$, sino que, con excepción del día 28 del experimento, domina la forma oxidada (Fig. 5.5). Además, a diferencia de lo observado en hojas, donde no hubo diferencias en los contenidos de AA y DHA entre las plantas control de ambos clones, en las raíces, las plantas control de ST67 poseen un mayor contenido del pool total con respecto a ALT (Fig. 5.5, en itálicas color verde).

No se observaron variaciones significativas en los contenidos de AA y DHA entre las plantas control e inundadas de ALT, excepto el día 28 (Fig. 5.5), donde el contenido de AA de ALT control fue significativamente mayor que el de las plantas inundadas. El contenido total de ascorbato fue significativamente menor en las plantas inundadas tanto al final de la inundación, como a la hora y a las 24 h de reoxigenación de la raíz; es decir que hubo una disminución en la cantidad total del pool, pero la relación entre AA y DHA no varió entre las plantas control e inundadas. 

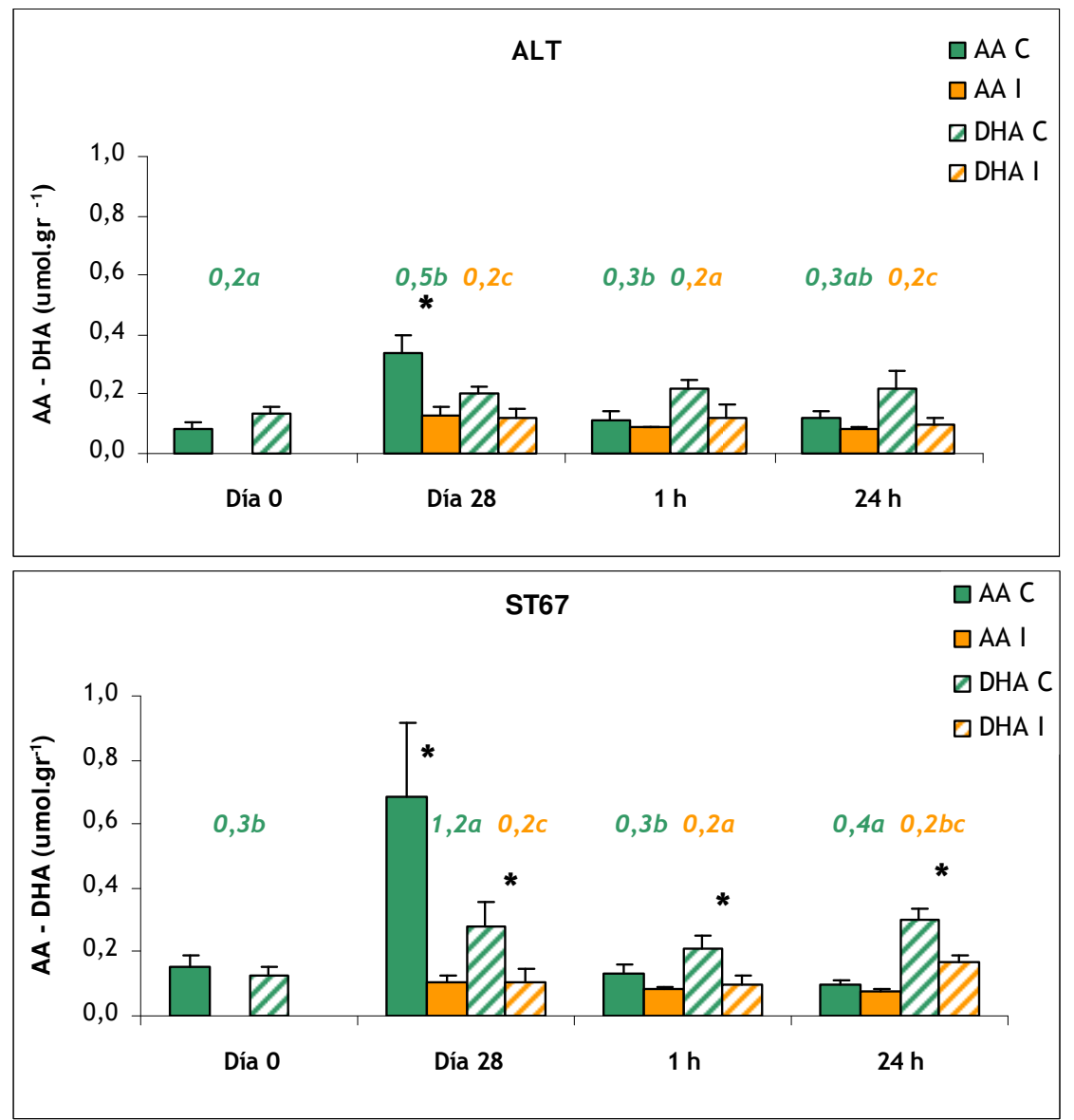

Fig. 5.5. Contenido de AA (barras sólidas) y DHA (barras rayadas) de raíz de los clones ALT y ST67, a los días 0 y 28 del período de inundación, y a $1 \mathrm{~h}$ y $24 \mathrm{~h}$ de iniciada la recuperación, en el experimento 2011-B. Verde: control, Naranja: inundado. Los datos están expresados con respecto al peso fresco de la muestra. Los datos de AA del día 28 fueron transformados a logaritmo natural para satisfacer los requerimientos del ANOVA, pero se expresan en los valores sin transformar. Los asteriscos señalan diferencias estadísticamente significativas ( $p<0.05$ LSD) entre las plantas control e inundadas. Barras verticales: error estándar de la media. En itálicas se indica el contenido total del pool (AA + DHA) por fecha, para cada clon y tratamiento (las medias con la misma letra no difieren significativamente, $p<0.05$ LSD).

En ST67, se observó también el día 28 un contenido significativamente mayor de AA en las plantas control con respecto a las inundadas (Fig. 5.5). A diferencia de ALT, en este clon también fue significativamente mayor el contenido de DHA de las plantas control en esta fecha. Durante la reoxigenación, no hubo diferencias en el contenido de 


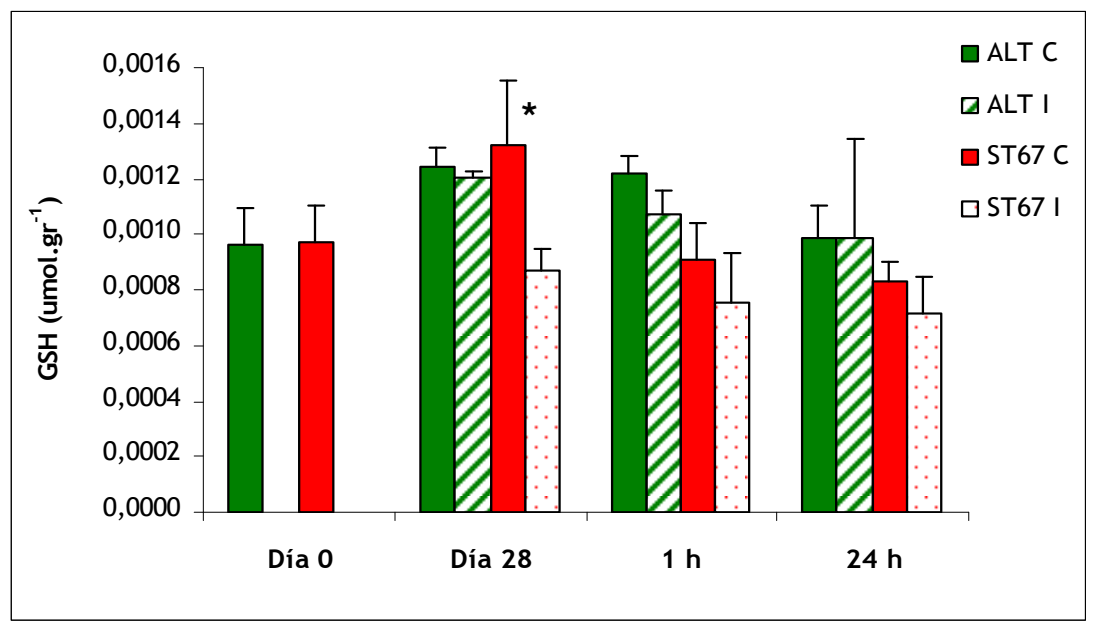

Fig. 5.6. Contenido de glutatión de raíz de los clones ALT (verde) y ST67 (rojo), a los días 0 y 28 del período de inundación, y a 1 h y 24 h de iniciada la recuperación, en el experimento 2011-B. C: control (barras sólidas), I: inundado (barras rayadas). Los datos están expresados con respecto al peso fresco de la muestra. Los datos de $24 \mathrm{~h}$ fueron transformados a logaritmo natural para satisfacer los requerimientos del ANOVA, pero se expresan en los valores sin transformar. Los asteriscos señalan diferencias estadísticamente significativas ( $p<0.05$ LSD) entre las plantas control e inundadas. Barras verticales: error estándar de la media.

AA entre las plantas control e inundadas, pero el contenido de DHA se mantuvo significativamente mayor en las plantas control con respecto a las plantas inundadas. El contenido total de ascorbato fue significativamente menor en las plantas inundadas tanto al final de la inundación, como a la hora y a las 24 h de reoxigenación, al igual que en ALT.

\subsubsection{Contenido de GSH y GSSG en la raíz}

El contenido de GSGG fue despreciable en la raíces en los dos clones, al igual que en las hojas. El contenido de glutatión total en las raíces de las plantas control fue menor que el observado en las hojas en ambos clones, siendo de alrededor del $4 \%$ con respecto al foliar. 
En ALT no hubo variaciones entre las plantas control e inundadas ni durante el episodio de inundación ni en la reoxigenación de la raíz ocasionada al permitir el drenaje del agua (Fig. 5.6, en verde). En ST67 se observó un mayor contenido de glutatión en las plantas control con respecto a las inundadas el día 28 , mientras que en la recuperación no hubo diferencias significativas (Fig. 5.6, en rojo).

\subsubsection{Contenido de antocianinas en la raíz}

Durante la extracción de muestras de raíz para la determinación de antioxidantes, se observaron diferencias en la pigmentación de las raíces por lo que se determinó espectrofotométricamente el contenido de antocianinas en una fracción del extracto.

El contenido de antocianinas de las plantas control de ST67 duplica al de las plantas control de ALT en todas las fechas (Fig. 5.7).

Al final del período de inundación se observó un gran aumento en el contenido de antocianinas en las plantas inundadas de ambos clones (Fig. 5.7, Día 28). Una vez finalizada la inundación, ALT inundado regresa a los valores de las plantas control, mientras que ST67 inundado aún posee valores de antocianinas significativamente mayores. A las 24 hs de finalizada la inundación, ya no se observan diferencias significativas entre las plantas control e inundadas en ninguno de los dos clones.

\subsubsection{Actividad de enzimas antioxidantes en la raíz}

A pesar de algunas variaciones en la actividad de PX en las plantas control de ALT, a lo largo del experimento las plantas control de ST67 mantuvieron un mayor nivel de actividad de PX que ALT. No hubo diferencias significativas en la actividad 


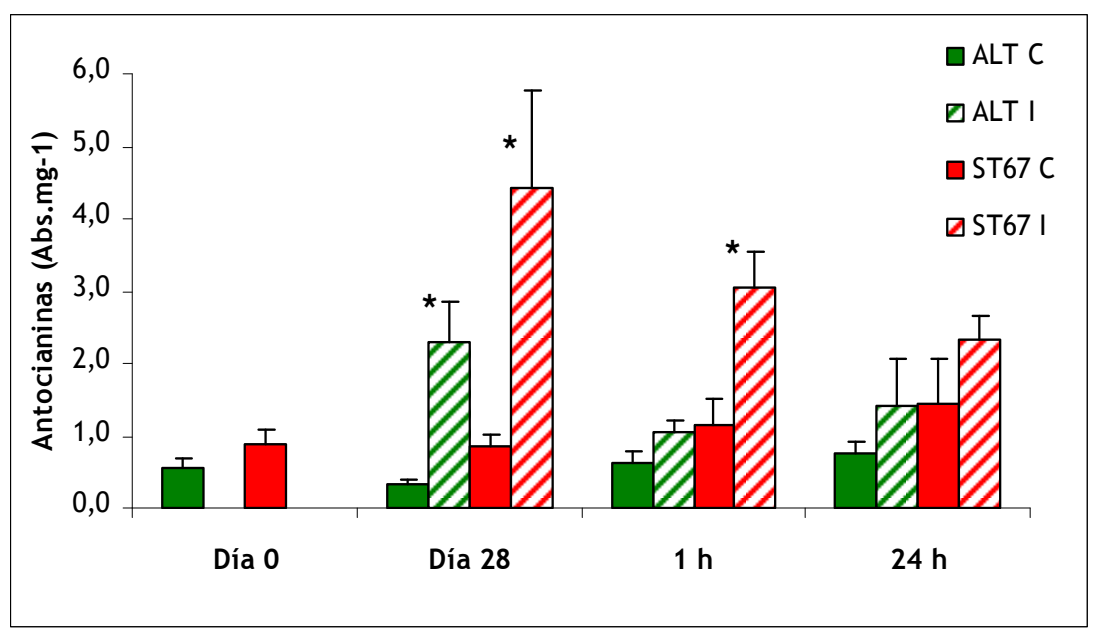

Fig. 5.7. Contenido de antocianinas de raíz de los clones ALT (verde) y ST67 (rojo), a los días 0 y 28 del período de inundación, y a 1 h y 24 h de iniciada la recuperación, en el experimento 2011B. C: control (barras sólidas), I: inundado (barras rayadas). Los datos están expresados en valores de absorbancia con respecto al peso fresco de la muestra. Los asteriscos señalan diferencias estadísticamente significativas $(p<0.05$ LSD) entre las plantas control e inundadas. Barras verticales: error estándar de la media.

especifica de PX entre las plantas control e inundadas en ninguna de las fechas, en ninguno de los dos clones (Fig. 5.8).

La actividad de APX fue en general mayor en las plantas control de ST67 que en las de ALT. Al final del período de inundación (Fig. 5.8, Día 28), no hubo variaciones entre las plantas control e inundadas de ALT, pero las plantas inundadas de ST67 mostraron una actividad significativamente mayor que la de las plantas control. Esta diferencia se mantuvo a lo largo de las 24 hs del período de recuperación (Fig. 5.8). A la hora de iniciada la recuperación, ALT inundado mostró un aumento significativo de la actividad de APX con respecto a ALT control, la cual disminuyó 24 hs después de la reoxigenación de la raíz (Fig. 5.8). 


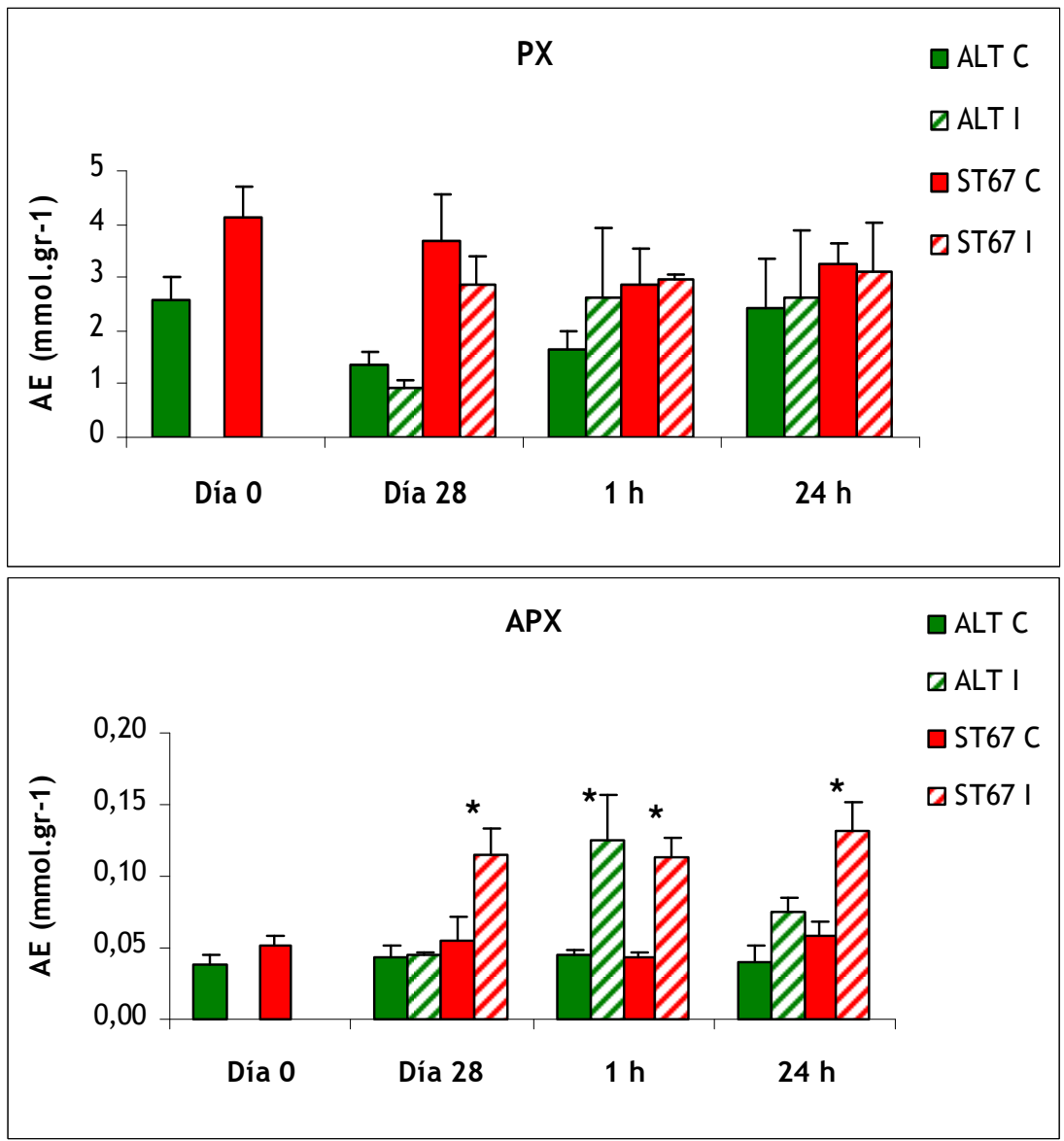

Fig. 5.8. Actividad de peroxidasas totales (PX) y ascorbato peroxidasas (APX) (en mmol / g raíz) de raíz de los clones ALT (verde) y ST67 (rojo), a los días 0 y 28 del período de inundación, y a 1 h y $24 \mathrm{~h}$ de iniciada la recuperación, en el experimento 2011-B. C: control (barras sólidas), I: inundado (barras rayadas). Los datos están expresados en con respecto al peso fresco de la muestra. Los asteriscos señalan diferencias estadísticamente significativas ( $p<0.05$ LSD) entre las plantas control e inundadas. Barras verticales: error estándar de la media. 


\subsection{DISCUSIÓN}

\subsubsection{Respuesta antioxidante de las hojas}

En las plantas de ALT inundadas, no se observó ninguna modificación en el contenido de ácido ascórbico (Fig. 5.3), ni en la cantidad total del pool de ascórbico $(\mathrm{AA}+\mathrm{DHA})$, ni en el estado redox (relación de $\mathrm{AA}$ a $\mathrm{DHA}$ ), el cual se mantuvo en valores de condiciones fisiológicas normales en hojas, alrededor de un $90 \%$ de $\mathrm{AA}$ (Smirnoff, 2000). Tampoco hubo variaciones en el contenido de glutatión (Fig. 5.4); GSGG fue indetectable a lo largo del experimento y la cantidad de glutatión total, que sería en la forma GSH, tampoco varió. La inundación seguida de un día de reoxigenación de las raíces no parece afectar el estado del nivel de estos antioxidantes en las hojas de las plantas de ALT inundadas.

En las plantas previamente inundadas de ST67, el contenido de DHA aumentó significativamente a la hora de iniciada la reoxigenación de las raíces, y a las 24 hs, volvió a los valores de las plantas control, mientras que el contenido de AA aumentó significativamente (Fig. 5.3). Además, el pool de ascorbato fue significativamente mayor, tanto a la hora como a las 24 hs. El glutatión total no se modificó a lo largo del experimento (Fig. 5.4). En álamos juveniles, las hojas maduras sintetizan ácido ascórbico y éste es transportado principalmente a las raíces (Herschbach et al., 2010). El aumento del pool de ascorbato en hojas puede haber sido una respuesta de este clon a la reoxigenación, aumentando la síntesis de ascorbato en las hojas para exportar hacia las raíces que están sufriendo estrés pos anóxico. Las diferencias significativas observadas en el contenido de DHA a la hora de finalizada la inundación y de AA las 24 hs, pueden deberse a reajustes en la tasa de fotosíntesis debidas a la reoxigenación de las raíces. A la hora de finalizada la inundación, el aumento de DHA podría deberse a la oxidación de AA producto de la eliminación de EAO originadas por desajustes 
metabólicos El mayor contenido de AA a las 24 hs, puede deberse a un aumento en la recuperación de las formas oxidadas, DHA y MDA, a través de la actividad de las enzimas DHAR y MDAR, utilizando poder reductor generado en la fotosíntesis.

\subsubsection{Respuesta antioxidante de las raíces}

A diferencia de las hojas, las muestras apicales de raíz de las plantas control de ambos clones, mostraron un mayor contenido de DHA con respecto a AA (Fig. 5.5). Esto puede deberse a que el mantenimiento del centro quiescente de la raíz está acompañado por un bajo contenido de AA y una elevada actividad de la enzima ascorbato oxidasa, y como resultado, el pool total de ascorbato está dominado por DHA (Kerk y Feldman, 1995; Liso et al., 2004). Tanto AA como GSH están involucrados en el crecimiento y desarrollo de las raíces debido a su función en la regulación redox (Herschbach et al., 2010). AA es necesario para la transición de G1 a S en el ciclo celular (Liso et al., 1998) y GSH aumenta el número de células meristemáticas que experimentan mitosis (Sanchez-Fernandez et al., 1997). El mayor contenido de AA y GSH al día 28 en las plantas control de ALT y ST67 puede estar relacionado con un activo crecimiento de las raíces de las plantas muestreadas en esa fecha.

Las plantas de ALT inundadas no sufrieron modificaciones en el contenido de AA, DHA o glutatión total durante la inundación con respecto a las plantas control (Fig. 5.5 y 5.6, respectivamente). El hecho de que PX y APX tampoco varíen entre las plantas control e inundadas durante la inundación (Fig. 5.8), sugiere que durante la inundación hay bajos niveles de EAO, aunque la disminución del contenido total del pool de acido ascórbico y el aumento de antocianinas al final del período de inundación (Fig. 5.7), indica que existe cierta presión de excitación y potencial daño oxidativo. Se ha sugerido que antocianinas y otros compuestos fenólicos remueven $\mathrm{H}_{2} \mathrm{O}_{2}$ de la vacuola durante estreses severos, contribuyendo al mecanismo global de protección contra estrés 
oxidativo (Yamasaki et al., 1997; Steyn et al., 2002). Durante la recuperación, el contenido de glutatión total (Fig. 5.6), AA y DHA (Fig. 5.5) de las plantas de ALT inundadas no difirieron significativamente con respecto a las plantas control, pero el contenido total del pool fue significativamente menor en la recuperación. La actividad de PX no se modificó significativamente entre las plantas control e inundadas, mientras que APX tuvo un aumento a la hora de finalizada la inundación, que desapareció a las 24 hs (Fig. 5.8). No hubo un aumento de DHA ni de GSGG, y la actividad de APX tuvo un aumento transitorio inmediato a la reoxigenación, por lo que estos resultados indican que los antioxidantes estarían removiendo EAO generadas durante el estrés pos anóxico sin que se exceda su capacidad de destoxificación.

En el caso de las plantas inundadas de ST67, el contenido total del pool de ascórbico fue menor con respecto a los controles, tanto al final de la inundación, como durante la recuperación (Fig. 5.5). El contenido de glutatión total también fue significativamente menor al final de la inundación y mostró una tendencia a disminuir durante la recuperación (Fig. 5.6). Además, tanto las antocianinas (Fig. 5.7) como APX de las plantas inundadas (Fig. 5.8), aumentaron hacia el final de la inundación y se mantuvieron mas elevadas durante la recuperación, con respecto a las plantas control. La respuesta de este clon sugiere que los antioxidantes estarían removiendo EAO generadas tanto por el estrés pos anóxico generado por la reoxigenación como por la inundación. La mayor magnitud de respuesta de las plantas inundadas de este clon con respecto a las de ALT refleja su mayor susceptibilidad a crecer durante un episodio de inundación.

Las plantas control del clon ST67, más susceptible a la inundación que ALT, se caracterizaron por contener un mayor nivel de ácido ascórbico, antocianinas, PX y APX que las plantas control de ALT, por lo que la mayor tolerancia a la inundación no está determinada por una mayor capacidad antioxidante en condiciones no estresantes. 


\subsection{CONCLUSIONES}

Los resultados obtenidos en este trabajo no validaron las hipótesis planteadas; en cambio, sugieren que el grado de tolerancia a la inundación en álamo no está determinado por una mayor inducción de los sistemas antioxidantes en respuesta a la inundación, ni por un mayor contenido de antioxidantes en condiciones no estresantes. ALT, el clon más tolerante a la inundación tiene un menor nivel de defensas contra el estrés oxidativo que ST67, el clon más sensible, y además, induce una menor respuesta antioxidante tanto durante la inundación como en la reoxigenación. 
CAPÍTULO 6

CONSIDERACIONES FINALES

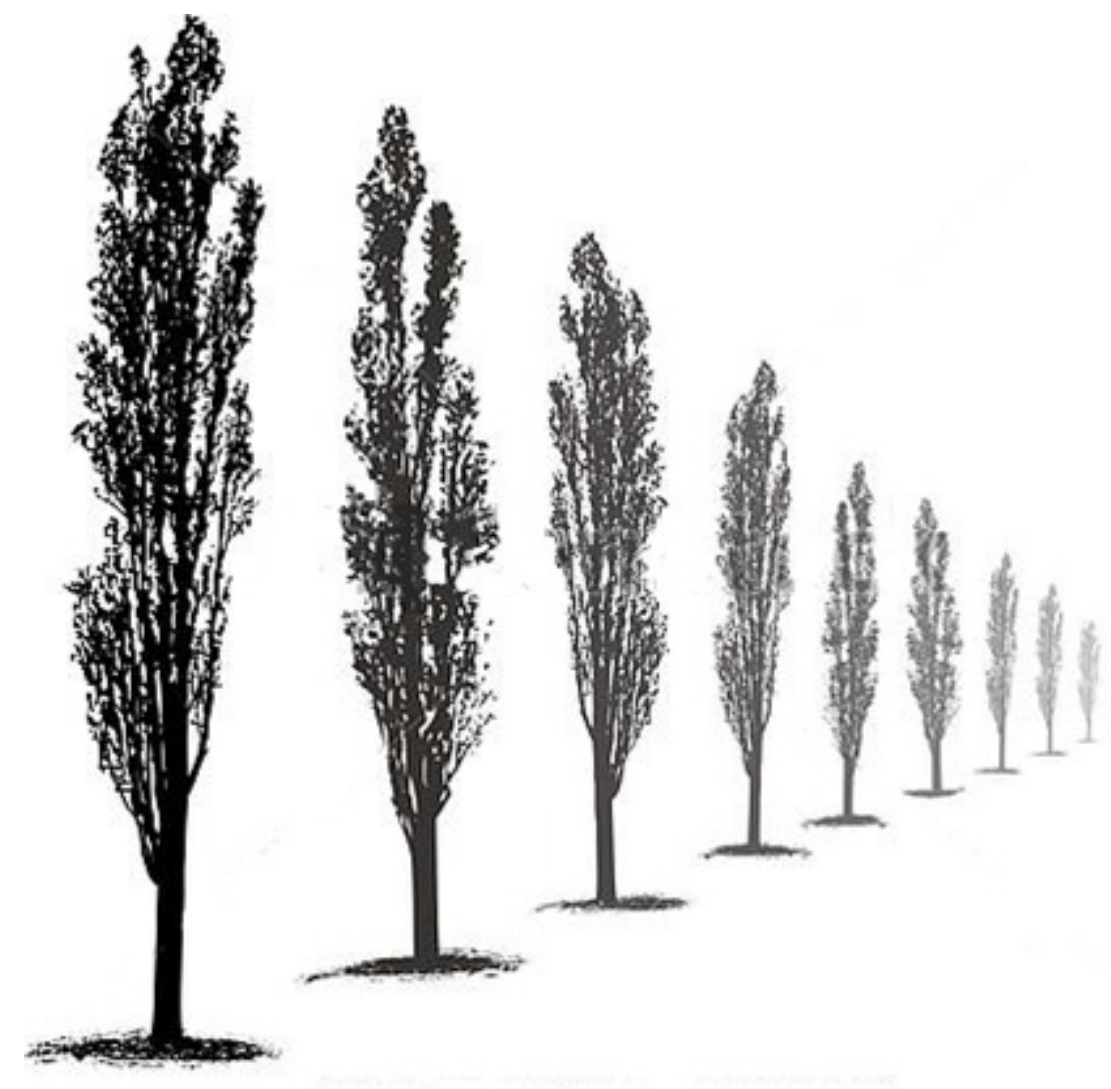




\subsection{CONTRASTE DE HIPÓTESIS}

\section{Hipótesis 1.}

Los clones más tolerantes a la inundación mantienen el crecimiento, gracias al desarrollo de respuestas adaptativas que les permiten retener una mayor área foliar y una mayor biomasa radical que los clones más susceptibles.

En esta tesis, se definen como tolerantes a los clones cuyo crecimiento resulta menos reducido durante la inundación. El crecimiento de la parte aérea del ALT fue muy poco afectado por la inundación, mostrando crecimiento del tallo, del número de hojas y del área foliar, similares a las de las plantas control. La inundación redujo el crecimiento en los clones ST67 y 149-82, principalmente en este último, en el que se redujeron significativamente la altura y el área foliar. ST67 inundado tuvo un comportamiento intermedio entre ALT y 149-82, mostrando reducción del crecimiento del tallo, pero manteniendo un área foliar similar al tratamiento control. ALT inundado no mostró prácticamente variaciones en las características foliares analizadas, que si ocurrieron en las plantas inundadas de los otros clones, coincidiendo con el hecho de que sus raíces y su parte área casi no fueron afectadas.

El mantenimiento del área foliar y de la biomasa radical en ALT, se relacionó con su capacidad de generar respuestas adaptativas a la inundación, como lenticelas hipertrofiadas, raíces ascendentes emergiendo desde el suelo a la superficie del agua y aerénquima. El clon ST67 también desarrolló estas respuestas adaptativas, pero su respuesta fue un poco más retrasada en el tiempo, mientras que 149-82, el clon más sensible a la inundación, no presentó desarrollo de estas estructuras, mostrando gran susceptibilidad a la inundación.

De acuerdo con los resultados obtenidos, la hipótesis planteada es aceptada. 


\section{Hipótesis 1.1.}

La hormona etileno está involucrada en la formación de aerénquima en álamos con raíces en condiciones de hipoxia.

En los experimentos de inundación realizados en maceta (experimentos 2009 y 2012-A) se observó la formación de aerénquima, generada por la hipoxia en la zona radical en el clon ALT. Para evaluar si en plantas de álamo se requiere etileno para la formación de aerénquima en respuesta a hipoxia como ocurre en maíz (Drew et al., 2000; Ram et al., 2002), se intentó evaluar la respuesta a tratamientos exógenos con etileno (etefón), con un enfoque experimental diferente al que se venía utilizando, que facilite la aplicación de los tratamientos.

Los efectos generados por la inundación en la raíz de $A L T$, no pudieron ser reproducidos en ninguno de los experimentos realizados, por lo que no pudo determinarse si el etileno es o no el iniciador interno de la formación de aerénquima en raíces de álamo sometidas a hipoxia por inundación. La dirección adoptada para evaluar esta hipótesis no fue la adecuada, por lo que deberían considerarse otras alternativas. Es por ello que la hipótesis planteada no puede ser aceptada ni rechazada.

\section{Hipótesis 2.}

Los clones más tolerantes a la inundación mantienen una mayor apertura estomática y actividad fotosintética que los clones más susceptibles.

La inundación promovió el cierre de estomas y la disminución de la fotosíntesis neta en todos los clones, pero en menor medida en ALT. Además de ser el clon más afectado en el cierre estomático y la disminución de la fotosíntesis neta, 149-82 experimentó daño en el PSII ocasionado por la inundación. Estos efectos parecen ser 
reversibles después de finalizado el estrés en todos los clones, pero las diferencias en la reanudación del crecimiento reflejan cuan afectado se vio cada clon.

La capacidad de mantener una mayor apertura estomática, y por lo tanto una mayor fotosíntesis neta por parte de ALT inundado, coincide con el hecho de ser el clon que es menos afectado por la inundación, y por lo tanto el más tolerante.

De acuerdo con los resultados obtenidos, la hipótesis planteada es aceptada.

\section{Hipótesis 3.}

La recuperación de los clones luego de un episodio de inundación, está determinada por su capacidad de detoxificar especies activas del oxígeno (EAO), reduciendo el impacto del daño pos anóxico causado por la vuelta a condiciones aeróbicas luego de un período de anoxia-hipoxia. La mayor capacidad de reiniciar el crecimiento luego de la inundación se relaciona con un mayor nivel de defensas contra el estrés oxidativo. Estas mayores defensas pueden ser inducidas en mayor medida por la inundación o la reoxigenación en los clones menos susceptibles, o ser mayores en estos clones incluso en condiciones no estresantes.

La inundación y posterior recuperación no produjo ninguna variación en los contenidos de AA, DHA y glutatión en las hojas de plantas inundadas de ALT. En las raíces las variaciones fueron mínimas, mostrando un aumento de antocianinas al final de la inundación, un aumento de la enzima ascorbato peroxidada (APX) al inicio de la recuperación, y un contenido menor del pool total de ascórbico al final de la inundación y durante la recuperación. En ST67, las variaciones fueron mayores. En hojas de plantas de ST67 previamente inundadas, se observaron variaciones en el contenido de ascorbato (AA) y dehidroascorbato (DHA) durante la recuperación. En raíces, las variaciones de $\mathrm{AA}$ y $\mathrm{DHA}$ no solo se observaron durante la recuperación, sino 
también al final de la inundación. Además, tanto las antocianinas como APX mostraron aumentos durante la inundación y la recuperación.

El hecho de que la capacidad antioxidante de ALT no se vea muy afectada durante la inundación y el periodo pos anóxico, se correlaciona con el hecho de que este clon no resulta muy afectado por la inundación. En cambio las plantas inundadas de ST67 despliegan una mayor respuesta, tanto durante la inundación, como durante la recuperación, lo que coincide con que este clon es más susceptible a la inundación. Las diferencias en el grado de tolerancia a la inundación entre estos dos clones, no parece estar determinada por un mayor contenido de antioxidantes en condiciones no estresantes, ya que ALT, el clon más tolerante a la inundación, es el que menos posee. La mayor capacidad de reactivar el crecimiento de ALT durante la recuperación, tampoco estaría determinada por la inducción de un mayor nivel de defensas contra el estrés oxidativo en comparación con ST67, ya que este último induce su nivel de defensa en mayor medida durante el período de recuperación pos inundación.

En cuanto a la hipótesis planteada sobre la mayor inducción de defensa antioxidante frente al estrés por el clon más tolerante, es rechazada ya que, ST67, el clon más susceptible, induce mayor respuesta antioxidante que ALT, tanto frente al estrés por inundación como al estrés por reoxigenación de la raíces.

En cuanto a la hipótesis sobre un mayor contenido intrínseco de las especies más tolerantes, también se rechaza ya que, ALT, el clon más tolerante a la inundación, es el que posee menor contenido de antioxidantes en condiciones no estresantes. 


\subsection{CONCLUSIONES GENERALES}

La tolerancia a la inundación en los álamos evaluados en esta tesis, está relacionada con la capacidad de desarrollar estructuras morfológicas y anatómicas adaptativas, como aerénquima, lenticelas hipertrofiadas y raíces en la superficie del agua. Estas estructuras permiten a los clones más tolerantes, retener mayor área foliar y biomasa de raíces durante el episodio de estrés, en comparación con los más susceptibles a la inundación. La retención de una mayor área foliar asociada a una mayor apertura estomática, permite mantener la capacidad fotosintética, lo que implicaría una mayor disponibilidad de fotoasimilados para hacer frente a la situación de estrés y para la etapa de recuperación posterior. El rápido desarrollo de nuevas raíces y la retención de mayor biomasa de raíces por los clones más tolerantes, les aseguraría el suministro de agua y nutrientes necesarios para reiniciar el crecimiento luego de finalizado el período de inundación. Además de la capacidad de generar estructuras que permiten una mejor difusión de oxígeno, los dos clones más tolerantes, ALT y ST67, fueron capaces de eliminar EAO generadas tanto durante la hipoxia debida a la inundación, como durante la reoxigenación que se produce en las raíces cuando acaba la inundación. La capacidad antioxidante intrínseca de una planta o el desarrollo de esta capacidad ante un evento estresante, evita el posible daño que pueden ocasionar las EAO, otorgándole a la planta una mejor capacidad de crecimiento durante el estrés, ya sea hipóxico o pos anóxico.

Las respuestas de los tres clones a la inundación fueron diferentes, siendo ALT el menos afectado y 149-82 el más afectado. La gran susceptibilidad de 149-82 se debió a que no desarrolló ni lenticelas hipertrofiadas ni raíces adventicias durante la inundación. De hecho, sus raíces se deterioraron tanto por la inundación, que no fue posible determinar la presencia de aerénquima o su capacidad antioxidante. 
Las plantas de ALT fueron más tolerantes a la inundación que las de ST67. Ambas desarrollaron aerénquima, lenticelas y raíces ascendentes, pero el crecimiento del tallo, las características foliares, la biomasa de raíces, la conductancia estomática, la fotosíntesis y la capacidad antioxidante de ALT fueron mucho menos afectadas por la inundación que las plantas de ST67. Sin embargo, las plantas de ST67 inundadas fueron tan productivas en el crecimiento como las de ALT, y más en condiciones no estresantes. Parecería que ST67 podría tener mejor performance a campo que ALT, ya que éste último crece menos en condiciones de suelo a capacidad de campo.

No obstante, las plantaciones de álamos en la región del Delta del Paraná, sufren alternancia de períodos de inundación y períodos de humedad de suelo normales $y$, en este contexto, el hecho de que ALT retenga mayor biomasa radical durante la inundación podría ser un rasgo muy importante. Los resultados muestran que ALT se recupera más rápido que ST67 en el período posterior a la inundación. El mantenimiento de la biomasa radical y el rápido desarrollo de nuevas raíces en $A L T$, no solo le asegurarían el reestablecimiento de un adecuado suministro de agua y nutrientes, sino que también le asegurarían el anclaje al suelo. En plantaciones a campo de álamos sujetas a episodios de inundación, la caída de árboles durante tormentas es más frecuente en plantaciones que no sufrieron inundaciones (Achinelli, observación personal). Esto enfatiza la importancia del sistema radical como anclaje al suelo de los árboles. El hecho de que ALT distribuya más recursos a las raíces que ST67 durante la inundación, le otorgaría la posibilidad de un mejor anclaje y, esta mayor estabilidad, resultaría en una menor caída de árboles; en consecuencia, las plantaciones de este clon tendrían una mejor productividad al final del período de rotación (entre 12 y 15 años en la región del Delta del Río Paraná, dependiendo del destino).

Las diferencias en el crecimiento en condiciones no estresantes y de tolerancia a inundación entre ALT, ST67 y 149-82, hacen que estos clones sean diferencialmente aptos para las distintas situaciones que ocurren en el Delta del Paraná. La mayor 
tolerancia de ALT a la inundación es importante en campos con sistema " $a$ zanja abierta", donde ocurren grandes inundaciones que pueden durar varios meses. En esta situación, ALT sobrevive a diferencia de otros clones que comienzan a morir rápidamente (Silvia Cortizo, observación personal), como ocurre con 149-82 y con ST67, que a los tres meses de inundación alcanza más de un $20 \%$ de mortalidad (Javier Álvarez, datos no publicados). Ante la posibilidad de ocurrencia de inundaciones, es preferible mantener una plantación, que a pesar de no ser altamente productiva, sea capaz de sobrevivir el estrés.

En condiciones no estresantes, como ocurre en los "sistemas cerrados" donde se protege de inundaciones mediante diques, ST67 es una mejor opción que ALT debido a su mayor crecimiento y productividad. 149-82 ha mostrado ser una mejor opción que ST67 en cuanto a productividad, siempre y cuando sean regiones en las que no existe posibilidad de inundación (Cortizo et al., 2009). 


\subsection{APORTES DE ESTA TESIS}

En cuanto a las metodologías utilizadas, la caracterización de las respuestas de las hojas en el período pos inundación realizada en esta tesis, es un acercamiento novedoso para evaluar la variabilidad en las respuestas a la inundación, ya que, además de no haberse hecho antes, permitió identificar que las respuestas ocasionadas por la inundación no solo perduran una vez finalizado el estrés, sino que varían entre clones con diferente susceptibilidad a la inundación. El hecho de que se observen variaciones en las respuestas foliares en el período pos inundación entre los distintos clones evaluados, enfatiza la importancia de caracterizar esas respuestas no solo durante el estrés por inundación, sino también en el período de recuperación posterior.

Los resultados obtenidos en esta tesis, muestran que hay variación en la tolerancia a la inundación en el material vegetal plantado actualmente en el área del Delta del Río Paraná, y que los efectos de la inundación en la arquitectura y fisiología de las plantas, no revierten fácilmente una vez que el episodio de estrés ha terminado. Incluso aunque un episodio de inundación no ocasione la muerte de la planta, puede alterar las características de las hojas, raíces y/o tallos, afectando a largo plazo el crecimiento y la productividad de la planta. Estos efectos no pueden ser desatendidos en los posibles escenarios de cambio climático predichos para la región, donde áreas con extensivas plantaciones de álamo experimentarán episodios de inundación de manera más frecuente.

Finalmente, en esta tesis se identificaron caracteres relacionados con la tolerancia a inundación en álamo, que pueden eventualmente ser utilizados en programas de mejoramiento genético, clásico o biotecnológico, con el fin de incrementar la tolerancia a la inundación en álamos plantados en la zona del Delta del Paraná. 


\subsection{RESUMEN DE LOS MECANISMOS QUE CONFIEREN TOLERANCIA A INUNDACIÓN EN ÁLAMO}

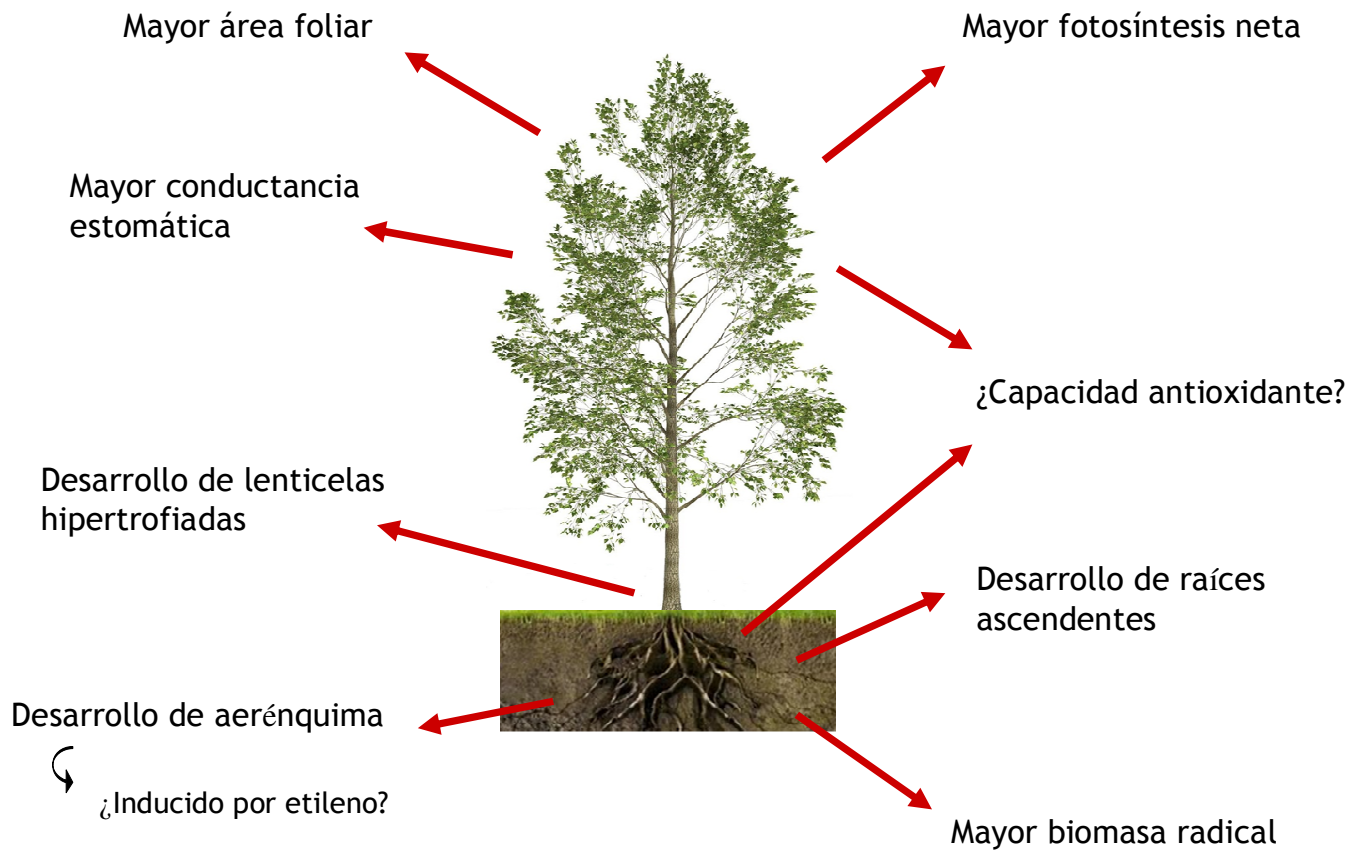

Fig. 6.1. Representación esquemática de los mecanismos involucrados en la tolerancia a inundación en $P$. deltoides, observados en los experimentos realizados en esta tesis.

En la Fig. 6.1 se representan esquemáticamente las respuestas observadas, tanto en las raíces como la parte aérea de la planta, a lo largo de los experimentos realizados, que contribuyeron a la tolerancia a inundación. ALT, el clon más tolerante, retuvo mayor área foliar y biomasa radical, mayor apertura estomática (medida como conductancia estomática) y fotosíntesis neta; tanto en ALT como en ST67, clon de tolerancia intermedia, se observó desarrollo de aerénquima, quedando pendiente la determinación sobre si su desarrollo es inducido o no por etileno en condiciones de 
hipoxia; ambos clones también desarrollaron lenticelas hipertrofiadas y raíces ascendentes, pero ALT las desarrolló en menor tiempo de inundación transcurrido.

En cuanto a la contribución de la capacidad antioxidante, su inducción parece ser importante para la tolerancia de los clones al momento de reoxigenación de la raíces, posterior a un período de inundación. Esto ocurre principalmente en ST67, el clon con susceptibilidad intermedia; en ALT sus niveles no se modificaron demasiado, coincidiendo con su mayor tolerancia a la inundación. 
CAPÍTULO 7

REFERENCIAS

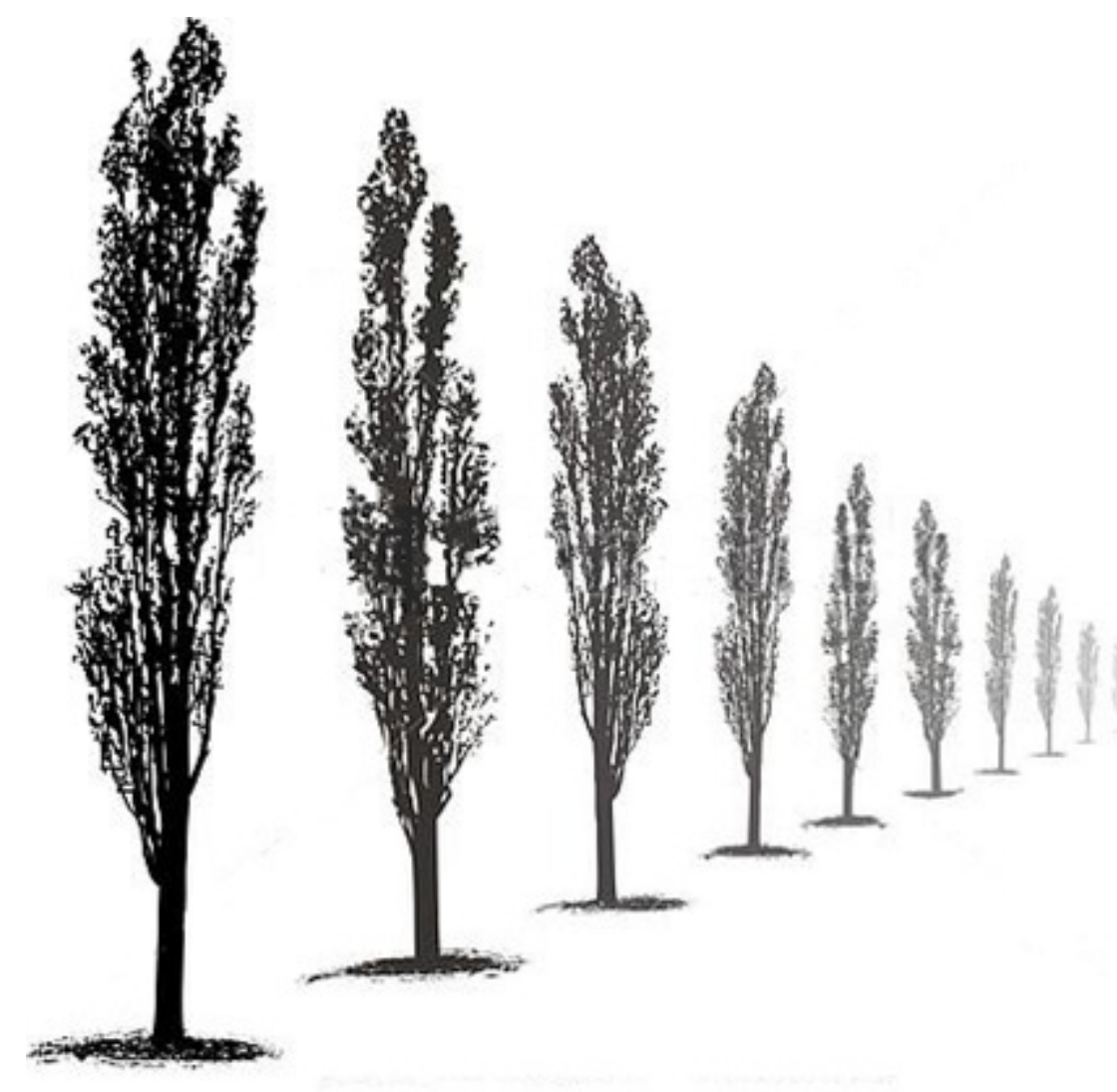




\subsection{REFERENCIAS}

Agarwal S, Grover A (2006). Molecular biology, biotechnology and genomics of flooding-associated low $\mathrm{O}_{2}$ stress response in plants. Critical Reviews in Plant Science 25: 1 - 21.

Al Afas N, Marron N, Ceulemans R (2006). Clonal variation in stomatal characteristics related to biomass production of 12 poplar (Populus) clones in a short rotation coppice culture. Environmental and Experimental Botany 58: $279-286$.

Allan AC, Fluhr R (1997). Two distinct sources of elicited reactive oxygen species in tobacco epidermal cells. Plant Cell 9: 1559 - 1572.

Amlin N, Rood SB (2001). Inundation tolerance of riparian willows and cottonwoods. Journal of the American Water Resources Association 37: 1709 - 1720.

Andersen PC, Lombard PB, Westwood MN (1984). Effect of root anaerobiosis on the water relations of several Pyrus species. Physiologia Plantarum 62: 245 - 252.

Angelov M, Sung SJS, Donng RL, Harms WR, Kormanik PP, Black CC (1996). Long and short-term flooding effects on survival and sink-source relationships of swamp-adapted tree species. Tree Physiology 16 (5): 477 - 484.

Arbona V, Hossain Z, López-Climent MF, Pérez-Clemente RM, Gómez-Cadenas A (2007). Antioxidant activity is linked to waterlogging stress tolerance in citrus. Physiologia Plantarum 132: 452 - 466.

Armstrong W (1979). Aeration in higher plants. Advances in Botanical Research 7: 225 332.

Armstrong W, Strange ME, Cringle S, Beckett PM (1994). Microelectrode and modelling study of oxygen distribution in roots. Annals of Botany 74: 287 - 299. 
Asada K (1999). The water-water cycle in chloroplasts: scavenging of active oxygen and dissipation of excess photons. Annual Review of Plant Physiology and Plant Molecular Biology 50: 601 - 639.

Asada K (2006). Production and scavenging of reactive oxygen species in chloroplast and their functions. Plant Physiology 141: 391 - 396.

Asada K, Takahashi S (1987). Production and scavenging of active oxygen in photosynthesis. En: Photoinhibition: Topics in Photosynthesis, vol. 9. Editores: Kyle DJ, Osmond CB, Arntzen CJ, Elsevier, Amsterdam, páginas: 227 - 287.

Baier M, Dietz KJ (1996). Primary structure and expression of plant homologues of animal and fungal thioredoxin-dependent peroxide reductases and bacterial alkyl hydroperoxide reductases. Plant Molecular Biology 31: 553 - 564.

Bailey-Serres J, Voesenek LACJ (2008). Flooding stress: acclimations and genetic diversity. Annual Review of Plant Biology 59: 313 - 339.

Balatinecz J, Kretschmann D, Leclercq A (2001). Achivements in the utilization of poplar wood- guideposts for the future. The Forestry Chronicle 77(2): 265269.

Ball MC, Hodges VS, Laughlin GP (1991). Cold-induced photoinhibition limits regeneration of snow gum at tree-line. Functional Ecology 5: 663 - 668.

Ball J, Carle J, Del Lungo A (2005). Contribución de álamos y sauces a la silvicultura sostenible y al desarrollo rural. Unasylva 221 (56): 3 - 9

Barros V, Menéndez A, Natenzon C, Kokot R, Codignotto J, Re M, Bronstein P, Camilloni I, Ludueña S, González S, Ríos D (2006). Vulnerability to floods in the metropolitan area of Buenos Aires under future climate change. AIACC Working Papers No 26. Acceso 12 de Mayo de 2011. Disponible en http://www.aiaccproject.org/working_papers/working_papers.html. 
Bartoli CG, Gómez F, Martínez DE, Guiamet JJ (2004). Mitochondria are the main target for oxidative damage in leaves of wheat (Triticum aestivum L.). Journal of Experimental Botany 55: 1663 - 1669.

Bartoli CG, Yu J, Gómez F, Fernández I, Mclntosh L, Foyer CH (2006). Interrelationships between light and respiration in the control of ascorbic acid synthesis and accumulation in Arabidopsis thaliana leaves. Journal of Experimental Botany 57 (8): $1621-1631$.

Bejaoui Z, Albouchi A, Abassi M, El Aouni MH (2006). Influence d'une hydromorphie modérée ou severe sur la production de biomasse et les échanges gazeux de plants de peuplier euraméricain. Canadian Journal of Forest Research 36: $2654-2665$.

Bleecker AB, Estelle MA, Somerville C, Kende H (1988). Insensitivity to ethylene conferred by a dominant mutation in Arabidpsis thaliana. Science 141: 1086 1087.

Blokhina OB, Virolainen E, Fagerstedt KV, Hoikkala A, Wähälä K, Chirkova TV (2000). Antioxidant status of anoxia tolerant and intolerant plant species under anoxia and reareation. Physiologia Plantarum 109: 396 - 403.

Blokhina O, Virolainen E, Fagerstedt KV, (2003). Antioxidants, oxidative damage and oxygen deprivation stress: a review. Annals of Botany 91: 179 - 194.

Blom CWPM, Voesenek LACJ (1996). Flooding: the survival strategies of plants. Trends in Ecology \& Evolution 11: 290 - 295.

Bonetto A, Hurtado S (1998). Delta Paranense. Región I. Cuenca del Plata. En: Los humedales de la Argentina: situación actual, conservación y legislación. Editores: Canevari P, Blanco D, Bucher E, Castro G, Davidson I. Wetlands International Publication no. 46. Buenos Aires: Wetlands International. Páginas $31-72$. 
Borodowski ED (2006). Álamos y sauces en el Delta del Paraná: situación del sector y silvicultura. Actas Jornadas de Salicáceas 2006. http://www.sagpya.mecon.gov.ar/.

Borodowski ED, Suárez RO (2004). El cultivo de álamos y sauces: su historia en el Delta del Paraná. SAGPyA Forestal 32: 5 - 13.

Bowler C, Montagu MV, Inzé D (1992). Superoxide dismutases and stress tolerance. Annual Review of Plant Physiology and Plant Molecular Biology 43: 83 - 116.

Braatne JH, Rood SB, Heilman PE (1996). Life history, ecology, and reproduction of riparian cottonwoods in North America. En: Biology of Populus and its Implications for Management and Conservation. Editores: Stettler RF, Bradshaw HD, Jr., Heilman PE, Hinckley TM. NRC Research Press, Ottawa, Ontario, Canada, páginas $57-85$.

Bradford KJ (1983). Effects of soil flooding on leaf gas exchange of tomato plants. Plant Physiology 73: 475 - 479.

Bradford KJ, Hsiao TC (1982). Stomatal behavior and water relations of waterlogged tomato plants. Plant Physiology 70: 1508 - 1513.

Braendle R, Crawford RMM (1999). Plants as amphibians. Perspectives in Plant ecology, Evolution and Systematics 2(1): 56 - 78.

Bunn SM, Rae AM, Herbert CS, Taylor G (2004). Leaf-level productivity traits in Populus grown in short rotation coppice for biomass energy. Forestry 77 (4): 307 $-321$.

Camilloni I (2005). Tendencias climáticas. El cambio climático en el Río de la Plata. Barros V, Menéndez A, Nagy G, Editores. http://www.cima.fcen.uba.ar/ Lcr/libros/index.htm, páginas 13 - 19.

Cao FL, Conner WH (1999). Selection of flood tolerant Populus deltoides clones for reforestation projects in China. Forest Ecology \& Management 117: 211 220. 
Cervera MT, Storme V, Soto A, Ivens B, Van Montagu M, Rajora OP, Boerjan W (2005). Intraspecific and interspecific genetic and phylogenetic relationships in the genus Populus based on AFLP markers. Theoretical and Applied Genetics 111: $1440-1456$.

Ceulemans R (2011). Short rotation culture of poplar and willow: aspects of ecology, growth and yield. Tercer Congreso Internacional de Salicáceas en Argentina, 2011, Neuquén, Argentina. Acceso: 31 de octubre, 2013. Disponible en: http://www.minagri.gob.ar/new/00/forestacion/salicaceas/jornadas\%20salicaceas\%202011/Actas/Inicio.htm

Ceulemans R, Impens I, Steenackers V (1984). Stomatal and anatomical leaf characteristics of 10 Populus clones. Canadian Journal of Botany 62: 513 - 518.

Ceulemans R, Impens I, Steenackers V (1988). Genetic variation in aspects of leaf growth of Populus clones, using the leaf plastochron index. Canadian Journal of Forest Research 18: $1069-1077$.

Ceulemans R, Van Praet L, Jiang XN (1995). Effects of $\mathrm{CO}_{2}$ enrichment, leaf position and clones on stomatal index and epidermal cell density in poplar (Populus). New Phytologist 131: 99 - 107.

Colmer TD (2003 a). Aerenchyma and an inducible barrier to radial oxygen loss facilitate root aeration in upland, paddy and deep-water rice (Oryza sativa L.). Annals of Botany 91: 301 - 309.

Colmer TD (2003 b). Long-distance transport of gases in plants: a perspective on internal and radial oxygen loss from roots. Plant Cell Environment 26: 17 36. 
Colmer TD, Gibbered MR, Wiengweera A, Tinh TK (1998). The barrier to radial oxygen loss from roots of rice (Oryza sativa L.) is induced by growth in stagnant solution. Journal of Experimental Botany 49: 1431 - 1436.

Colmer TD, Voesenek LACJ (2009). Flooding tolerance: suites of plant traits in variable environments. Functional Plant Biology 36: 665 - 681.

Corpas FJ, Barroso JB, del Río LA (2001). Peroxisomes as a source of reactive oxygen species and nitric oxide signal molecules in plant cells. Trends in Plant Science 6: $145-150$

Cortizo, S (2011). Mejoramiento genético del álamo, una ciencia en apoyo a la producción forestal sostenible. Tercer Congreso Internacional de Salicáceas en Argentina, 2011, Neuquén, Argentina. Disponible en: http://www.minagri.gob.ar/new/00/forestacion/salicaceas/jornadas\%20salicaceas\%202011/Actas/Inicio.htm

Cortizo S, Abbiati N, Nema V (2009). Nuevas posibilidades para ampliar la diversidad clonal de las plantaciones de álamo del Delta del Paraná. Segundo Congreso Internacional de Salicáceas en Argentina, 2009, Mendoza, Argentina. Disponible en: http://minagri.siia.gob.ar/new/00/forestacion/biblos/JS\%202009/Trabajos/2\%20Trabajos\%20Tecnicos/22\%20Gen\%E9tica,\%20Mejoramiento\%20y\%20Conservaci\%F3n\%20de\%20Recursos/Cor tizo1.pdf

Crawford RMM, Braendle R (1996). Oxygen deprivation stress in a changing environment. Journal of Experimental Botany 47: 145 - 149.

D `ambrogio de Argueso A (1986). Manual de técnicas en histología vegetal. Hemisferio Sur Editorial.

Das DK, Jat RL (1977). Influence of three soil-water regimes on root porosity and growth of four rice varieties. Agronomy Journal 69: 197 - 200. 
Dat J, Vandenabeele s, Vranová E, Van Montagu M, Inzé D, Van Breusegem F (2000). Dual action of the active oxygen species during plant stress responses. Cellular and Molecular Life Sciences 57: 779 - 795.

Davies WJ, Kozlowski TT (1975). Effects of applied abscisic acid and plant water stress on transpiration of woody angiosperms. Forest Science 22: 191 - 195.

Davies FS, Flore JA (1986). Short-term flooding effects on gas exchange and quantum yield of rabbiteye blueberry (Vaccinium ashei Reade). Plant Physiology 81: 289 292.

Dickmann DI (2006). Silviculture and biology of short-rotation woody crops in temperate regions: then and now. Biomass and Bioenergy 30: 696 - 705.

Dickmann DI, Kuzovkina J (2008). Poplars and willows, with emphasis on silviculturally important species. Poplars and willows in the world, chapter 2. Forest Resources Development Service. Working Paper IPC/9-2, FAO, Rome, Italy. 135 páginas.

DiFazio SP, Slavov GT, Joshi CP (2011). Populus: A premier pioneer system for plant genomics. En: Genetics, genomics and breeding of poplar. Editores: Joshi CP, DiFazio SP, Kole C. Science Publishers, Enfield, páginas 1 - 28.

Dillen SY, Marron N, Koch B, Ceulemans R (2008). Genetic variation of stomatal traits and carbon isotope discrimination in two hybrid poplar families (Populus deltoides S9-2 x Populus nigra Ghoy and P. deltoides S9-2 $\times$ P. trichocarpa V24). Annals of Botany 102: 399 - 407.

Dixon DP, Cummins I, Cole DJ, Edwards R (1998). Glutathione-mediated detoxification systems in plants. Current Opinion in Plant Biology 1: 258 - 266.

Drew MC, Jackson MB, Giffard SC, Campbell R (1981). Inhibition by silver ions of gas space (aerenchyma) formation in adventitious roots of Zea mays L. subjected to exogenous ethylene or to oxygen deficiency. Planta 153: 217 - 224. 
Drew MC, He CJ, Morgan PW (2000). Programmed cell death and aerenchyma formation in roots. Trends in Plant Science 5: 123 - 127.

Dron M, Clouse SD, Dixon RA, Lawton MA, Lamb CJ (1988). Glutathione and fungal elicitor regulation of a plant defense gene promoter in electroporated protoplasts. Proceedings of the National Academy of Sciences, USA 85: 6738 6742.

Eckenwalder JE (1996). Systematics and evolution of Populus. En: Biology of Populus and its Implications for Management and Conservation. Editores: Stettler RF, Bradshaw HD, Jr., Heilman PE, Hinckley TM. NRC Research Press, Ottawa, Ontario, Canada, páginas 7 - 32.

Else MA, Tiekstra AE, Crocker SJ, Davies WJ, Jackson MB (1996). Stomatal closure in flooded tomato plants onvolves abscisic acid and a chemically unidentified antitranspirant in xylem sap. Plant Physiology 112: 239 - 247.

Evans DE (2003). Aerenchyma formation. New Phytologist 161: 35 - 49.

Folzer H, Dat JF, Capelli N, Rieffel D, Badot PM (2006). Response of sessile oak seedlings to flooding: an integrated study. Tree Physiology 26: 759 - 766.

Foyer $\mathrm{CH}$, Lelandais $\mathrm{M}$ (1993). The roles of ascorbate in the regulation of photosynthesis. En: Photosynthetic Responses to the Environment. Editores: Yamamoto Hy, Smith CM). Páginas: 88 - 101. American Society of Plant Physiologists, Rockville.

Foyer $\mathrm{CH}$, Derscourvières $\mathrm{P}$, Kunert KJ (1994 a). Protection against oxygen radicals: an important defense mechanism studied in transgenic plants. Plant, Cell and Enviroment 17: 507 - 523.

Foyer $\mathrm{CH}$, Lelandais $\mathrm{M}$, Kunert KJ (1994 b). Photooxidative stress in plants. Physiologia Plantarum 92: $696-717$. 
Foyer CH, Noctor G (2005). Redox Homeostasis and antioxidant signaling: A metabolic interface between stress perception and physiological responses. Plant Cell 17: $1866-1875$.

Foyer CH, Noctor G (2009). Redox regulation in photosynthetic organisms: signaling, acclimation, and practical implications. Antioxidants and Redox Signaling 11 (4): $861-905$.

Foyer $\mathrm{CH}$, Noctor G (2011). Ascorbate and Glutathione: The Heart of the Redox Hub. Plant Physiology 155: 2 - 18.

Galvez-Valdivieso G, Mullineaux PM (2009). The role of reactive oxygen species in signalling from chloroplast to the nucleus. Physiologia Plantarum 138: 430 - 439.

Gibberd MR, Gray JD, Cocks PS, Colmer TD (2001). Waterlogging tolerance among a diverse range of Trifolium accessions is related to root porosity, lateral root formation and aerotropic rooting. Annals of Botany 88: 579 - 589.

Gill CJ (1970). The flooding tolerance of woody species - a review. Forestry Abstracts 31: $671-688$.

Glenz C, Schlaepfer R, lorgulescu I, Kienast F (2006). Flooding tolerance of Central European tree and shrub species. Forest Ecology \& Management 235: 1 - 13.

Goggin DE, Colmer TD (2005). Intermitent anoxia induces oxidative stress in wheat seminal roots: assesment of the antioxidant defence system, lipid peroxidation and tissue solutes. Functional Plant Biology 32: 495 - 506.

Golfari L (1958). Condiciones ecológicas del cultivo de las salicáceas en la Argentina. Revista de Investigaciones Agrícolas 12 (2): 173 - 224.

Gómez F, Fernández L, Gergoff G, Guiamet JJ, Chaves A, Bartoli CG (2008). Heat shock increases mitochondrial $\mathrm{H}_{2} \mathrm{O}_{2}$ production and extends postharvest life of spinach leaves. Postharvest Biology and Technology 49: 229 - 234. 
Gong JR, Zhang XS, Huang YM, Zhang CL (2007). The effects of flooding on several hybrid poplar clones in Northern China. Agroforestry System 69: 77 - 88.

Grant JJ, Loake GJ (2000). Role of reactive oxygen intermediates and cognate redox signaling in disease resistance. Plant Physiology 124: 21 - 29.

Grassmann J, Hippeli S, Elstner EF (2002). Plant's defence and its benefits for animals and medicine: role of phenolics and terpenoids in avoiding oxygen stress. Plant Physiology and Biochemistry 40: 471 - 478.

Gravatt DA, Kirby CJ (1998). Patterns of photosynthesis and starch allocation in seedlings of four bottomland hardwood tree species subjected to flooding. Tree Physiology 18: $411-417$.

Griffith OW (1980). Determination of glutathione and glutathione disulfide using glutathione reductase and 2-vinylpyridine. Analytical Biochemistry 106 (1): $207-212$.

Gunawardena A, Pearce DM, Jackson MB, Hawes CR, Evans DE (2001). Characterisation of programmed cell death during aerenchyma formation induced by ethylene or hypoxia in roots of maize (Zea mays L.). Planta 212: 205 214.

Guo XY, Huang Z, Xu A, Zhang X (2011). A comparison of physiological, morphological and growth responses of 13 hybrid poplars clones under flooding. Forestry 84: 1 - 12.

Hammond-Kosack KE, Jones JDG (1996). Resistance gene-dependent plant defense responses. Plant Cell 8: 1773 - 1791.

Hamzeh M, Perinet P, Dayanandan S (2006). Genetic relationships among species of Populus (Salicaceae) based on nuclear genomic data. Journal of the Torrey Botanical Society 133: 519 - 527.

Harrington CA (1987). Responses of red alder and black cottonwood seedlings to flooding. Physiologia Plantarum 69: 35 - 48. 
He CJ, Finlayson SA, Drew MC, Jordan WR, Morgan PW (1996). Ethylene biosynthesis during aerenchyma formation in roots of maize subjected to mechanical impedance and hypoxia. Plant Physiology 112: 1679 - 1685.

Herschbach C, Scheerer U, Rennenber H (2010). Redox state of glutathione and ascorbate in root tips of poplar (Populus tremula $\times$ P. alba) depend on phloem transport from the shoot to the roots. Journal of Experimental Botany 61 (4): $1065-1074$.

Hetherington AM, Hunter MI, Crawford RMM (1982). Contrasting effects of anoxia on rhizome lipids of Iris species. Phytochemistry 21: 1275 - 1278.

Inskeep WP, Bloom PR (1985). Extintion coefficients of chlorophyll a and b in N,NDimethylformamide and 80\% acetone. Plant Physiology 77: 483 - 485.

Jackson MB (1990). Hormones and developmental change in plants subjected to submergence or soil waterlogging. Aquatic Botany 38: 49 - 72.

Jackson MB (2004). The impact of flooding stress on plants and crops. Acceso 22 de Octubre de 2013. Disponible en:

http://www.plantstress.com/Articles/waterlogging_i/waterlog_i.htm.

Jackson MB, Armstrong W (1999). Formation of aerenchyma and the processes of plant ventilation in relation to soil flooding and submergence. Plant Biology 1: 274 287.

Jackson MB, Saker LR, Crisp CM, Else MA, Janowiak F (2003). Ionic and pH signalling from roots to shoots of flooded tomato plants in relation to stomatal closure. Plant and Soil 253: 103 - 113.

Jansson S, Douglas CJ (2007). Populus: a model system for plant biology. Annual Review of Plant Biology 58: 435 - 458.

Justin SHFW, Armstrong W (1987). The anatomical characteristics of roots and plant response to soil flooding. New Phytologist 106: 465 - 495. 
Kaiser WM (1979). Reversible inhibition of the Calvin cycle and activation of oxidative pentose phosphate cycle in isolated intact chloroplasts by hydrogen peroxide. Planta 145: 377 - 382.

Kerk NM, Feldman LJ (1995). A biochemical model for the initiation and maintenance of the quiescent centre: implications for organization of root meristem. Development 121: 2825 - 2833.

Kozlowski TT (1997). Responses of woody plants to flooding and salinity. Tree Physiology Monograph No 1. Acceso 15 de enero de 2013. Disponible en http://www.pucrs.br/fabio/fisiovegetal/Encharcamento.pdf.

Kreuswieser J, Papadopoulou E, Rennenberg H (2004). Interaction of flooding with carbon metabolism of forest trees. Plant Biology 6: 299 - 306.

Kreuswieser J, Hauberg J, Howell KA, Carroll A, Rennenberg H, Millar AH, Whelan J (2009). Differential response of gray poplar leaves and roots underpins stress adaptation during hypoxia. Plant Physiology 149: 461 - 473.

Krol M, Gray GR, Hurry VM, Öquist G, Malek L, Huner NPA (1995). Low-temperature stress and photoperiod effect an increased tolerance to photoinhibition in Pinus banksiana seedlings. Canadian Journal of Botany 73: 1119 - 1127.

Laemmli UK (1970). Cleavage of structural proteins during the assembly of the head of bacteriophage T4. Nature 227: 680 - 685 .

Larson RA (1988). The antioxidants of higher plants. Phytochemistry 27 (4): 969 - 978.

Leggett JE, Frere MH (1971). Growth and nutrient uptake by soybean plants in nutrient solutions of graded concentrations. Plant Physiology 41: 457 - 460.

Lendzian KJ (2006). Survival strategies of plants during secondary growth: barrier properties of phellems and lenticels towards water, oxygen, and carbon dioxide. Journal of Experimental Botany 57 (11): 2535 - 2546. 
Li S, Pezeshki SR, Shields FD Jr. (2006). Partial flooding enhances aeration in adventicious roots of black willow (Salix nigra) cuttings. Journal of Plant Physiology 163: $619-628$.

Liao CT, Lin CH (1994). Effect of flooding stress on photosynthetic activities of Momordica charantia. Plant Physiology and Biochemistry 32: 479 - 485.

Liao CT, Lin CH (2001). Physiological adaptation of crop plants to flooding stress. Proceedings of the National Council, Republic of China (B) 25 (3): 148 - 157.

Liso R, Innocenti AM, Bitonti MB, Arrigoni O (1998). Ascorbic acid-induced progression of quiescent center cells from G1 to S phase. New Phytologist 110: 469 - 471.

Liso R, De Tullio MC, Ciraci S, Balestrini R, La Rocca N, Bruno L, Chiappetta A, Bitonti B, Bonfante P, Arrigoni O (2004). Localisation of ascorbic acid, ascorbic acid oxidase, and glutathione in roots of Cucurbita maxima L. Journal of Experimental Botany 55: 2589 - 2597.

Liu Z, Dickmann DI (1992). Responses of two hybrid Populus clones to flooding, drought and nitrogen availability.I. Morphology and growth. Canadian Journal of Botany 70: $2265-2270$.

Liu Z, Dickman DI (1993). Responses of two hybrid Populus clones to flooding, drought and nitrogen availability. II. Gas exchange and water relations. Canadian Journal of Botany 71: 927 - 938.

Liu Z, Dickman DI (1996). Effects of water and nitrogen interaction on net photosynthesis, stomatal conductance and water-use efficiency in two hybrid poplar clones. Physiologia Plantarum 97: 507 - 512.

Long SP, Humphries S, Falkowski PG (1994). Photoinhibition of photosynthesis in nature. Annual Review of Plant Physiology and Plant Molecular Biology 45: 633 662. 
Love J, Björklund S, Vahala J, Hertzberg M, Kangasjärvi J, Sundberg B (2009). Ethylene is an endogenous stimulator of cell division in the cambial meristem of Populus. PNAS 106: 5984 - 5989.

Luquez VMC, Achinelli F, Cortizo S (2012). Evaluation of flooding tolerance in cuttings of Populus clones used for forestation at the Paraná River Delta, Argentina. Southern Forests 74: $61-70$.

Malvárez Al (1999). El Delta del Río Paraná como mosaico de humedales. En: Tópicos sobre humedales subtropicales y templados de Sudamérica. Editor: Malvarez Al. UNESCO Montevideo, Uruguay. Páginas 35 - 53.

Marron N, Villar M, Dreyer E, Delay D, Boudoresque E, Petit JM, Delmotte FM, Guehl JM, Brignolas F (2005). Diversity of leaf traits related to productivity in 31 Populus deltoides x Populus nigra clones. Tree Physiology 25: 425 - 435.

Masarovicova E (1991). Leaf shape, stomata density and photosynthetic rate of the common oak leaves. Biologia Plantarum 33: 495 - 500.

Masle J, Gilmore SR, Farquhar GD (2005). The ERECTA gene regulates plant transpiration in Arabidopsis. Science 436: 866 - 869.

Maxwell DP, Wang Y, Mclntosh L (1999). The alternative oxidase lowers mitochondrial reactive oxygen production in plant cells. Proceedings of the National Academy of Sciences of the United States of America 96: 8271 - 8276.

Maxwell K, Johnson GN (2000). Chlorophyll fluorescence-a practical guide. Journal of Experimental Botany 51 (345): 659 - 668.

May MJ, Vernoux T, Leaver C, Van Montagu M, Inzé D (1998). Glutathione homeostasis in plants: Implications for environmental sensing and plant development. Journal of Expermiental Botany 49: 649 - 667.

Mclntyre DS (1970). The platinum micro-electrode method for soil aeration measurement. Advances in Agronomy 22: 235 - 283. 
Mehlhorn H, Lelandais M, Korth HG, Foyer CH (1996). Ascorbate is the natural substrate for plant peroxidases. FEBS Letters 378: 203 - 206.

Mergemann H, Sauter M (2000). Ethylene induces epidermal cell death at the site of adventitious root emergence in rice. Plant Physiology 124: 609 - 614.

Mielke MS, De Ameida AAF, Gomes FP, Aguilar MAG, Mangabeira PAO (2003). Leaf gas exchange, chlorophyll fluorescence and growth responses of Genipa americana seedlings to soil flooding. Environmental and Experimental Botany 50: 221 - 231.

Mittler R (2002). Oxidative stress, antioxidants and stress tolerance. Trends in Plant Science 7: 405 - 410.

Monclus R, Dreyer E, Delmotte FM, Villar M, Delay D, Boudouresque E, Petit J, Marron N, Bréchet C, Brignolas F (2005). Productivity, leaf traits and carbon isotope discrimination in 29 Populus deltoides x Populus nigra clones. New Phytologist 167: $53-62$.

Monk LS, Braendle R, Crawford RMM (1987 a). Catalase activity and post-anoxic injury in monocotyledonous species. Journal of Experimental Botany 38: $233-246$.

Monk LS, Fagerstedt KV, Crawford RMM (1987 b). Superoxide dismutase as an anaerobic polypeptide. Plant Physiology 85: 1016 - 1020.

Nakano Y, Asada K (1981). Hydrogen peroxide is scavenged by ascorbate-specific peroxidase in spinach chloroplasts. Plant and Cell Physiology 22 (5): 867 - 880.

Navrot N, Rouhier N, Gelhaye E, Jacquot JP (2007). Reactive oxygen species generation and antioxidant systems in plant mitochondria. Physiologia Plantarum 129: 185 - 195.

Neuman DS, Wagner M, Braatne JH, Howe J (1996). Stress physiology - abiotic. En: Biology of Populus and its Implications for Management and Conservation. Editores: Stettler RF, Bradshaw HD, Jr., Heilman PE, Hinckley TM. NRC Research Press, Ottawa, Ontario, Canada, páginas 423 - 458. 
Noctor G, Foyer CH (1998). Ascorbate and glutathione: keeping active oxygen under control. Annual Review of Plant Physiology and Plant Molecular Biology 49: 249 279.

Pallardy SG, Kozlowski TT (1979). Frequency and length of stomata of 21 Populus clones. Canadian Journal of Botany 57: 2519 - 2523.

Parent C, Capelli N, Berger A, Crèvecoeur M, Dat J (2008). An overview of plant responses to soil waterlogging. Plant stress 2(1): $20-27$.

Pereira JS, Kozlowski TT (1977). Variations among woody angiosperms in response to flooding. Physiologia Plantarum 41: 184 - 192.

Pezeshki SR (2001). Wetland plant responses to soil flooding. Environmental and Experimental Botany 46: 299 - 312.

Pezeshki SR, Chambers JL (1985 a). Stomatal and photosynthetic response of sweet gum (Liquidambar styraciflua) to flooding. Canadian Journal of Forest research $15(2): 371-375$.

Pezeshki SR, Chambers JL (1985 b). Responses of cherrybark oak (Quercus falcate var. pagodaefolia) seedlings to short-term flooding. Forest Science 31 (3): 760 - 771.

Pezeshki SR, Pardue JH, DELaune RD (1996). Leaf gas exchange and growth of floodtolerant and flood-sensitive tree species under low soil redox conditions. Tree Physiology 16: $453-458$.

Pezeshki SR, Anderson PH (1997). Responses of three bottomland species with different flood tolerance capabilities to various flooding regimes. Wetlands Ecology and Management 4: 245 - 256.

Pincemin JM, Monlezun SJ, Zunino H, Cornaglia PS, Borodowski E (2007). Sistemas Silvopastoriles en el Delta del Río Paraná: Producción de materia seca y estructura de gramíneas templadas bajo álamos. APPA ALPA- Cusco, Perú. http://www.produccionanimal.com.ar/produccion_y_manejo_pasturas/manejo\% 20silvopastoril/82- Pincemin-silvopastoril.pdf. 
Pociecha E, koscielniak J, Filek W (2008). Effects of root flooding and stage of development on the growth and photosynthesis of field bean (Vicia faba L. minor). Acta Physiologiae Platarum 30: 529 - 535.

Ponnamperuma FN (1972). The chemistry of submerged soil. Advances in Agronomy 24: $29-96$.

Puntarulo S, Sánchez RA, Boveris A (1988). Hydrogen Peroxide Metabolism in Soybean Embryonic Axes at the Onset of Germination. Plant Physiology 86: 626 - 630.

Rae AM, Robinson KM, Street N, Taylor G (2004). Morphological and physiological traits influencing biomass productivity in short-rotation coppice poplar. Canadian Journal of Forest Research 34: 1488 - 1498.

Ragonese AE, Rial Alberti F, Ciocchini RG, García A (1987). Fitotecnia de Salicáceas en el Centro Nacional de Investigaciones Agropecuarias Castelar (INTA). Anales de la Academia Nacional de Agronomía y Veterinaria 41: 5 - 30.

Ram PC, Singh BB, Singh AK, Ram Parashu, Singh PN, Singh HP, Boamfa J, Harren F, Santosa E, Jackson MB, Setter TL, Reuss J, Wade LJ, Singh VP, Singh RK (2002). Submergence tolerance in rainfed lowland rice: physiological basis and prospects for cultivar improvement through marker-aided breeding. Field Crops Research 76: 131 - 152.

Regehr DL, Bazzaz FA, Bogess WR (1975). Photosynthesis, transpiration and leaf conductance of Populus deltoids in relation to flooding and drought. Photosynthetica 9: 52 - 61.

Rennenberg H (1982). Glutathione metabolism and possible biological roles in higher plants. Phytochemistry 21: 2771 - 2781.

Rood SB, Goater LA, Mahoney JM, Pearce CM, Smith DG (2007). Flood, fire, and ice: disturbance ecology of riparian cottonwoods. Canadian Journal of Botany 85: $1019-1032$. 
Rood SB, Nielsen JL, Shenton L, Gill KM, Letts MG (2010). Effects of flooding on leaf development, transpiration and photosynthesis in narrowleaf cottonwood, a willow-like poplar. Photosynthesis Research 104: 31 - 39.

Sairam RK, Kumutha D, Ezhilmathi K (2009). Waterlogging tolerance: nonsymbiotic haemoglobin - nitric oxide homeostasis and antioxidants. Current Science 96 (5): $674-682$.

Sánchez-Fernández R, Fricker M, Corben LB, White NS, Sheard N, Leaver CJ, Van Montagu M, Inzé D, May MJ (1997). Cell proliferation and hair tip growth in the Arabidopsis root are under mechanistically different forms of redox control. Proceedings of National Academy of Sciences, USA 94: 2745 - 2750.

Schluter, U, Muschak, M, Berger, D, Altmann, T (2003). Photosynthetic performance of an Arabidopsis mutant with elevated stomatal density (sdd1-1) under different light regimes. Journal of Experimental Botany 54: 867 - 874.

Seago JL, Marsh LC, Stevens KJ, Soukup A, Votrubová O, Enstone DE (2005). A reexamination of the root cortex in wetland flowering plants with respect to aerenchyma. Annals of Botany 96: 565 - 579.

Sena Gomes AR, Kozlowski TT (1980 a). Effects of flooding on Eucalyptus camaldulensis and Eucalyptus globulus seedlings. Oecología 46: 139 - 142.

Sena Gomes AR, Kozlowski TT (1980 b). Growth responses and adaptations of Fraxinus pennsylvanica seedlings to flooding. Plant Physiology. 66: 267 - 271.

Shimamura S, Yamamoto R, Nakamura T, Shimada S, Komatsu S (2010). Stem hypertrophic lenticels and secondary aerenchyma enable oxygen transport to roots of soybean in flooded soil. Annals of Botany 106: 277 - 284.

Smillie RM, Hetherington SE (1999). Photoabatement by anthocyanin shields photosynthetic systems from light stress. Photosynthetica 36: 451 - 463.

Smirnoff $N$ (1996). The function and metabolism of ascorbic acid in plants. Annals of Botany 78: $661-669$. 
Smirnoff $N$ (2000). Ascorbic acid: metabolism and functions of a multi-facetted molecule. Current Opinion in Plant Biology 3: 229 - 235.

Smit BA, Stachowiak M (1988). Effects of hypoxia and elevated carbon dioxide concentration on water flux through Populus roots. Tree Physiology 4: 153 165.

Smit BA, Stachowiak M, Van Volkenburgh E (1989). Cellular process limiting leaf growth in plants under hypoxic root stress. Journal of Experimental Botany 40: 89 - 94.

Smit BA, Neuman DS, Stachowiak M (1990). Root hypoxia reduces leaf growth. Role of factors in the transpiration stream. Plant Physiology 92: 1021 - 1028.

Stanton BJ, Eaton J, Johnson J, Rice D, Schuette W, Moser, B (2002). Hybrid poplar in the Pacific Northwest: the effects of market-driven management. Journal of Forestry 100 (4): 28 - 33.

Stanton BJ, Neales DB, Shanwen L (2010). Populus breedeing: from the classical to the genomic approach. En: Genetics and Genomics of Populus, Plant Genetics and Genomics: Crops and models 8. Editores: Jansson S, Bhalerao R, Groover A. Páginas: 309 - 348.

Stettler RF, Bradshaw HD, Jr, Heilman PE, Hinckley TM (1996). Biology of Populus and its implications for management and conservation. NRC Research Press, Ottawa, Ontario, Canada. 539 páginas.

Steyn WJ, Wand SJE, Holcroft DM, Jacobs G (2002). Anthocyanins in vegetative tissues: a proposed unified function in photoprotection. New Phytologist 155: $349-361$.

Striker GG (2012). Flooding Stress on Plants: Anatomical, Morphological and Physiological Responses, Botany (Editado por John Mworia), ISBN: 978-953-510355-4, InTech. Disponible en: 
http://www.intechopen.com/books/botany/flooding-stress-on-plantsanatomical-morphological-andphysiological-responses.

Striker GG, Insausti P, Grimoldi AA, Vega AS (2007). Trade-off between root porosity and mechanical strength in species with different types of aerenchyma. Plant, Cell \& Environment 30: 580 - 589.

Syvertsen JP, Zablotowicz RM, Smith ML Jr (1983). Soil temperature and flooding effects on two species of citrus. I. Plant growth and hydraulic conductivity. Plant and Soil 72: $3-12$.

Taiz L, Zeiger E. (2002). Plant physiology, 3er edition, Sinauer Associates.

Tanaka Y, Sugano S, Shimada T, Hara -Nishimura I (2013). Enhancement of leaf photosynthetic capacity through increased stomatal density in Arabidopsis. New Phytologist 198: 757 - 764.

Taylor G (2002). Populus: Arabidopsis for forestry. Do we need a model tree? Annals of Botany 90: $681-689$.

Thomas CE, McLean LR, Parker RA, Ohlweiler DF (1992). Ascorbate and phenolic antioxidant interactions in prevention of liposomal oxidation. Lipids 27: 543 550.

Tietze F (1969). Enzymic method for quantitative determination of nanogram amounts of total and oxidized glutathione: Applications to mammalian blood and other tissues. Analytical Biochemistry 27 (3): 502 - 522.

Tuskan GA, DiFazio S, Jansson S, Bohlmann J, Grigoriev I, Hellsten U, Putnam N, Ralph S, Rombauts S, Salamov A, Schein J, Sterck L, Aerts A, Bhalerao RR, Bhalerao RP, Blaudez D, Boerjan W, Brun A, Brunner A, Busov V, Campbell M, Carlson J, Chalot M, Chapman J, Chen GL, Cooper D, Coutinho PM, Couturier J, Covert S, Cronk Q, Cunningham R, Davis J, Degroeve S, Déjardin A, dePamphilis C, Detter J, Dirks B, Dubchak I, Duplessis S, Ehlting J, Ellis B, Gendler K, Goodstein D, Gribskov M, Grimwood J, Groover A, Gunter L, 
Hamberger B, Heinze B, Helariutta Y, Henrissat B, Holligan D, Holt R, Huang W, Islam-Faridi $\mathrm{N}$, Jones $\mathrm{S}$, Jones-Rhoades $\mathrm{M}$, Jorgensen $\mathrm{R}$, Joshi $\mathrm{C}$, Kangasjärvi J, Karlsson J, Kelleher C, Kirkpatrick R, Kirst M, Kohler A, Kalluri U, Larimer F, Leebens-Mack J, Leplé JC, Locascio P, Lou Y, Lucas S, Martin F, Montanini B, Napoli C, Nelson DR, Nelson C, Nieminen K, Nilsson O, Pereda V, Peter G, Philippe R, Pilate G, Poliakov A, Razumovskaya J, Richardson P, Rinaldi C, Ritland K, Rouzé P, Ryaboy D, Schmutz J, Schrader J, Segerman B, Shin H, Siddiqui A, Sterky F, Terry A, Tsai CJ, Uberbacher E, Unneberg P, Vahala J, Wall K, Wessler S, Yang G, Yin T, Douglas C, Marra M, Sandberg G, Van de Peer Y, Rokhsar D (2006). The genome of black cottonwood, Populus trichocarpa. Science 313: 1596 - 1604.

Vartapetian BB, Jackson MB (1997). Plant adaptations to anaerobic stress. Annals of Botany 79 (A): 3 - 20.

Verma KK, Singh M, Gupta RK, Verma CL (2013). Photosynthetic gas exchange, chlorophyll fluorescence, antioxidant enzymes, and growth responses of Jatropha curcas during soil flooding. Turkish Journal of Botany. 37(1): 1- 11.

Vervuren PJA, Blom CWPM, De Kroon H (2003). Extreme flooding events on the Rhine and the survival and distribution of riparian plant species. Journal of Ecology 91: $135-146$

Visser EJW, Cohen JD, Barendse GWM, Blom CWPM, Voesenek LACJ (1996). An ethylene-mediated increase in sensitivity to auxin induces adventitious root formation in flooded Rumex palustris Sm. Plant Physiology 112: 1687 - 1692.

Visser EJW, Colmer TD, Blom CWPM, Voesenek LACJ (2000). Changes in growth, porosity, and radial oxygen loss from adventitious roots of selected mono- and dicotyledonous wetland species with contrasting types of aerenchyma. Plant, Cell and Environment 23: 1237 - 1245. 
Visser EJW, Voesenek LACJ (2004). Acclimation to soil flooding - Sensing and signal-transduction. Plant and Soil 254: 197 - 214.

Visser EJW, Bögemann GM (2006). Aerenchyma formation in the wetland plant Juncus effusus is independent of ethylene. New Phytologist 171: 305 - 314.

Vriezen WHVRCPE, Voesenek LAC, Mariani C (1997). A homologue of the Arabidopsis ERS gene is actively regulated in Rumex palustris upon flooding. Plant Journal 11: $1265-1271$.

Vu CV, Yelenosky G (1991). Photosynthetic responses of citrus trees to soil flooding. Physiologia Plantarum 81: 7 - 14.

Wample RL, Davis RW (1983). Effect of flooding on starch accumulation in chloroplasts of sunflower (Helianthus annuus L.). Plant Physiology 73: 195 - 198.

Whitehead FH, Myerscough PJ (1962). Growth analysis of plants. The ratio of mean relative growth rate to mean relative rate of area increase. New Phytologist 61: $314-321$.

Willekens H, Inzé D, Van Montagu M, Van Camp W (1995). Catalase in plants. Molecular Breeding 1: 207 - 228.

Willekens H, Chamnongpol S, Davey M, Schraudner M, Langebartels C, Van Montagu M, Inzé D, Van Camp W (1997). Catalase is a sink for H2O2 and is indispensable for stress defence in C-3 plants. The EMBO Journal 16(16): 4806 - 4816.

Wingate VPM, Lawton MA, Lamb CJ (1988). Glutathione elicits a massive and selective induction of plant defense genes. Plant Physiology 87: $206-210$.

Wullschleger SD, Jansson S, Taylor G (2002). Genomics and forest biology: Populus emerges as the perennial favorite. Plant Cell 14: $2651-2655$.

Yamamoto F, Sakata T, Terazawa K (1995). Physiological, morphological and anatomical responses of Fraxinus mandshurica seedlings to flooding. Tree Physiology 15: $713-719$. 
Yamasaki H, Sakihama Y, Ikehara N (1997). Flavonoid-peroxidase reaction as a detoxification mechanism of plant cells against $\mathrm{H}_{2} \mathrm{O}_{2}$. Plant Physiology 115: 1405 $-1412$.

Yordanova RY, Popova LP (2001). Photosynthetic response of barley plants to soil flooding. Photosynthetica 39: 515 - 520.

Yordanova RY, Alexieva VS, Popova LP (2003). Influence of root oxygen deficiency on photosynthesis and antioxidants in barley plants. Russian Journal of Plant Physiology 50 (2): $163-167$.

Yordanova R, Christov K, Popova L (2004). Antioxidative enzymes in barley plants subjected to soil flooding. Environmental and Experimental Botany 51: 93 - 101.

Zsuffa L, Giordano E, Pryor LD, Stettler RF (1996). Trends in poplar culture: some global and regional perspectives. En: Biology of Populus and its Implications for Management and Conservation. Editores: Stettler RF, Bradshaw HD, Jr., Heilman PE, Hinckley TM. NRC Research Press, Ottawa, Ontario, Canada, páginas 515-539. 